\title{
Tourism Distribution Channels in the Northern Tourist Circuit of Tanzania
}

\author{
Peter Judca Mkumbo
}

\begin{abstract}
A thesis
submitted to Victoria University of Wellington in partial fulfilment of the requirements for the degree of

Master of Tourism Management
\end{abstract}

Victoria University of Wellington

2010 


\section{Acknowledgements}

I would like to take this opportunity to thank numerous people who assisted me in getting this thesis done. Special thanks are due to my supervisors Prof Doug Pearce and Dr Adam Weaver who tirelessly provided me close supervision and excellent guidance throughout, from developing the proposal to compiling the report. You are the best! Also, I am extremely grateful for the scholarship that NZAID offered to me without which my studies in New Zealand would not be possible. My extended thanks go to all New Zealanders as the scholarship fund that was provided to me came from taxes that you pay. Thank you all!

Thank you to the Ministry of Natural Resources and Tourism and Tanzania Tourist Board officials who gave me relevant documents for my thesis. I am also indebted with all businesses in the northern tourist circuit of Tanzania which participated in this research; you volunteered to give me important information and your time, thank you very much!

Finally, I would also like to thank my family and friends for their support and those who prayed for me, specifically my grandparents Aron and Safina Kaali. Thank you very much. You are the most valuable people in my life! Special thanks also to my parents, uncles, aunts, brothers and sisters for all your support to date. May Almighty God bless you all! Lastly, a special thank you goes to my classmates Rogerio Dias, Nguyen Thi Hong Hanh and Tina Rønhovde Tiller. You have been so supportive of me throughout this tough journey. To all of you, mentioned and not mentioned, this research is a result of your generosity, support and humour during times of pressure. Thank you! 


\begin{abstract}
This study investigates the structure of tourism distribution channels in the northern tourist circuit of Tanzania. It explores factors influencing channel structures and also examines operational characteristics of the channels. It is a destination-based study that takes a supply-side approach. The study is based on in-depth interviews with different businesses across tourism sector at the destination. The northern tourist circuit is the heart of tourism industry in Tanzania; it is a core in a peripheral country.
\end{abstract}

Tourists in the northern tourist circuit are primarily attracted by mountain climbing adventures, photographic and hunting safaris. Putting together different activities involved in a safari or adventure product requires the presence of ground tour operators. The former have links with all the suppliers at the destination and are the most knowledgeable about the destination among channel members in the destination. There is a complex relationship among channel members in the northern tourist circuit which partly contributes to the complexity of the distribution channels used. The majority of tourists who visit northern tourist circuit book their holidays through overseas agents; a few purchase directly from the suppliers. The majority of those who shop through overseas agents are package or customized tourists while most independent travellers buy their holidays directly, often making multiple purchases. Ground tour operators in Kenya are important channel members as well. This is because a significant number of tourists who visit the northern tourist circuit come through Kenya and ground tour operators there pass them down to their counterparts in Tanzania. Hunting tourists access the destinations through professional hunters, either directly or through overseas marketing agents. Secondary activities like cultural tourism rely more on "at destination" distribution as their drawing power is less than wildlife resources and adventure attractions.

Factors which influence the structure of distribution in the northern tourist circuit include size of the business, nature of the attraction, tourists' preference, distance from market to destination, lack of capital and marketing knowledge. 
Channel performance is based on two main criteria: volume of clients the channel produces and the profit generated from the channel. Indirect channels produce more clients while direct channels are observed to generate more profit per client than indirect channels.

Information technology is mainly used for creating awareness and communications. All the businesses interviewed have websites for those purposes. 
Acknowledgements i

Abstract ii

List of Tables vii

List of Figures viii

List of Abbreviations $\mathrm{X}$

Chapter One: Introduction

1.1Introduction 1

1.2 Tanzania and its tourism sector 3

1.2 Research objectives 7

1.4 Thesis organization 8

Chapter Two: Literature Review

2.1 Introduction 10

2.2 Distribution Channels 10

2.2.1 Distribution Channels in Tourism 12

2.2.2 Direct and indirect distribution channels

2.3 Members in distribution channels 14

2.3.1 Suppliers 14

2.3.2 Intermediaries 14

2.3.3 Consumers 16

2.4 Distribution in developing and least developed countries 17

2.5 Tourism distribution in peripheral destinations 19

2.6 Tanzania as a developing country and as a peripheral destination 20

2.7 Safari tourism and its distribution 23

2.8 Research on tourism distribution channels and gaps 25 Chapter Three: Methodology

3.1 Introduction 30

3.2 Study area ___ 31

3.3 Study sample ___ 32

3.4 Semi-structured in-depth interviews_____ 37

3.5 Analysis ___ 39

3.6 Strengths, limitations and challenges ___ 40 
Chapter Four: Tourism in the Context of Tanzania

4.1 Introduction 43

4.2 Tanzania and its tourism industry - history and development 44

4.3 The importance of tourism to Tanzania's economy 47

4.4 Attractions in Tanzania 50

4.5 Market demand for destination Tanzania 53

4.6 Seasonality 60

4.7 Coping with seasonality 65

4.8 Marketing strategy 68

4.9 Safari tourism 70

4.10 Tourism in the Northern Tourist Circuit of Tanzania 71

4.11 Conclusion 73

\section{Chapter Five: Distribution Structures}

5.1 Introduction 77

5.2 Channels of distribution for photographic safaris 79

5.2.1 International package tourists

5.2.1.1 International package tourists direct to Tanzania 81

5.2.1.2 International package tourists through Kenya

5.2.2 International independent travellers

5.2.2.1 International independent travellers direct to Tanzania

5.2.2.2 International independent travellers through Kenya

5.2.3 Expatriates and volunteers

5.2.4 Domestic tourists 81

5.3 Channels of distribution for mountain climbing 86

5.3.1 International package tourists 87

5.3.2 Expatriates and volunteers 91

5.3.3 International independent travellers and domestic tourists 93

5.4 Channels of distribution for hunting safaris 93

5.5 Distribution channels for cultural and heritage sites 95

5.6 Distribution channels by sectors 98

$\begin{array}{lr}\text { 5.6.1 Accommodation } & 100 \\ \text { 5.6.1.1 Backpacker accommodation } & 100 \\ \text { 5.6.1.2 Hotels } & 101 \\ \text { 5.6.1.3 Wildlife lodges } & 103 \\ \text { 5.6.2 Local transport } & 104 \\ \text { 5.6.2.1 Car rentals_a } & 107 \\ \text { 5.6.2.2 Air charters } & 107 \\ \text { 5.6.2.3 Local travel agents } & 108\end{array}$

5.7 Factors influencing the channel structures 108 
5.8 Differences in distribution channels between local and foreign owned companies

5.9 Relationships among channel members

5.10 Conclusion

\section{Chapter Six: Operational Characteristics of the Channels of Distribution}

6.1 Introduction 121

6.2 Roles of different channel members 122

6.3 Choice of channel members 124

6.4 Operational characteristics of channels 130

6.5 Arranging and designing packages 135

6.6 Performance of channels and perceived issues 137

6.7 General visitors' booking behaviour 143

6.8 Application of information technology

6.9 Conclusion 145

Chapter Seven: Conclusions and Recommendations

7.1 Introduction 148

7.2 The structures of tourism distribution channels in the northern tourist circuit

7.3 Factors influencing channel structures

7.4 Operational aspects and measuring channel performance

7.4.1 Choice of channel members

7.4.2 Designing of tour packages

7.4.3 Evaluation of channel performance

7.5 Relationship between channel members and interdependence 155

7.6 Implications for businesses 157

7.7 Implications for the government 159

7.8 Overall conclusion 160

7.9 Recommendations 163

7.10 Avenues for future research 164

References 167 


\section{List of Tables}

Table 1.1: Total international arrivals in Tanzania (2000-2008) page 6

Table 2.1: Companies that were interviewed page 35

Table 4.1: Number of international arrivals and corresponding receipts page 49

Table 4.2: Visitors' length of stay and average expenditure per day page 50

Table 4.3: International visitor arrivals 2000-2008 page 54

Table 4.4: The top ten markets (countries) by arrivals page 55

Table 4.5: Purpose of visit to Tanzania page 56

Table 4.6: Visitors' travel arrangements page 57

Table 4.7: Percentage of visitors by age group: 2004-2006 page 57

Table 4.8: Modes of transport used by visitors page 60

Table 4.9: Visitor arrivals by month 2005-2008 page 63 


\section{List of Figures}

Figure 1.2: Zebra, Wildebeests and Black rhinos in Ngorongoro Conservation Area page 5

Figure 1.1: Map of Tanzania page 5

Figure 2.1: Multiple tourism distribution channels Page 13

Figure 2.2: Map of East African countries page 21

Figure 4.1: Map of Tanzania page 45

Figure 4.2: National parks and Game reserves in Tanzania 52

Figure 4.5: Major tourist arrival routes page 58

Figure 4.4: Participation of Tanzania in international trade fairs page 68

Figure 4.5: London city bus with advertisement of destination Tanzania page 69

Figure 4.6: The big five mammals page 70

Figure 4.7: Northern Tourist Circuit page 73

Figure 5.1:Distribution channels for photographic safaris (International market) page 80

Figure 5.2: Distribution channels for photographic safaris (Domestic market) page 87

Figure 5.3: Mount Kilimanjaro page 88

Figure 5.4: Mount Meru page 88

Figure 5.5: The peak of Mount Kilimanjaro page 89

Figure 5.6: Distribution channels for mountain climbing (International market) page 91 
Figure 5.7: Distribution channels for mountain climbing (Domestic market) page 94

Figure 5.8: Distribution channels for hunting safaris page 98

Figure 5.9: Maasai bomas in Ngorongoro Conservation Area page 98

Figure 5.10: Distribution channels for cultural and heritage sites page 99

Figure 5.11: Distribution channels for backpacker accommodation page 102

Figure 5.12: Distribution channels for hotels page 104

Figure 7.1: Simplified diagram showing relationships among major members of channels page 150 


\section{List of Abbreviations}

BoT - Bank of Tanzania

MNRT - Ministry of Natural Resources and Tourism

NBS - National Bureau of Statistics

NCA - Ngorongoro Conservation Area

NCAA - Ngorongoro Conservation Area Authority

TANAPA - Tanzania National Parks

TTB - Tanzania Tourist Board

TTBA - Tanzania Tourist Board Act

UN - United Nations

UNCTAD - United Nations Conference on Trade and Development

WCA - Wildlife Conservation Act

WTO - World Tourism Organization 


\section{Chapter One: Introduction}

\subsection{Introduction}

Tourism distribution is the way in which tourism, and tourism-related services and products, are delivered to consumers; the activities involved, and who participates in the channels used. This area has been increasingly receiving the attention of researchers in different countries. Its crucial role in businesses' marketing strategies is just one of the reasons it is attracting attention. Increasingly, it is being recognised as a critical source of competitive advantage for firms (Pearce and Taniguchi, 2007; Smith, 2007; Buhalis, 2000). Rosenbloom et al. (2004) add that it is becoming too difficult to hold onto a competitive edge via product, pricing and promotional strategies alone. Further, Knowles and Grabowski (1999) argue that the importance of distribution as an element in the marketing mix has shifted over the last four decades. Previously considered as having the least importance, distribution is now of primary importance. Tan (2002) emphasizes the importance of distribution as a function of marketing; without it, a product cannot be made available for purchase in the market.

Tourism distribution has been defined in various ways by different writers, but it can be put very simply: getting the consumer all they need; facilitating their access to the destination; and consuming what is being produced there. More definitions on tourism distribution from different perspectives are highlighted in Chapter Three.

The distribution of services and products to consumers can be direct or indirect. According to Morrison (1989, p. 274) “...direct distribution occurs when the organization assumes total responsibility for promoting, reserving and providing services to customers." Conversely, indirect distribution exists when all or part of the responsibility for these functions is given to a third party, usually a travel intermediary. The balance between direct and indirect channels largely depends on the nature and appeal of the product or activity; the destination location and its stage of growth, (whether matured or emerging); the advancement in technology and development of other infrastructure. What could easily be said, then, is that indirect distribution channels are more complex than direct ones, as they involve 
more people than just producers and consumers. Businesses or people who link up producers and consumers perform a range of tasks; and they may be located at destinations and at markets. These players are collectively referred to as intermediaries.

From what has been highlighted above, three groups of players in distribution channels are identified: producers, intermediaries and consumers. Producers or suppliers create or design activities or attractions. Where the attractions and activities are distributed indirectly, it is in most cases the intermediaries, specifically ground tour operators, who put together individual activities, services and attractions into bundles; thus making them readily available for purchase by consumers. In some cases the intermediary may also be a supplier; one example is where a transport provider might be both a supplier of transport, and also act as an intermediary between the tourist and attraction or activity provider.

The structure of distribution channels varies depending on a number of factors: nature of the attraction or activity, target markets and distance between destination and the markets. The perceptions of the structures vary depending on who is being asked to describe them: supplier, intermediary or consumer. The supplier's description of distribution structures and the factors influencing those structures may, understandably, differ from that of the intermediary or consumer. They all have different perspectives and, to a large extent, play different roles in those structures or channels.

Studies on different aspects of tourism distribution channels have been conducted by a reasonable number of researchers. Particular emphasis has been given on the nature of the products, surface transport and to relationships between tour operators and hotels, especially by researchers working in Europe, New Zealand, the Mediterranean and the Caribbean (Bastakis, Buhalis, and Butler, 2004; Buhalis, 2000; Karamustafa, 2000; Kimes and Lord, 1994; Medina-Muñoz, Medina-Muñoz and García-Falcón, 2003; Pearce and Sahli, 2007; Schott, 2007; Stuart, Pearce and Weaver, 2005). Generally, most of the research has focused on package leisure travel. More recently, researchers have recognized that different types of tourism and tourists generate different distribution channel structures, 
behaviours and issues (Smith, 2007). Studies that investigate the distribution of accommodation have focused primarily on the hotel sector; those with an interest in distribution in the transport sector have concentrated almost exclusively on airlines (Pearce and Sahli, 2007); and those which examine the distribution of attractions tend to focus more on beach holidays (Buhalis, 2000). Comparatively, most distribution research, not only in tourism but also in other sectors, has been carried out on the context of developed countries rather than in third world countries (Samiee, 1993). Among many other areas that still need more research about tourism distribution, is how African tourism products are distributed. Not only is this area under-researched but also, with exception of Wynne, et al (2001), there are no studies on tourism distribution channels that have been conducted in the context of Africa. This is one of the reasons for conducting this study. Other reason is the importance of distribution strategies for country like Tanzania which seeks to develop its tourism industry.

This study was conducted in the northern tourist circuit of Tanzania. The following sections provide a brief introduction about Tanzania and the tourism industry in the country. A more detailed discussion is presented in the later chapters. Before the conclusion section of this chapter, research objectives are stated, and a "road map" for the organization of this thesis is presented, as well.

\subsection{Tanzania and its tourism sector}

Tanzania (Figure 1.1) is one of five countries that form the East African Community (EAC). The others are Kenya, Uganda, Rwanda and Burundi. The name Tanzania was derived from the unification of Tanganyika (the mainland) and the Zanzibar Islands in 1964, which formed the United Republic of Tanzania. Dar es Salaam is by far the biggest commercial capital in the country. Dodoma, located in the central part of the country, is the political capital. The country has an estimated population of 40 million. Economically, Tanzania, like the majority of developing countries, is largely reliant on agriculture. Eighty percent of the country's population, particularly in rural areas, depend on agriculture for their livelihood (BoT, 2008). Although the country possesses vast areas of fertile land 
for agriculture, the lack of modern agricultural technology limits this potentially leading economic sector to only $4 \%$ of the total land. Other fast growing economic sectors are tourism, mining, and the recently-discovered natural gas. Again, lack of overall development has hampered the extraction of these various resources.

Right after the country's independence in 1960, the government had a major shareholding in the tourist industry. However foreign companies were reluctant to invest in the country due to the then socialist policies governing the country's economy (Wade, Mwasaga and Eagles, 2001). In 1990s, the government began to liberalize the tourist sector, thus revitalizing the tourist industry. The government created the Tanzania Tourist Board in 1992. The board is responsible for marketing the destination Tanzania in and out of the country. It carries out some marketing surveys in collaboration with other government departments such as the National Bureau of Statistics, the Bank of Tanzania and the Tourism Division.

Tanzania is endowed with a variety of tourist attractions. They vary from landscapes, national parks, and cultural diversity. Mount Kilimanjaro is the best known attraction, and Africa's highest mountain. Serengeti National Park is world-famous and has spectacular seasonal migrations of animals. The Ngorongoro Conservation Area is an extinct volcanic caldera with excellent game-viewing from the crater rim. The conservation area has large herds of wildebeest and zebra, lions, and the endangered black rhinoceros (Figure 1.2). Tourism is also focused on the coast, especially on the islands of Zanzibar, Pemba and Mafia. Beach tourism (sun bathing), sports fishing and diving are just some of the tourist activities in these islands. Although not as popular as wildlife, cultural diversity is another type of tourist attraction in Tanzania but it is largely unexplored. 
Figure 1.1: Map of Tanzania

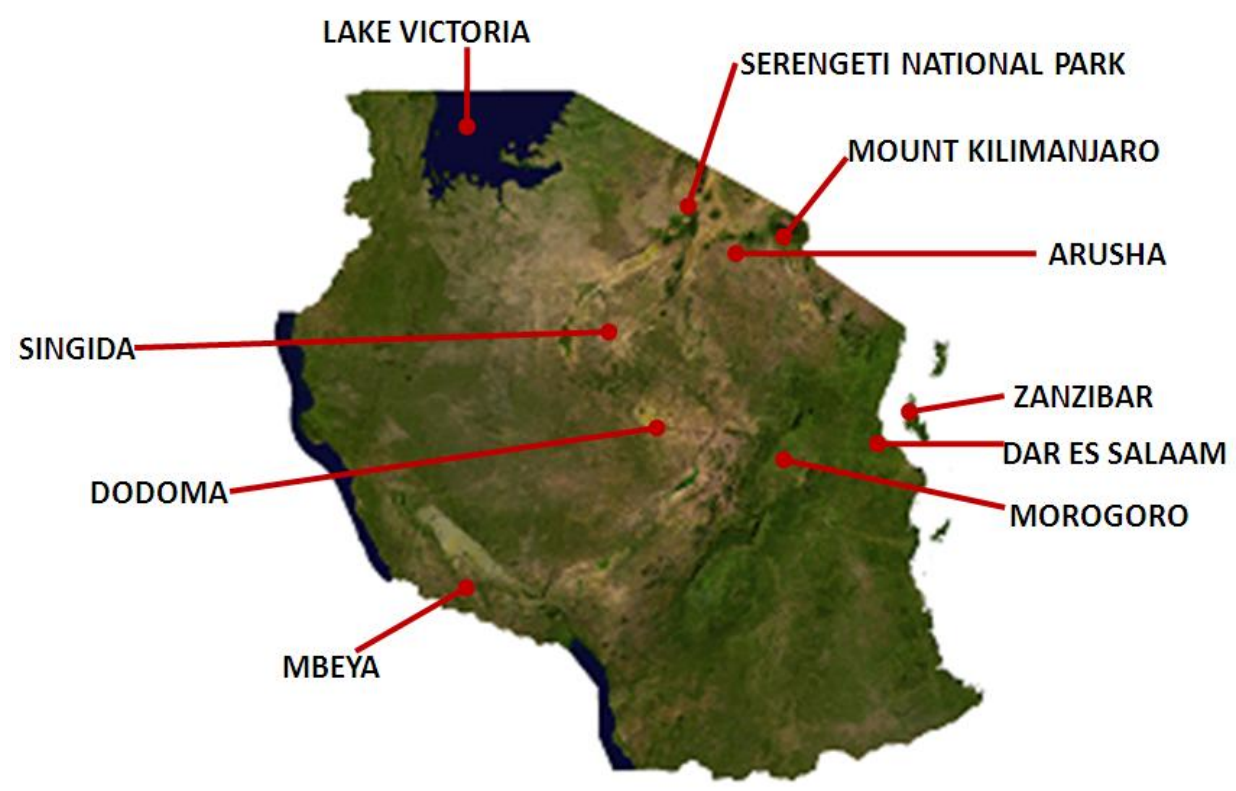

Source: Adapted from United Nations Cartographic Section

Figure 1.2: Zebra, Wildebeests and Black rhinos in Ngorongoro Conservation Area

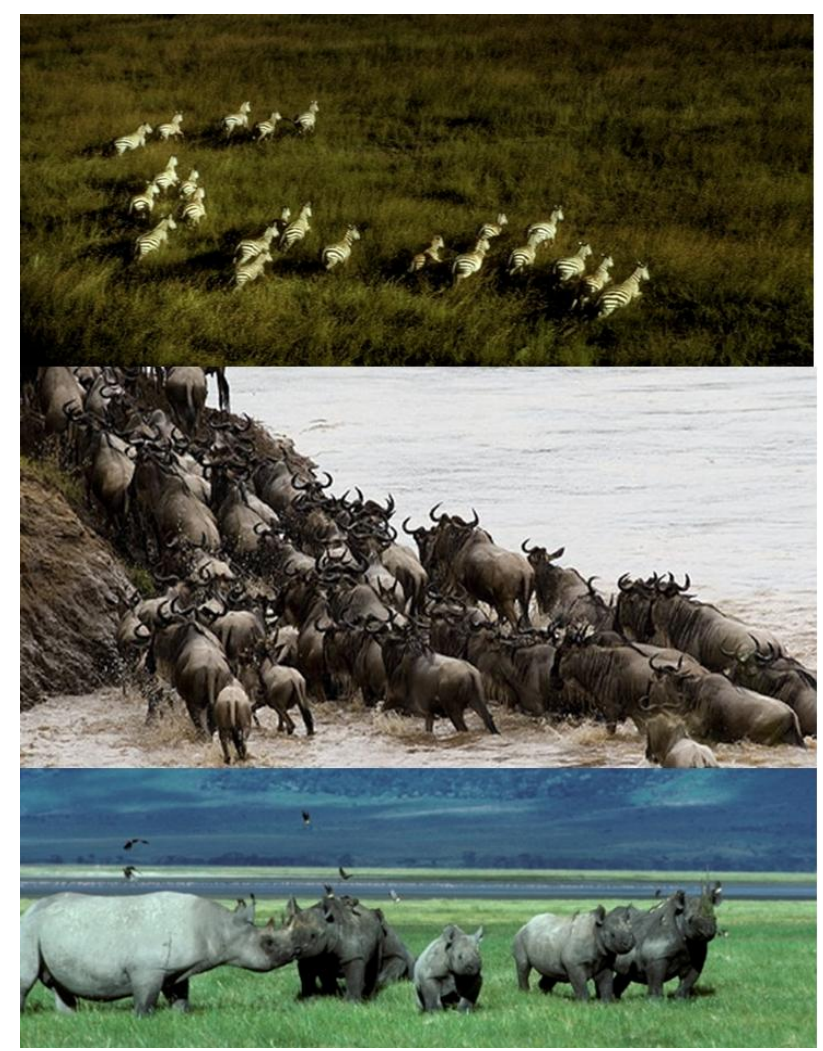

Source: Adapted from TANAPA 
These attractions have made Tanzania stands out as one of the competitive SubSaharan Africa destinations. The tourism industry has been growing steadily for the last nine years (Table 1.1).

The majority of international tourists visiting the country are from Europe and North America. These two sources of markets contributed approximately $43 \%$ of total international arrivals in the country in 2008 (MNRT, 2008). This shows an increasing demand for the destination. The three international markets that produced the largest number of international arrivals in 2008 were: Kenya $(184,269)$, the United States $(66,953)$, and the United Kingdom $(58,245)$.

Table 1.1: Total international arrivals in Tanzania (2000-2008)

\begin{tabular}{|l|l|l|l|l|l|l|l|l|l|}
\hline Year & $\mathbf{2 0 0 0}$ & $\mathbf{2 0 0 1}$ & $\mathbf{2 0 0 2}$ & $\mathbf{2 0 0 3}$ & $\mathbf{2 0 0 4}$ & $\mathbf{2 0 0 5}$ & $\mathbf{2 0 0 6}$ & $\mathbf{2 0 0 7}$ & $\mathbf{2 0 0 8}$ \\
\hline TOTAL & 501,669 & 525,122 & 575,296 & 576,198 & 582,807 & 612,754 & 644,124 & 719,031 & 770,376 \\
\hline
\end{tabular}

Source: MNRT (2008)

The majority of international arrivals in Tanzania are holiday-makers followed by business people including expatriates. The average length of stay for holiday makers is 12 days.

The northern tourist circuit is the core of Tanzania's tourism. It is where the majority of the country's world famous attractions such as Serengeti National Park, Ngorongoro Conservation Area and Mount Kilimanjaro are located. Arusha is the main hub in this circuit and is considered to be the tourism capital of Tanzania. Arusha is truly the gateway for Tanzania's tourism. Tourism infrastructure in this circuit is relatively well developed in comparison to other parts of the country. There are more than 300 tourism-related businesses operating in this tourist circuit. They include accommodation providers, attraction and transport providers. These businesses work together in different channels in an effort to make sure visitors get the experience they deserve at the destinations. The broader details of the existing structures of tourism distribution in the northern tourist circuit are presented in Chapter Five and Six. 
Tourism plays a crucial role in the economy of Tanzania. The sector leads in the country for total exports, and in 2008 tourism contributed 25\% of Tanzania's GDP (MNRT, 2008). In 2007 tourism generated a total of 198,557 jobs in the country (Kweka and Ngowi, 2007). Total receipts from the sector have increased by $390 \%$ over the last thirteen years: from US\$ 259.44 million in 1995 to US\$ 1,269.68 million in 2008. This has made tourism the top foreign exchange earner for the country (MNRT, 2008).

However, with all the signs of growth in this industry and its importance to the economy of Tanzania, there are still very few studies which have been conducted on tourism that examine different aspects of the industry. In Tanzania such studies are important for a number of reasons; they include improving management through informed recommendations and decisions both in government and the private sector. This underscores the importance of this study in this country and especially in the tourism heart of the country; the northern tourist circuit.

\subsection{Research objectives}

As noted earlier, the majority of distribution-oriented research projects are conducted in developed countries and not in third world countries. This study is therefore a response to the observed shortage of research work in developing countries and the need for such studies in these countries particularly Tanzania for them to develop their tourism industries. It focuses on tourism distribution channels in the northern tourist circuit of Tanzania. The research objectives are:

- To investigate tourism distribution channels in the northern tourist circuit;

- To reveal the structures of distribution in this circuit;

- To examine factors influencing distribution structures; and

- To explore operational characteristics in the channels of distribution.

Along with these objectives, other broad issues such as the performance of channels, and the way channels are evaluated in this tourist circuit, are also investigated. This research also probes the use of information technology by businesses in their distribution systems. 
This is a destination-based study. It focuses on suppliers and intermediaries located in the northern tourist circuit of Tanzania. Interviews were the main means of data collection, and were conducted with managers of different businesses in that area. Chapter Three sets out the methodological details.

The findings of this research are expected to explain distribution systems in the northern tourist circuit of Tanzania, thus increasing understanding of how these systems function, and adding to knowledge in the general literature on tourism distribution channels.

\subsection{Thesis organization}

This thesis is divided into seven chapters.

Chapter One focuses on providing the background to distribution channels and their importance, and provides a general briefing on the broad structures of direct and indirect distributions. It also provides background of the study context: Tanzania and specifically the northern tourist circuit. A general outline of the tourism industry in the country is also provided.

Chapter Two presents a review of the literature on broader tourism distribution channels. First, it reviews the concept of tourism distribution channels; then it touches on relevant aspects of tourism, including destinations in peripheral and developing countries. It also identifies gaps in the literature and highlights those that this study attempts to fill.

Chapter Three provides details on the methodology used. It discusses how the research was carried out, and highlights the field logistics. The validity and relevance of the methods used are also presented. The chapter aims to provide the reader with a necessary understanding of how data for this study was collected.

Chapter Four draws attention to the contextual characteristics i.e. Tanzania. It presents a brief history of the country together with detailed information about tourism industry that includes the main attractions, the significance of the industry to Tanzania's economy, the demand patterns and seasonality. 
Chapter Five analyses in detail the distribution structures of different tourism products such as photographic and hunting safaris. It also presents the structures of distribution channels in other sectors such as accommodation and local transport. Factors influencing the distribution structures are also discussed.

Chapter Six continues with the analysis; focusing more on the operational aspects of the distribution channels such as how channel members are chosen, package design, and how the performance of different channels is measured.

Chapter Seven provides an overall discussion, summarises the key findings and links them with the general literature on tourism distribution channels. Implications for businesses and government are also highlighted. Finally, the chapter presents recommendations and avenues for future research. 


\section{Chapter Two: Literature review}

\subsection{Introduction}

This chapter presents a broad discussion of the concept of distribution channels. It focuses on highlighting previous studies in this area. Specifically, it examines aspects relevant to focus of this study. Thus, the literature review presented here aims to inform the reader about tourism distribution studies, and to better enable them to follow the concepts discussed in the following chapters. Finally, this chapter aims to enhance the reader's understanding the reason behind methodology adopted in this study which will be discussed in the next chapter.

In any business there should be ways in which targeted customers can access and consume products or services offered. In this context, 'ways' are referred to as distribution channels. Stern and El-Ansary (1992), and Kotler et al (1996) define distribution as a pattern of interdependent organizations involved in the process of making a product or service known to possible consumers. Distribution is the bridge linking supply and demand (Gartner and Bachri, 1994). In tourism, it is a vital link between markets and destinations (Knowles and Grabowski, 1994); it also connects cores and peripheries (Stuart, Pearce and Weaver, 2005). Alcazar Martinez (2002:17) as quoted in Stuart, Pearce and Weaver (2005), further emphasises the objective of distribution being "... to make the product available to the consumer in the quantity needed at the right time, place, state and possession utility to the consumer, thereby facilitating sales". But since in the tourism industry, products are mainly consumed at destinations, the distribution objective is therefore to facilitate visitors access to tourism products at destinations.

\subsection{Distribution Channels}

Distribution channels have been defined in different ways and from different perspectives. From a supply perspective, Middleton (1994: 202) defines 
distribution channels as “...any organised and serviced system paid for out of marketing budgets and created or utilized to provide convenient points of sale and/or access to consumers, away from the location of production and consumption" This definition does not say anything about the channel members involved, and it focuses mainly on the traditional distribution system from the supply side. It does not consider the informal distribution systems that are common in developing countries and in some developed ones (Jamison, 2003). Further, this definition assumes that access points for consumers are located away from the location of production and consumption. However, in some cases the access points are located at the same place where production and consumption take place. The definition also ignores the promotional and marketing research activities undertaken by members of the distribution channel (Buhalis, 2001). Wanhill (1993:189) defines distribution channels more broadly, and considers the role of intermediaries as being, “...to bring buyers and sellers together, either to create markets where they previously didn't exist or to make existing markets work more efficiently and thereby to expand market size." In this definition, therefore, Wanhill highlights the role of intermediaries as channel members, bringing suppliers and buyers together and therefore facilitating business. However, the definition is not sufficiently comprehensive, for it ignores the roles played by other channel members, such as suppliers and consumers. The definition also generalizes that in all distribution systems there are intermediaries, whilst direct distribution does not involve any intermediaries. "Distribution channels are operating structures, systems or linkages of various combinations of travel organization, through which a producer of travel products describes and confirms travel arrangement to the buyers" (McIntosh 1985:8). This definition downplays the promotional aspect of distribution systems, highlighting information provision instead (Stuart, 2005). A more general definition of a distribution channel has been offered by the World Tourism Organisation (WTO, 1975): “A distribution channel can be described as a given combination of intermediaries who cooperate in the sale of a product. A distribution system can be and in most instances is composed of more than one distribution channel, each of which operates parallel to and in competition with other channels". This definition might seem rather out-dated when 
compared with the advances made in defining distribution since then, but it still has value. The WTO definition encompasses the structure and the complexity of the distribution system; it also recognises the presence of intermediaries, and the main purpose of the channel which is to sell the product. It is within the WTO definition that this study precedes.

\subsubsection{Distribution Channels in Tourism}

Unlike distribution in manufacturing industries, tourism and other service industries distribute their products with the aim of facilitating consumer access to services, in this case, tourism attractions at the destination. This is because tourism products, contrary to manufactured products, are somewhat intangible. A consumer in the tourism industry must travel from their place of origin to the destination, so as to consume the product bought while at their place of origin, en route, or at destination (Richardson, 1996). Tourism products therefore do not require the logistics involved in moving manufactured products such as physically transporting the products, warehousing, and managing stock turnover. The transport involved in tourism is mainly to facilitate visitors' access to the destination rather than physically distributing products as in the manufacturing industries.

\subsubsection{Direct and indirect distribution channels}

Distribution channels structures are of two main types: direct or indirect. A direct distribution channel is where suppliers or providers sell their products directly to consumers or tourists (Figure 2.1). Such a channel is made up of the supplier and the consumer only. Direct distribution systems come in various forms: advertising, public relations, sales, promotion, direct mail, personal selling and websites (Wahab, Crampon and Rothfield, 1976). Selling a product through direct sales can take place at either the supplier's location, or where the consumer is located. Whilst the direct distribution channel is the shortest 
channel, it is not always the most cost effective for suppliers. On the other hand, the distribution channel is considered to be indirect if it involves one or more intermediaries between supplier and consumer. The intermediaries involved might be either in the markets or at the destination. Intermediaries are involved so as to extend or improve the strategy of market access. However, the choice of whether to sell the products directly or indirectly will depend on the provider's attitude towards the different channels, the cost involved and the preference of the target markets (Stuart, Pearce \& Weaver, 2005; Pearce and Tan, 2004). The issue of volume versus yield is also critical in deciding which distribution channel strategy is to be used. A study by Pearce and Tan (2004) in heritage and cultural tourism identifies three distinctive factors that influence a supplier's choice of distribution channels and structure: breadth of product appeal, capacity issues, and whether a product is commissionable or not. It is currently unknown how the distribution structures in safari tourism are and function, let alone the factors influencing choice of the channels.

Figure 2.1: Multiple tourism distribution channels

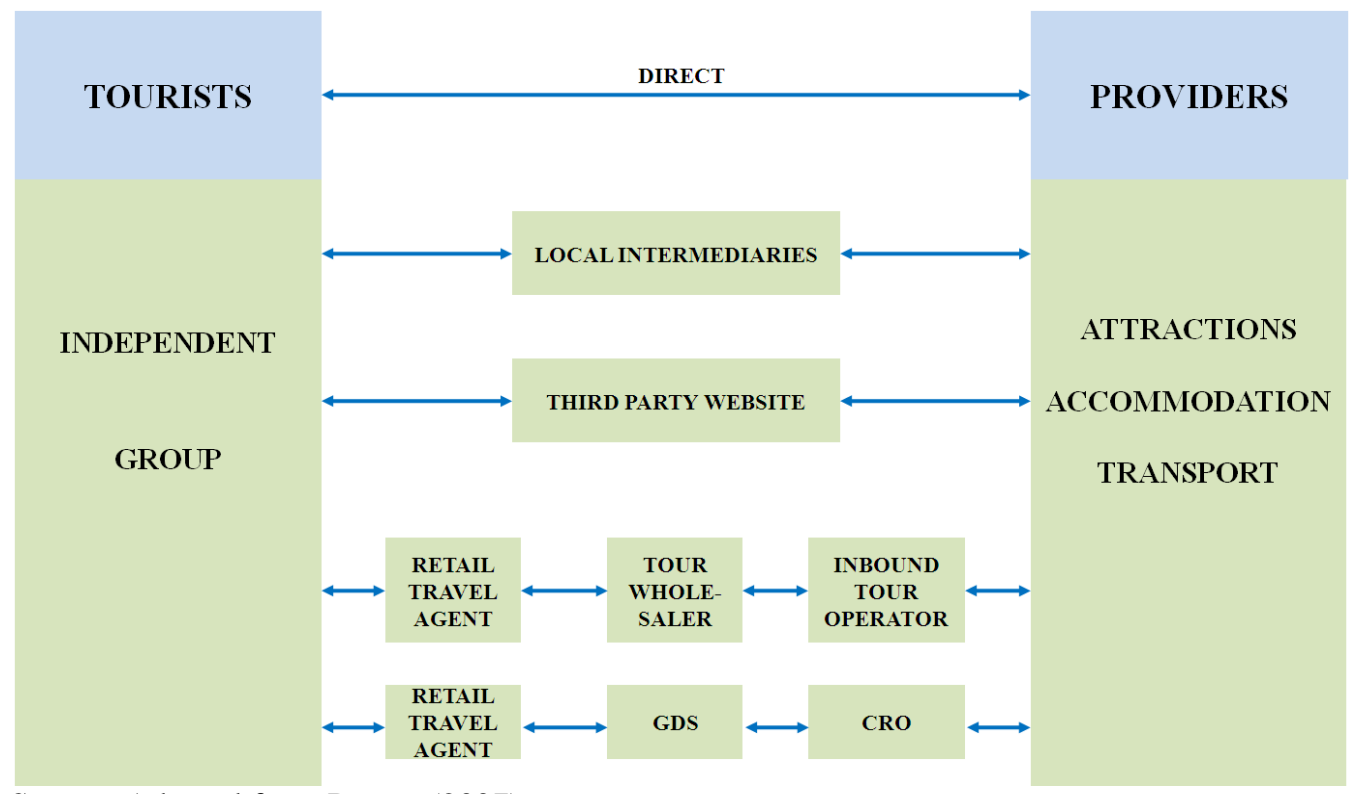

Source: Adapted from Pearce (2007) 


\subsection{Members in distribution channels}

As stated earlier, the use of the term 'distribution' in the tourism industry means the organizations and arrangements that together help the visitor access and consume the product; it includes all channel members involved in the process, and how the members relate to each other. Channel members in tourism are grouped mainly into three groups: suppliers, intermediaries, and consumers. There are also sub classifications within the groups, based mainly on their different functions and geographical locations of these subgroups. The three groups - suppliers, intermediaries, and consumers are discussed in turn.

\subsubsection{Suppliers}

Suppliers are amongst the principal actors in the distribution channels. The majority of other members are dependent on suppliers to create the products and services. The created products or activities are then sold to consumers individually or bundled together into packages of different composition. Suppliers are of all types, but the main ones are providers of attractions, transport (local and international), accommodation and hospitality. In developing countries, suppliers are largely formed by small and medium-sized enterprises (SMEs) compared to multinational corporations in the tourism industry (Richardson, 1996).

\subsubsection{Intermediaries}

These are the 'middle men' between suppliers and consumers or between suppliers and other intermediaries. They distribute products and activities and may or may not be involved in other marketing functions. Intermediaries, particularly those located in the markets, often present suppliers' products in the marketplace in addition to their main businesses. In insisting on the 
importance of intermediaries, Christopher (1992) attests that this group of channel members bridge five gaps: time, space, quantity, variety, and communication of information. Intermediaries therefore make it easier for a consumer to shop for their holidays, especially those who prefer to shop indirectly. Stuart (2005) however notes the general notion that destinationbased intermediaries have little importance in the overall context of tourism distribution systems.

Members within an intermediary group are of different types. Those located at the destination are mainly Inbound Tour Operators (IBOs) and Inbound Travel Agents. The market-based intermediaries are either Outbound Tour Operators (OBOs), Outbound Travel Agents, or Wholesalers. The diverse functions of these intermediaries are highly influenced by destination attributes such as available attractions, geographical location, and the development of associated infrastructure.

Generally, intermediaries located overseas promote and sell individual components or packaged tourism products to consumers. They are overseas purchase outlets that are convenient to potential visitors in generating markets (Holloway, 1989; Buhalis, 2001). These intermediaries carry little financial risk as they do not stock travel products (Hudson et al, 2001). These are information-intense channel members. They are expected to provide full travel and holiday information to potential customers with different needs and interests. Some of the intermediaries and especially travel agents have access to both the Central Reservation Systems (CRS) and the Global Distribution Systems (GDS) of different accommodation providers and airlines respectively. This helps them to book these services for clients thus selling them indirectly.

Inbound Tour Operators perform the main function of providing packaged products either to Outbound Travel Agents or directly to consumers. The 
Inbound Tour Operators are important in situations where the Outbound Tour Operators have limited information about the destination. They are able to handle the ground aspects of tourism products on behalf of Outbound Tour Operators (Stuart, 2005; Gee et al, 1989). They assemble individual products into tour packages (Buhalis, 2001). Inbound Tour Operators often have links with suppliers of different activities, attractions and other services at the destination. They are important in organising a complex process of scattered individual products into convenient packages that are easy to be sold. This would cost a lot of time and money for a customer choosing to organize the entire trip themselves. Competence in organising such a complex process is among the key areas that keep tour operators competitive as consumer tastes change (Stuart, 2004). This group of intermediaries make their profit by applying the principle of economies of scale: bulk buying individual products to 'bundle them up' and sell to Outbound Operators, or sometimes selling them direct to consumers. However, the role played by tour operators differs from destination to destination and is also influenced by the nature of the activities and products involved (Stuart, 2004). Inbound tour operators are observed to be the least-studied members of distribution channels in tourism when compared to other channel members (Buhalis, 2001).

\subsubsection{Consumers}

Consumers or tourists are amongst the focal points which the majority of other channel members target. All the arrangements in different channels aim, directly or indirectly, at facilitating consumers' desire to access the destination and have a good experience. All activities performed by other members in a channel of distribution are intended to meet the needs of this group. However, consumers of tourism products are very diverse. They come from different geographical locations; they have different 'tastes' and they also visit destinations for different interests and purposes. Change in consumer taste potentially influences the channel systems and structure (Stuart, 2004; Cooper and Lewis, 2001). Consumer choices and decisions are sometimes influenced 
by the existing distribution systems and this occurs in the various stages of planning their holidays: while at their place of origin, en route, or at the destination (Buhalis, 2000). Stuart (2004:30) concludes “... information provided by distribution channels adds to awareness, particularly through the use of images in order to positively influence destination choice."

\subsection{Distribution in developing and least developed countries}

Least developed countries are those countries that have standards of governments, social programmes and human rights that are yet to develop to those standards in the West (UNCTAD, 2001). These countries are referred to as developing countries or least developed countries (LDC). Studies in developing countries, specifically those related to tourism, have been more periodic with no sustained momentum in comparison to developed countries (UNCTAD, 2008). This has lead to an incomplete understanding of how different systems work in developing countries. These countries, regardless of their individual geographical locations, have a number of common governance problems. The primary and secondary information that they use in decisionmaking processes is questionable, especially when considering the methods used and level of objectivity in data collection (Toyne and Walters, 1989). For developing countries, this leads to uninformed decisions being made in different sectors.

Literature about distribution channels in least-developed countries, specifically those in Africa, is scant (Samiee, 1993). Most of the distribution channel studies in LDCs have been conducted from the perspective of manufacturing industries, which have considered these countries as markets and consumers of products from multinational companies in developed countries (Samiee, 1993). Older studies of distribution channels in LDCs observed a number of characteristics of distribution systems common to these countries. Their distribution systems are fragmented and composed of numerous channel 
members (Malhorta, 1986; Stern and El-Ansary, 1988; Batra, 1997). Having many channel members makes it easy for channel members to switch from one partner to another at relatively low cost (Frazier and Summers, 1984). Channel members in these countries are generally burdened with poor infrastructure, including inadequate communication systems (Cateora, 1987; Drucker, 1958). Technological advancements in these countries are still low and unable to compete with those in developed countries. Intermediaries in these countries are much more dependent on personal communication; the majority of them are small and medium-sized businesses which, in most cases, cannot afford some of the marketing costs crucial to their businesses (Samiee, 1993). The presence of so many formal and informal channel members in LDCs is observed to be a barrier to opportunities to grow into large enterprises in least developed countries (Tybout, 2000). Relationships between channel members are highly influenced by culture. However, the influence of culture on distribution structure has received little coverage in the literature. General observation shows that in developing countries, channel members tend to take on many functions; they become more focused and specialised with economic development (Samiee, 1993).

Most of these developing countries are dependent on agrarian economies. The main economic activities for the majority of the population are agriculturerelated activities. In such agrarian economies distribution channels are fairly short; producers are also the main consumers, and agricultural production is more subsistence-based. The economies in these contexts are commonly influenced by cultures that rely heavily on personal relationships and friendships (Samiee, 1993).

Informal channels and partners are common in developing countries. The presence of many informal channels, particularly in rural areas, means that the processes of product distribution are very informal; and thus multinationals (manufacturers) have little direct control over the quality or the image of products delivered to end users (Katsiekas, Goode and Katsiekas, 2000). 
Multiple levels are caused by the increasing number of street traders. Formal channel members often find themselves in price and supply competition with informal channel members, the micro vendors. Marketers in informal sectors in LDCs are less likely to manifest and maintain loyalty to any particular brand. Such informal and 'grey market' distribution channels potentially confound distribution plans for LDCs. This is because marketers are often driven by short term goals (Frazier et al, 1988). Despite the many problems associated with marketing and distribution systems in LDCs, these markets still represent a significant market expansion opportunity for multinationals (Cavusgil, 1997).

\subsection{Tourism distribution in peripheral destinations}

Peripheral destinations are those destinations which are located far from generating markets (Brown and Hall, 2000). Such destinations are usually remotely located. They naturally occur in different geographical contexts: rural, coastal, island, LDCs or developed countries (Wanhill and Buhalis, 1999). The concept of peripheriality originated from development studies. It was later applied in different fields and advanced to develop the theory of dependency (Stuart, 2004).

Being peripherally located, such destinations suffer a number of disadvantages which include increased costs of access, sparse population densities, and reliance on traditional industries (Wanhill, 1997). Stuart (2004) attests that peripheral destinations are faced with numerous issues, and if cores are facing similar issues, then the magnitude in the peripheries is relatively high. Studies show the majority of tourism enterprises in peripheries are SMEs (Friel, 1999). Britton (1982) and Buhalis (1999) contend that large multinational enterprises located in core economies often tend to control the tourism industry in peripheries. For most of them this is largely due to their high level of expertise, sufficient capital and long experience in the industry. This makes 
peripherally-located suppliers dependent on the 'giants' located in the core (Ujma, 2001).

Lack of knowledge of markets, especially international ones, and also lack of experience in running a business in a foreign country, is among factors that hinder SMEs located in peripheries effectively accessing these markets (Stuart, 2004). The means to access markets are probably too complex for these SMEs to handle; thus the need to work with other intermediaries with full market knowledge is inevitable. This then leads to more power in the channels being in overseas' hands or with market-located agents. Relationships between suppliers and intermediaries are largely negative for the peripherally-located SME supplier (Britton, 1982; Buhalis, 2000) due to centralization of power in offshore intermediaries. Expansion of SMEs will be possible if they gain power and control over the channels from core-based intermediaries. It is the fast growth of information technology and the increasing use of the internet, among other things in peripheral destinations, which will empower suppliers in remote areas to achieve greater control over the channels.

\subsection{Tanzania as a developing country and as a peripheral destination}

Tanzania "Authentic Africa" the "land of Kilimanjaro, Serengeti and Zanzibar" is one of five East African countries. The others are Uganda, Kenya, Rwanda and Burundi (Figure 2.2). Tanzania is endowed with a network of nature reserves; and about 30 percent of the country's land, an area roughly the size of New Zealand, is under legal conservation status (MNRT, 2008). These include national parks, Ngorongoro conservation area, game reserves and forestry reserves. The country is amongst the top African countries in terms of its high population density and the diversity of wildlife species. Although not the only tourist attraction, it is this richness of wildlife that attracts increasing numbers of international visitors to the country (Tables 
1.1 and 4.1). The wildlife and landscape resources in the country attract visitors with different interests: game viewers (savannah safaris), researchers, photographers, mountain climbers, and hunters. Tourism is a leading export, followed by the mining and agriculture sectors.

\section{Figure 2.2: Map of East African countries}

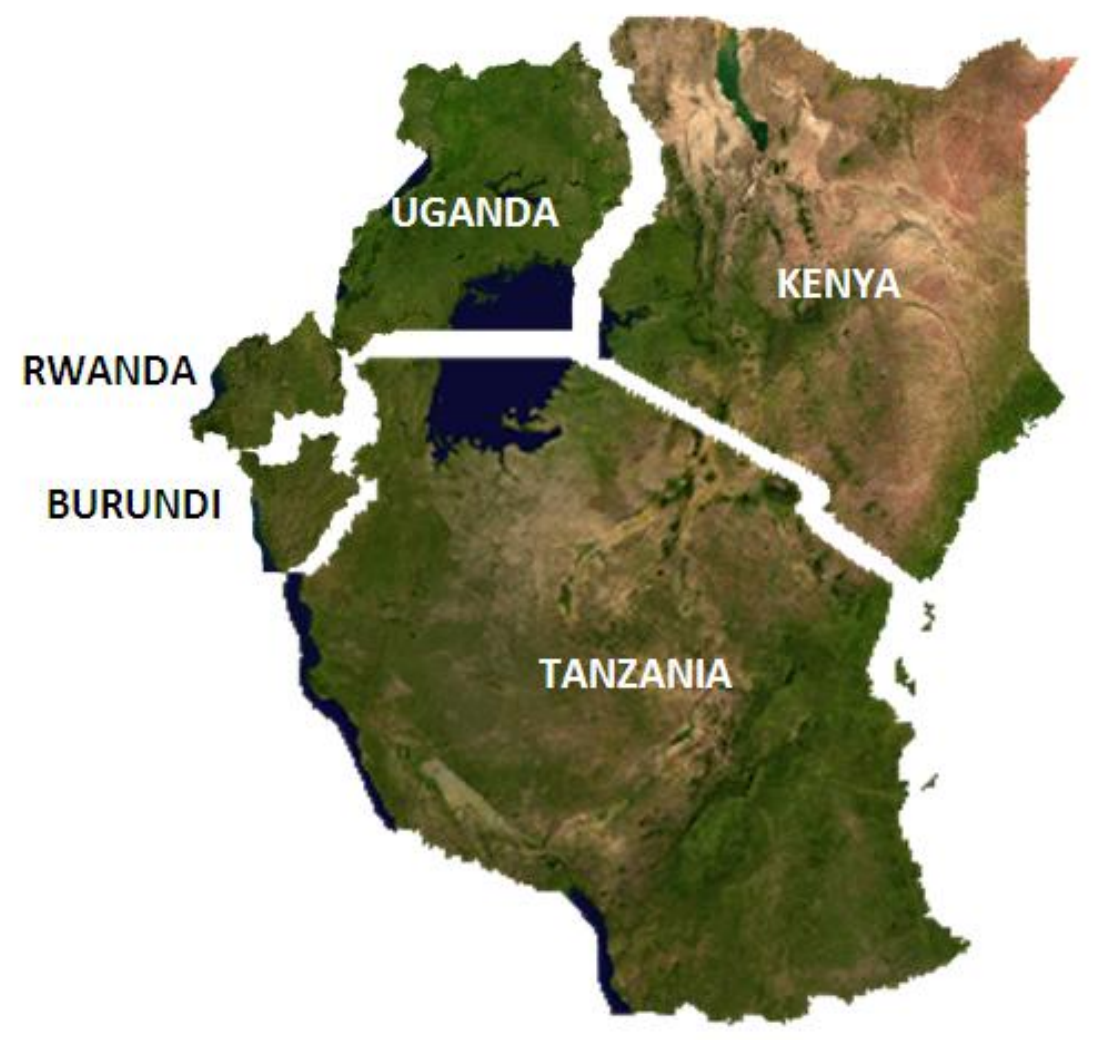

Source: United Nations Cartographic Section

Tanzania as a destination is both a developing country and a peripherallylocated destination in relation to the origins of most of its visitors (Europe and North America). The country experiences visitor seasonality partly due to weather but also due to poor development of its infrastructure. There are mainly three seasons: low season, which starts from March and continues through April and May; high season, from June to mid-November and peak season from mid-December to February. The main economic activity for locals is agriculture and is at subsistence level. The majority of businesses in 
the country are at the scale of small and medium sized enterprises (URT, 2002).

In addition to the wildlife safaris, Tanzania offers adventure tourism, mainly mountain climbing due the presence of a number of mountains in the country including the highest in Africa, the Mount Kilimanjaro. Different studies have looked at different aspects of adventure tourism. Consumer experiences of adventure tourism, particularly mountaineering, have been explored (Beedie, 2003b; Pomfret, 2006); white-water rafting (Fluker and Turner, 2000), and white-water kayaking (Kane and Zink, 2004). Some of the literature (Walle, 1997; Ryan, 2003; Gyimóthy and Mykletun, 2004) tends to focus on the risks related to adventure tourism, while others (Bentley and Page, 2001; Bentley et al., 2001a, b; Callander and Page, 2003; Morgan and Fluker, 2003) have paid attention to the implications of accidents and associated injuries in adventure activities' tourism.. In addition, adventure tourism has been investigated as a wider cultural phenomenon (Cloke and Perkins, 1998; Cloke and Perkins, 2002). Only a few authors have looked at the distribution of adventure tourism: distribution of man-made adventure attractions (Schott, 2007); investigation of adventure tourists through distribution channels (PATA, 2003; Sung, 2004) Swarbrooke et al. (2003) broadly examine distribution channels in adventure tourism.

PATA (2003) did a survey of adventure tourists from Australia and New Zealand aimed at investigating their methods of booking transport and accommodation. They found that the majority booked their product directly and relied on word of mouth as the major source for information. Contrary to PATA (2003), Sung (2004) found friends as a source of information was ranked second by the majority of adventure tourists in North America after the magazine; these tourists preferred partially exclusive arrangements for their adventure holidays. 'At destination' distribution was found to be dominant in the adventure activities in Queenstown (New Zealand) and it is generally described to be complex (Schott, 2007), and differs little from cultural and 
heritage distribution (Pearce and Tan, 2006). Adventure suppliers in Queenstown consider that adventure tourists rely more on 'at destination' booking for their adventure. They are reluctant to book early while are at their origins simply because this would limit their flexibility, restricting their search for the best value, and for the most update product: it is always easier to do that at destination rather than at the origins (Schott, 2007).

Swarbrooke et al. (2003) note that distribution channels can be complex, and that the distribution of adventure tourism products often involves the use of numerous channels. Distribution of adventure tourism is still largely underresearched in developed countries, let alone in developing countries and with specifically nature-based adventure in the context of Africa.

This study was conducted in the northern tourist circuit of the country. The circuit receives the largest volume of visitors in the country (MNRT, 2008). Although this circuit is in both a peripheral and a developing country, within the country, and in the regional bloc, the circuit is certainly more of a core tourist area than a peripheral destination. More detail about the northern tourist circuit is given in Chapter Four. Before this study was conducted, no study had been carried out to identify the main tourism products in this circuit and how are they distributed to clients. The country is therefore the best study site for this project as it offers many attributes that are of interest. The findings of this study will contribute significantly to the understanding of tourism distribution channels and to the general literature.

\subsection{Safari tourism and its distribution}

Safari tourism or wildlife safari is arguably the main tourism product in most Sub-Sahara African destinations. It is unique in the sense that it involves guided game viewing and hunting in the natural environment (Akama and 
Kieti, 2003); it is supported by the rich diversity of the wildlife with which Africa is blessed.

Such African safaris have been attracting an increasing number of international visitors, and particularly in Tanzania; they come mainly from Europe and North America (Tables 4.3 and 4.4). As safari destinations, particularly those in Tanzania, are located far from the origins or markets this underscores the need for well- organized distribution channels. The cultural difference between locals and visitors also necessitates the importance of having channel members with a good understanding of different cultures. It is important that channels members work together so as to meet the expectations of long-haul travellers who visit these destinations.

The trend in safari tourism demand has, at least in part, depended on the economic potential of African destinations. Less developed infrastructure, unstable security, and poor marketing strategies are just some of the factors that hinder the pace of demand for safari tourism (World Economic Forum, 2008). For this reason, African countries offering safari tourism have intensified the development and promotional activities of their tourism industry (Adejuwon, 1986; MNRT, 2006).

The demand for safari tourism in Tanzania is observed to be increasing (URT, 2002; MNRT, 2008). One of the main reasons for the growth of international tourism in the country is the uniqueness and diversity of the wildlife mentioned earlier; the very rich geographical resources such as climate with good sunshine all year round, pleasant beach fronts, and cultural and historical sites, also contribute. Unlike other forms of tourism, wildlife safaris in Tanzania and Sub-Saharan Africa are unique attractions which make the region among the competitive tourist destinations in the world.

Research on safari tourism has tended to be general and focus on other areas: nature tourism and ecotourism (Charnley, 2005), measuring tourist satisfaction (Akama and Kieti, 2003), experience of nature and reproduction of 
environmental discourse (Norton, 1999), general wildlife-based tourism (Sindiga, 1995), the role of intermediary institutions in marketing rural tourism (Forstner, 2004), history and market analysis of tourism in Tanzania (Wade, Mwasaga and Eagles, 2001) and ecotourism in the third world (Cater, 2002). None of these studies have attempted to describe safari tourism, nor have they examined distribution channels of safari tourism.

Generally, no research has been carried out to find out how safari products are distributed and any factors influencing such distribution structures. Understanding of how safari products are distributed and important for businesses in the tourism industry as Rosenbloom, Larsen, and Smith (2004) contend that it has become too difficult to hold onto a competitive edge via product, pricing and promotional strategies; and (Pearce and Taniguchi, 2007) observe that distribution is increasingly being recognized as a critical source of competitive advantage in the marketing mix. Research on the structure of distribution channels in safari tourism and other forms of tourism in the African context is urgently needed in this era of increasingly competition among businesses within the destination as well as competition among different destinations in world.

\subsection{Research on tourism distribution channels and gaps}

It is only in the past two decades that research on tourism distribution channels has received serious attention (Pearce, 2007; Schott, 2007). Most of the studies are in the context of developed and well established destinations (Stuart, Pearce and Weaver, 2005). Distribution channels in peripheral destinations have not been the object of much study. Initial studies were scattered, and thus difficult to organize into a fully understood concept. Studies with more detail (Mill and Morrison, 1992; Cooper et al, 1993; Pearce \& Tan, 2001; Buhalis \& Licata, 2002) emerged in the 1990s. Some of the studies explored the concept of distribution channels from an economic perspective (Ujma, 2001), while 
others explored the distribution structure itself (Pearce and Tan, 2007). Some investigate approaches certain segments of tourists, activities and attractions (Schott, 2007; Smith, 2007; Pearce and Tan, 2006). Due to the fast growth of information technology and its widespread applications, studies that focus on the impact of the internet on distribution channels and strategy are also emerging (Reinders and Barker, 1998; Wynne et al, 2001; Buhalis and Licata, 2002; Choi and Kimes, 2002). The broader literature on distribution channels is dedicated to relationships between channel members, tourists and travel agents (Opperimun, 1998), travel agents and hotels (Garcia-Falcon and Medina-Munoz, 1999), travel agents and tour operators (Radburn \& Goodall, 1990), travel agents and airlines (Ali-Knight and Wild, 1999; Morrell, 1998), suppliers and wholesalers (Crotts, Azzi and Rischild, 1998; Buhalis, 2000), suppliers and inbound operators (March, 1996) and inbound operators and wholesalers (March, 1997; 2000; Lumsdon and Swift, 1999). A few studies (Fortyth and Smith, 1992; March, 1996; Yamamoto and Gill, 2002; Pearce, 2002; Stuart, Pearce and Weaver, 2005) have also explored the structures of distribution channels. Stuart (2004) conducted a study that investigated distribution channels in a peripheral region-Southland, the southern region of New Zealand-while March (1996) carried out a supply-based study that focused on inter and intra relationships among channel members in the context of the Japanese tourism industry. Generally, there are different approaches to the study of tourism distribution. Some studies examine particular channel members and relationships among them. Other studies take a destination focus and examine the distribution channels that shape tourism at a particular destination.

After a wider review of the literature, numerous gaps have been found in the general literature on tourism distribution channels. Only tourism distribution in South Africa has been sparingly studied. Tourism distribution in other parts of African has not been examined. Wynne et al (2001) did a study on tourism distribution in South Africa and focused on the impact of the internet on the tourism distribution value chain. While African destinations share many common attributes with other peripheral destinations and developing 
countries, there is still a high likelihood of identifying some key contrasts. Neglect of African destinations leaves a big gap in the literature on tourism distribution channels. Buhalis (2001) observes paucity in the literature on Inbound Operators among members of distribution channels. Since then, only a few studies (Stuart, Pearce and Weaver, 2005; Sharda and Pearce, 2006; Pearce and Tan, 2004) highlight the role of inbound tour operators have been conducted. Most studies tend to omit IBOs in tourism distribution channels. We therefore have a very limited understanding about these channel members. The characteristics of channels and the structural elements of distribution channels in peripheral destinations are not yet fully explored (Stuart, 2004). Power relationships and control of distribution channels have been investigated in a number of studies but, again, not in the context of African destinations; the impact of the destination's attributes on power and control of the distribution channel is still unknown in the literature. Issues of power and control of distribution channels is particularly important when looking at tourism in developing countries and the influence of overseas corporations such as out bound operators and travel agents.

Furthermore, the general literature on tourism distribution channels lacks analysis of the relationship between suppliers in developing countries' destinations. Specifically, it is largely unknown whether there is a tendency for suppliers to be dependent on each other, which are being more depended on by others, and factors that might be influencing this. It is also completely unknown how destination attributes such as scale, infrastructure development and the attractions offered contribute to the choice of the preferred channels in peripheral destinations. Neither commonalities nor contrasts about tourism distribution systems between developing countries and other peripheral destinations are known. Studies in developed countries show that the fast growth of information technology has largely influenced the change in structures of distribution channels; what is as yet unexplored is how information technology affects the structure of tourism distribution channels in developing countries and peripheral destinations. 
After a broader review of the literature on distribution channels in African countries, Samiee (1993) observes that culture in African countries has a potential influence, not only on how people live, but also on how they do business. It is possible that in those countries in Africa, culture may have an influence in the choice of channel of distribution and relationships between channel members. Last but not least, there is still a small volume of destination and supply-based field studies and data showing what structures exist and why (Pearce and Tan, 2006), again particularly in developing countries. Schott (2007) also observes that the underlying factors determining the choice of channels of distribution remain under-researched.

Generally speaking, tourism distribution channels in the context of Africa are largely unknown let alone under-researched. While it is beyond this study to address all the observed literature gaps, some of them form the main objectives and research questions of this study. This project intends to open the door to studies about tourism distribution channels in African destinations, specifically Tanzania. It takes a destination-based approach. The study seeks to explore distribution channels in a region (the northern tourist circuit) of Tanzania and factors that influence channel members' choice in selecting their preferred channels. It further investigates forms of tourism in the region to find out what the distribution structures are. It examines the relationships between suppliers of different services and activities. The findings will contribute to the general literature on tourism distribution channels focusing on supply side, destination-based, peripheral destinations, and in the context of developing countries. It is important to note that this thesis is among the very earliest studies of tourism distribution channels in an Africa context.

The next chapter provides the methodological detail adopted for this study. Specifically the chapter discusses: study area, sampling procedures, method of data collection and the strengths and limitations of this study. All these aim to 
provide the reader with a better understanding of the methods used, before discussion of the findings in the following chapters. 


\section{Chapter Three: Methodology}

\subsection{Introduction}

This chapter presents a description of methodological aspects designed to form a framework for data collection to investigate tourism distribution channels in the northern tourist circuit, and so fill some gaps identified in the previous chapter. The main gap is data on tourism distribution channels - in Africa and specifically in the context of Tanzania. Investigation of distribution systems in the context of Africa, and in Tanzania specifically, has not been attempted in the past. Just one study by Wynne et al (2001) touched on the impact of the internet on the distribution value chain in South Africa. This study, therefore, extends the research on tourism distribution channels in developing countries' destinations. This is a destination-based study that focuses on suppliers. It takes a qualitative approach using face-to-face interviews to collect data and relevant information. In order to understand the structure of distribution systems in their entirety, and in a context where little is known about that structure, qualitative methods, such as indepth interviews, are observed to be the most useful; qualitative methods permit the seeking out of detailed information from information-rich sources (Tan, 2002).

It is important to understand that interviewing only one sector in a broad range of sectors involving more than one stakeholder, will produce information from one particular view point (Healey \& Rawlinson, 1993). It was therefore decided to conduct interviews with different business sectors at the destination. This approach, commonly referred to as "comprehensive destination-based study" (Stuart, 2004) is important for several reasons. Research on tourism distribution channels in Africa is scarce; the approach could also reveal avenues for further studies in future; finally, it is considered a better approach to gain understanding of the relationships among partners in channels. 
The sections that follow describe the study area; they present detail on the sampling techniques used, and on the sample itself. The procedure adopted for analysis is also highlighted. At the end of the chapter, strengths, limitations and challenges are presented. These aim to provide a clear understanding of the whole methodological process, from the design of data collection tools and field experience, through to the analysis of the information collected and its presentation.

\subsection{Study area}

The study area is the northern tourist circuit of Tanzania (Figure 4.7). This is the busiest tourist circuit in the country. It is in this circuit that the most popular attractions in the country are located. The region is also the main tourism gateway for the country. It is made up of a chain of well-known national parks: the Serengeti, Lake Manyara, Arusha, Tarangire, Kilimanjaro and Mkomazi National Parks are all located in this region. Ngorongoro Conservation Area is also in this circuit. Companies with operations in this area have their offices in Arusha, Karatu or Moshi.

The fieldwork started in Arusha, where the majority of tourism businesses have their offices. The city is commonly referred to as the 'Tourist Capital of Tanzania' due to the many tourism activities there; it is also known as the 'Geneva of Africa', due to its good climate and long experience of hosting international conferences at the well-known Arusha International Conference Centre (AICC). Arusha city is also home to the UN's International Criminal Tribunal for Rwanda (ICTR), and to the headquarters of the East African Community (EAC). Some refer to the city as 'Half London'. Arusha is at the heart of the northern tourist circuit (Figure 4.7). 
Arusha is where the majority of offices of the different tourism businesses are located. Tanzania National Parks (TANAPA), the government body responsible for managing all national parks in the country, has its headquarters in Arusha. Based on the national census of 2002, the population of the city of Arusha is 270,485; that of Moshi is 143,799, and that of Karatu is 9,437(NBS, 2002).

Moshi is the capital town for the Kilimanjaro region and lies at the foot of Mount Kilimanjaro. It is the most famous town in Tanzania, being home to the country's well known entrepreneurs, the Chagga people. Main economic activity in Moshi comprises the whole range of businesses including tourism related activities and coffee bean production. It is the place which has arguably the most educational institutions in the country, and thus the majority of its inhabitants are relatively well educated.

Karatu is a small town along the main road from Arusha to Serengeti. The town lies between Lake Manyara National Park and Ngorongoro Conservation Area. Karatu is a very famous stopover point for travellers visiting Tarangire, Lake Manyara, Ngorongoro and Serengeti National Parks. Although infrastructure in the town is not well developed, Karatu has all the signs of potential for future growth as a tourist town.

\subsection{Study sample}

A qualitative study can rarely cover the whole population in such a way that all sub-groups can all be looked-at in detail. The art of designing qualitative research lies in identifying some individuals who are true representatives of the population being studied, and then contacting and interviewing those identified individuals to reveal detailed insights. 
A sample size of 70 companies was determined before going out into the field, using the list of licensed tourism companies in Tanzania for the year 2008/2009. This list is available on the websites of Tanzania National Parks (TANAPA) and the Ministry of Natural Resources and Tourism (MNRT). The list has 633 companies on it for the whole country. From the list, 343 companies with operations in the northern tourist circuit were identified, using the physical addresses available together with the company list. On this list of northern tourist circuit companies, the businesses were grouped into their respective categories: hotels, photographic safaris, travel agents, hunting safaris, air charter companies, mountaineering companies, cultural and nature-based attraction providers, and car rental companies. The companies in each group were then sub-grouped into those owned by locals and those owned by foreigners. This was done purposely so as to investigate whether there were differences in the distribution channels used between local and foreign-owned businesses. The intention was to have a sample that included a range of businesses. Systematic random sampling was then used to identify a sample of businesses that was of a more manageable size (Appendix 2).

Interviews in Arusha were conducted in two phases between May and September 2009. The first phase was between May and July, and the second phase was from August to September. After the first phase of interviews in Arusha, interviews were conducted with business managers in Moshi town. The town is $90 \mathrm{~km}$ east of Arusha. It is located at the foot of Mt Kilimanjaro. Moshi town is the gateway for Mount Kilimanjaro. It is where most mountaineering businesses are located. Two weeks, early to mid July, were spent in this town for interviews with different businesses: mountaineering, hoteliers, travel agents, and some safari companies. Carrying out interviews in Moshi was much easier compared to Arusha as most businesses there were receptive. The following two weeks, mid to late July, were spent in the small town of Karatu. This small town lies between three national parks: Lake Manyara, Ngorongoro and Serengeti. After these two weeks, fieldwork continued for the second phase in Arusha which ran for the whole of August. 
Efforts were made in the field to approach businesses that appeared on the list. To start with, the researcher attended the Karibu Tourism Fair in Arusha-Tanzania. This fair is a crucial meeting place for the overseas-located wholesalers and locally-located suppliers. It was therefore deemed to be an important area since it was where most businesses on the sample list would be met for either an interview or to arrange appointments. Unfortunately, no interviews were able to be conducted at the fair, as most businesses were occupied with fair-related activities; only appointments were made during this time. The follow-up for the fixed appointments came after the fair ended. Companies that appeared on the sample list but did not participate at the fair were also approached at this time. However, approaching only the businesses listed on the sample list was not an effective strategy as often people with the authority to participate in the study were away, busy, or unwilling to participate. Such circumstances which arose in the field dictated the need for adjustments in both sample composition and size. It was therefore decided to approach any available company in the study area so as to save time and other field resources; thus the original systematic sample changed and became a convenience sample. It was also observed that the business would have been more willing to participate in the interview if they had known the researcher, or if the researcher had been introduced to the business by someone they already knew. Only a few businesses placed value on the importance of the research findings. The study sample is therefore a convenience sample.

A total of 102 companies were approached. In 24 companies, the relevant persons could not be found in the offices to enable the researcher to introduce himself and request the company's participation in the research through interviews. In 78 companies, the relevant people were found in their offices, so the researcher had an opportunity to introduce himself and his research. Ten companies rejected the invitation to participate in the research; the majority of them were hunting companies (seven); two were safari companies; one other was a car rental company. The remaining 68 companies agreed to be interviewed, and 
appointments (date and time of day) were made. Forty-three appointments were delayed or postponed in different durations, ranging from one to three weeks; and some never took place. Twenty five appointments took place as scheduled. In the end, a total of 53 companies/organizations were successfully interviewed (Table 2.1). The list includes businesses from all categories that were initially targeted.

That the researcher was conducting his research during the peak tourist season in Tanzania is among the reasons why some appointments did not take place. This is the busiest time of the year for the tourism companies and businesses, not only in Tanzania but in the whole region of East Africa. The main tourist attraction in the region is the wildlife resources that attract visitors from Europe and North America. The summer holidays in North America and Europe occur at the same time as the high season for tourism in Tanzania. The busy tourism season was the only time the field work could be conducted due to time constraints, specifically, having to complete this thesis in a timely manner.

Table 2.1: Companies that were interviewed

\begin{tabular}{|l|l|}
\hline Company category & Number of businesses \\
\hline Photographic tour operators & 8 \\
\hline Mountaineering/Adventure companies & 14 \\
\hline Hotels/Lodges/Backpackers & 10 \\
\hline Travel agents & 3 \\
\hline Hunting Safaris & 7 \\
\hline Car hires/rentals & 3 \\
\hline Air charters & 2 \\
\hline $\begin{array}{l}\text { Nature-based and cultural attraction providers } \\
\text { Relevant Organizations (Tanzania Tourist Board } \\
\text { and Department of Tourism) }\end{array}$ & 2 \\
\hline
\end{tabular}


The information sheet was given to the respondent several days ahead of the actual interview. This was considered important so the respondent had some information on what the interview was going to be about. The sheet contained brief details about the study such as information about the project's background and purpose. The interviewee was allowed to keep the information sheet as a record for any future reference. The information sheet also gave the interviewee the option of withdrawing from the project, at any stage before the process of data analysis started. Along with that, a consent form was also handed out prior to the start of the interview and the interviewees were asked to sign and acknowledge the same. The consent form was a written confirmation of their participation in the study. It also gave the option of allowing or disallowing the attribution of information to their organization in the reporting of the findings of this research. For research that involves human subjects, preparing and using consent form is part of the ethics approval process at Victoria University of Wellington. Managers gave their permission of attribution to their positions and business names in reporting the findings. Participants were also given a choice as to whether or not they wished to receive a summary of the project's findings upon its completion. The procedure described above was the same for all the interviews conducted for this project.

In order to accumulate the depth of data required for the research, interviews were voice recorded with the exception to two interviewees who did not want to be voice recorded. In these two cases detailed notes were taken instead and the voice recorded interviews were later transcribed. In order to develop a broader picture and better understanding of the processes, interviews were also conducted with two relevant organizations: Tanzania Tourist Board and the Department of Tourism. Tanzania Tourist Board is the governmental organization responsible for promoting Destination Tanzania both inside the country and overseas, while the Department of Tourism, among other functions, is responsible for developing different tourism policies and enforcing regulations. 


\title{
3.4 Semi-structured in-depth interviews
}

The semi-structured, in-depth interviews were the main method used for data collection in the field. The interviews were semi-structured in the sense that a checklist of questions to be asked was prepared beforehand. This approach entails asking questions, listening and recording the answers from the interviewee. This might be followed by additional questions to clarify or explain in detail the issue in question. The approach is commonly used in the study of tourism distribution channels (March, 1996, 1997, 2000; Buhalis, 2000; Reinders and Baker, 1998; Tan, 2002). Semi-structured interviews allow free-flow responses from the informant, and with fewer constraints. Peterson (1994:489) adds that “...individual in-depth interviews are useful in qualitative research when the goal of the research is to understand the process". Buhalis (2000:119), in his study on the relationships between hotels and tour operators, adds:

\begin{abstract}
"In-depth, structured personal interviews were used in order to collect sufficient data to support the explanatory research. Personal interviews were regarded as the only data collection method which could provide the response rate and the wealth of information required in order to support qualitative analysis, the approach also established an element of trust between interviewees and the researcher and enabled them to offer truthful and accurate answers"
\end{abstract}

This approach also allows the opportunity for the researcher to probe deeply, to uncover new clues, to open up new dimensions of a problem, and to secure vivid, accurate, inclusive accounts that are based on personal experience (Burgess, 1982 in Walker, 1985). In-depth interviews also constitute the main means of data collection from supply side and destination-based studies in tourism distribution channels (Sharda, 2005; Yamamoto and Gill, 2002; Pearce and Tan, 2002; Pearce, Tan and Schott, 2003). This is therefore an appropriate approach as this is 
a destination-based study of tourism distribution channels. With the objective being to investigate the existing distribution channel mix in the northern tourist circuit of Tanzania where no such studies have been conducted before, the use of in-depth interviews is deemed appropriate.

A pre-determined set of checklist questions was prepared (Appendix 1). Openended questions were asked during the interviews with different suppliers and relevant organizations in the northern tourist circuit of Tanzania. Having openended questions in the interviews does not mean that the process was completely unstructured. The open-ended nature of the questions enabled particular issues to be deeply explored. During the interview, the researcher constantly appraised the meaning of emerging data for the problem and used the resulting insights to phrase questions that further developed the implications of the collected data. As Walker $(1985,47)$ suggests:

"In preparing for interviews a researcher will have, and should have some broad questions [in mind or on a checklist] and the more interviews they do, the more patterns they see in the data, the more they are likely to use this grounded understanding to want to explore in certain directions rather than others. The process of interviewing is one in which researchers are continually making choices, based on their research focus and prior theories about which data they want to pick up and explore further with interviewee and those they do not; making these choices constantly imposing and adjusting some structures".

Therefore, open-ended questions are frequently used in in-depth interviews as they give greater freedom for respondents to answer in their own terms rather than within the confines of set alternatives in closed questions (Walker, 1985). It is a better tool in understanding interviewees' knowledge of the area being researched. The approach also allows the discussions with respondents to take 
their natural course. This approach enabled detailed information to be collected. This was important as little is known of the existing structure of distribution in Tanzania.

The initial questions intended to probe the general characteristics of the business such as: when the business was established; the reasons for establishing it; the number of employees; and the target markets. These were then followed by more specific questions such as, "How do you do marketing", and, "How are your products or activities distributed to clients". At the end of the interviews businesses were asked if they had any future plans; they were also given the chance to ask the researcher any questions. The interviews lasted for an average of 50 minutes. This was enough time to explore important information about the research topic. To be able to relate each channel member with another, and to enable an entire structure to emerge, the questions on the checklist asked in interviews had similar focuses across different businesses.

\subsection{Analysis}

The interviews were transcribed after being carried out. It is recognized, however, that the qualitative approach of semi-structured interviewing poses some challenges in establishing key themes and drawing them into a cohesive whole. Given that 53 interviews were carried out across businesses sectors in the three places (Arusha, Moshi and Karatu), comparative analysis was employed. Having the same checklist of questions made the analysis process systematic. The interview transcripts were read and re-read and similar responses were highlighted with the same colour and grouped together. In this way, responses to the same questions from different businesses and within business sectors could be compared. This enabled the identification of the major themes relating back to the research questions. Some of the identified themes provide the structure for the analysis chapters that follow. The structural diagrams for each theme are drawn to support the explanations of the distribution systems. This is considered important as distribution channels are complicated, particularly in tourism; the need to have 
a diagram together with an explanation is important; it enables the emerged themes to be understood.

Unlike quantitative research where findings are summarized in the form of numbers and figures, in most qualitative research, findings are reported by verbatim quotations.

"In analysing qualitative data, a researcher will be mainly concerned to identify and describe the range of behaviour and opinions rather than to indicate whether people feel strongly or how many hold each view. In all cases the description [...] should be supported by evidence in the form of verbatim quotations from the interviews or discussions. This is the important part of the discipline of analysis and reporting on qualitative material. The collection of quotations (or the failure to find supporting quotations) is an essential corrective to false impressions that may be formed during the reading of the transcripts" (Walker, 1985, 41).

As Walker highlights above, whatever the research is, qualitative or quantitative, evidence should support findings and conclusions drawn thereafter. In this report therefore, relevant quotations are highlighted to support the analysis. In addition to the quotations, distribution structural diagrams are presented to enhance the understanding of the explanations.

\subsection{Strengths, limitations and challenges}

The main strength of the methodology is the fact that an open-ended in-depth interview is well-suited to finding out about the phenomenon being studied. Using this method it was possible for the researcher to deeply explore the 
respondent's point of view, feelings and perceptions about the research topic (in this case, distribution channels). Interviews with business owners and managers are considered to be a prime source of information (Healey \& Rawlinson, 1993). In this sense the approach yielded much needed information, given the fact that each interview took an average of 50 minutes. A wide coverage of businesses interviewed enabled the best quality information to be collected across sectors. The in-depth interviews included general areas such as: how channel members choose partners; the criteria they use; and which factors they consider in deciding which channel to use. They also included probing questions about the performance of different channels, power relationship among partners and the use of the internet in the distribution process. Paterson, (1994) says that qualitative findings may be limited by the skill, experience and understanding of the person gathering the information. However, this was far outweighed by the fact that the researcher is a Tanzanian student who had lived in Moshi. He therefore had a good understanding of the study area and the best ways to ask questions which, as mentioned above, enabled rich information about the research topic to be collected.

However the in-depth approach poses some challenges. It demands that a researcher be a skilled listener; to notice and react to nonverbal clues; to be flexible, open minded, and to be willing to release power and control during the interview.

As is the case in any research methodology, qualitative research has limitations which must be noted. A number of limitations were also noted in this study. At the operational level, the constraints were mostly associated with businesspeople being too busy, hence the inability to find time for an interview. Also there is the element of, 'Who knows you' and 'How important is the person who introduced you', a situation which posed some challenges. Within the context of Tanzanian business culture, asking strangers for an interview is difficult. Limitations are innate to any research methods; however they should be identified so that the 
findings may be understood in their context and in the circumstances surrounding them.

At a wider level, it is recognised that industry-based research offers only one perspective in the distribution channel. For example, in a study of relationships between supplier and intermediary, the reasons given for intermediary behaviour cannot be taken as fact, instead as an indication of some of the perceived issues from the perspective of the supplier. To gain a complete picture of the channel, all members are to be included the research and collected information be matched.

Nonetheless, the detailed supply-side information derived from this research presents valuable insights into the general literature on tourism distribution channels in the periphery destination and particularly in the context of the northern tourist circuit of Tanzania. 


\section{Chapter Four: Tourism in the Context of Tanzania}

\subsection{Introduction}

This chapter discusses tourism in the context of Tanzania in general terms. It builds on the content in Chapter One. It provides details about the industry in the country. Specifically the chapter focuses on the history and growth of the industry, attractions, marketing strategy, the northern tourist circuit, safari tourism, and the economic role the industry plays in the country. Due to the scarcity of academic literature on Tanzania's tourism, the majority of the references used in this chapter come from documents of different government bodies, mainly the Tourism Division, the Tanzania Tourist Board (TTB), Tanzania National Parks (TANAPA), Ngorongoro Conservation Area Authority (NCAA) and the Ministry of Natural Resources and Tourism (MNRT).

The United Republic of Tanzania was born as a result of the unification of Tanganyika and Zanzibar on $24^{\text {th }}$ April 1964. Tanzania shares a border with Kenya and Uganda in the north, with Burundi, Rwanda, and Democratic Republic of Congo on the western border, and in the south, the country borders Zambia, Malawi and Mozambique; the Indian Ocean is on the eastern side of the country. Tanzania has a population of 40 million people (NBS, 2009). It is the largest country in the East African Region.

Tanzania, like the majority of other developing countries, relies on a traditional agricultural economy (BoT, 2008). The majority of its population engage in agricultural activities for their livelihood. However, due to the use of out-dated agricultural technologies, Tanzania does not realise the real value of its vast and fertile agricultural land. Agricultural production costs are enormously high, thus making agricultural products less competitive compared to those imported 
(BoT, 2008). Lack of sufficient processing industries for agricultural products is another drawback in the sector. Agricultural products are often exported as raw materials to European and Asian countries. The country would benefit more from the sector by exporting value-added products.

Tourism in Tanzania, as in many peripheral destinations and developing countries, is mainly nature based. Wildlife is the main attraction, beach tourism is another. Cultural, heritage, landscapes and historical attractions are largely considered as add-ons. The main tourism products in Tanzania are wildlife safaris, beach holidays and adventure activities.

This chapter offers a general overview of tourism in Tanzania that provides the context for this study of distribution. The following sections provide descriptions of Tanzania and the characteristics of its tourism industry including the role that tourism plays in the country's economy, market demand, and seasonality.

\subsection{Tanzania and its tourism industry - history and development}

Tanganyika and Zanzibar united to form the United Republic of Tanzania in 1964 (Figure 4.1). There are two governments: the United Republic of Tanzania (URT) which is the main government, and the Revolutionary Government of Zanzibar. According to the national census conducted in 2002, the country has a population of about 40 million (NBS, 2002). Both Tanganyika and Zanzibar have moved from socialist to market-based economies, and the privatisation of state assets is underway. The institutional reforms started in the early 1990s marked a major shift from government-led to private sector-led development (MNRT, 2004). The role of government is changing from direct engagement in commercial activities in the tourism sector to policy formulation, regulation, marketing, facilitation of supporting infrastructure, and 
investment and service promotion. The country has also introduced macroeconomic reforms. Thus GDP has grown at a tremendous pace, with agriculture, tourism, and mining largely fuelling the growth (Kweka and Ngowi, 2007).

\section{Figure 4.1: Map of Tanzania}

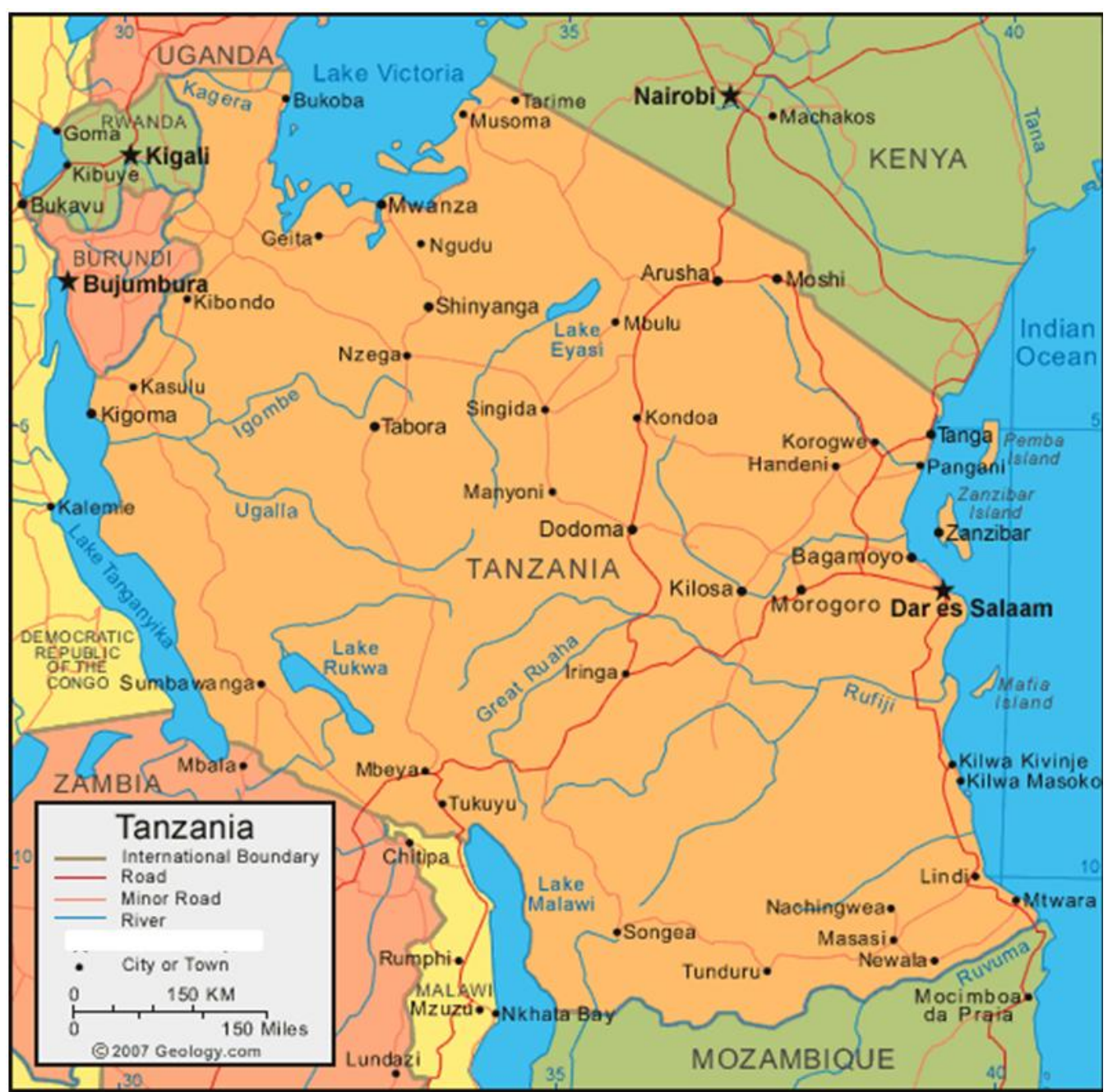

Source: Tanzania Tourist Board

Before the institutional changes, all economic sectors were run, managed and controlled by the central government. Investment by the private sector was discouraged and so the private sector had little chance of contributing to the national economy. Foreign investment was not encouraged either and tourism was not promoted internationally. The country's economy as a whole was 
stifled under this regime of state control. Different economic sectors including tourism did not perform well. Systems and processes were unnecessarily long and bureaucratic. There was a need for a change, and it was in the mid 1980s that this much-needed change started, when the liberalization of economic activities was set in motion. Since then, there has been encouragement of private investment in different economic sectors. Efforts were also made to attract Foreign Direct Investment (FDI), and the Tanzania Investment Centre (TIC) was established. TIC is the governmental board responsible for attracting investments, particularly foreign ones, to Tanzania. Tourism marketing and promotion began along with the development of tourism policies and a master plan in the early 1990s. Since then the FDI has been growing impressively. The mining and tourism sectors have been the leading FDI recipients, averaging 30 and 14 percent respectively (Kweka and Ngowi, 2007); agriculture, however, is left behind at seven percent of the total FDI received in the country. FDI growth has led to an increase in foreign-owned and operated hotels and tour operations, together with a liberalization of air transport. All this has stimulated economic growth.

The government has also attracted productive private investment in existing and new tourism destinations within the country, stimulating additional value-added activities such as photographic safaris and canoeing in Lake Manyara National Park. This has had the result of increasing the value-added content of existing locally produced tourism goods and services, and strengthening sector linkages within the country. The benefits of these measures can be seen, for example, in the construction of world class Serena hotels and lodges in Tarangire, Lake Manyara, Ngorongoro and Serengeti National Parks; soft adventure activities around these hotels and lodges, including visiting cultural attractions by walking, have emerged.

As in other developing countries, tourism statistics in Tanzania are weak in many areas because of the difficulties linked to their collection due to a lack of human resources and insufficient budgets (MNRT, 2004). The government 
started to address the issue by conducting an extensive visitor survey in 2001 in the northern tourist circuit. In addition, the government has formed a working group (Ministry of Natural Resources \& Tourism, Bank of Tanzania and Department of Immigration) to review the process of data collection for tourism and move towards the implementation of a Tourism Satellite Account as recommended by UNWTO.

There are more than 650 ground tour operators who design packages, sort and arrange tours within the country. They provide local transport, and coordinate all related services for tourists. Of these, 633 are licensed and the rest are unlicensed and part of the informal sector. However, not all licensed tour operators are members of the Tanzania Association of Tour Operators (TATO). Even though there are a large number of ground tour operators, this sector of the industry is largely dominated by a handful of large operators, such as Leopard Tours, Abercrombie and Kent, and Ranger Safaris, who account for well over half of the total business volume (MNRT, 2004). The networks amongst stakeholders in the tourism industry within the country are weak; with poor co-operation and lack of defined coordination clearly in evidence.

Domestic air transport is improving following deregulation of the service industry in the early 1990s. There are now more than 28 air charter operators country-wide, the majority of which are based in Dar es Salaam, Tanzania's biggest city. Registered aircraft for passengers number over 100. Air Tanzania and Precision Air take more than a half of the total business volume (MNRT, 2004).

\subsection{The importance of tourism to Tanzania's economy}

Well-planned and managed tourism contributes significantly to a country's economy through the generation of hard currency, jobs, and increased revenue 
for government. Tourism is also attractive for small and medium-sized enterprises and consequently can foster an enterprise economy; it also has strong linkages to other sectors of the economy like agriculture and transport (Eagles and Wade, 2006). A study by Kweka and Ngowi (2007) established that the output multiplier for tourism in Tanzania is 1.8, far exceeding the multipliers for agriculture, manufacturing industries and other services. The study also observes that tourism requires $44 \%$ of its inputs from other sectors, a rate that is above the average of all sectors. The most important input sectors for tourism in Tanzania are agriculture (fruits and vegetables), livestock (beef, lamb and pork), poultry (eggs and chicken), fisheries (fish and sea foods), dairy, manufacturing (equipment, furniture and building materials), nonperishable foods (sugar, rice, and flour) ground transport (tour operator transfers and packages, and local taxis) and handicrafts (Makonde carvings and souvenirs). Many of the products are sourced locally (Kweka and Ngowi, 2007).

Tourism is Tanzania's leading export industry. The Bank of Tanzania (BoT) indicates that receipts on the travel account amounted to $25 \%$ of total exports of goods and services in 1995 but they have risen to $33 \%$ of total exports of goods and services in 1998/1999, and 40\% in 2008. In 1995 the tourism sector was estimated to have contributed $7.5 \%$ of GDP, $13 \%$ in 2000 and 2008 the sector contributed $25 \%$ of the country's GDP (MNRT, 2008).

The tourism sector generated about 29,000 jobs in 2000, the majority in hotels, lodges and tour operations. Since then, the number had risen nearly sevenfold (198,557 jobs) by 2004 (Kweka and Ngowi, 2007). Tourism is believed to have significant direct and indirect employment effects because of its strong linkages with other sectors. Using an employment multiplier effect for tourism of 5.4 (Kweka et al 2003) jobs generated by the tourism sector in 2004 may have been as high as 868,050 . 
Table 4.1 shows that receipts from tourism have risen in the last thirteen years by $293 \%$, from US\$ 322.37 million in 1996 to US\$ 1,269.68 million in 2008 . This has made tourism the top foreign exchange earner for the country (MNRT, 2008). Average tourist expenditure is US $\$ 290$ per day for package tourists and US\$ 160 per day for non-package tourists (Table 4.2). Tanzania's economy has thus benefited significantly from the industry.

Table 4.1: Number of international arrivals and corresponding receipts

\begin{tabular}{|l|l|l|l|l|}
\hline Year & $\begin{array}{l}\text { Number of } \\
\text { Visitor Arrivals }\end{array}$ & $\begin{array}{l}\text { Annual Change } \\
(\%)\end{array}$ & $\begin{array}{l}\text { Receipts } \\
(\text { US \$ Mill) }\end{array}$ & $\begin{array}{l}\text { Receipts } \\
\text { (TZS Mill) }\end{array}$ \\
\hline 1996 & 326,188 & 10.46 & 322.37 & 194,220 \\
\hline 1997 & 359,096 & 10.09 & 392.39 & 235,446 \\
\hline 1998 & 482,331 & 34.32 & 570.00 & 370,500 \\
\hline 1999 & 627,325 & 30.06 & 733.28 & 586,624 \\
\hline 2000 & 501,669 & -20.03 & 739.06 & 628,201 \\
\hline 2001 & 525,000 & 4.65 & 725.00 & 665,115 \\
\hline 2002 & 575,000 & 9.52 & 730.00 & 705,618 \\
\hline 2003 & 576,000 & 0.17 & 731.00 & 759,070 \\
\hline 2004 & 582,807 & 1.18 & 746.02 & 812,676 \\
\hline 2005 & 612,754 & 4.8 & 823.05 & 929,058 \\
\hline 2006 & 644,124 & 5.12 & 950.00 & $1,079,137$ \\
\hline 2007 & 719,031 & 11.62 & 1037.33 & $1,290,542$ \\
\hline 2008 & 770,376 & 7.14 & 1,269 & $1,520,429$ \\
\hline S0ur & \multicolumn{3}{|l}{} \\
\hline
\end{tabular}

Source: MNRT, 2008

The figures in Table 4.2 exclude earnings from air travel and other carrier receipts (NBS and MNRT, 2008). The average length of stay has also increased in parallel with the receipts and the total number of international arrivals. In the last ten years the length of stay has increased by $70 \%$. The difference in expenditure per day between package and non package tourists amounts to more than US\$ 100. 
Table 4.2: Visitors' length of stay and average expenditure per day

\begin{tabular}{|c|c|c|c|c|c|c|c|c|c|}
\hline Year & 2000 & 2001 & 2002 & 2003 & 2004 & 2005 & 2006 & 2007 & 2008 \\
\hline $\begin{array}{l}\text { Earnings in } \\
\text { US\$ million }\end{array}$ & 739 & 725 & 730 & 731 & 746 & 823 & 950 & 1,199 & 1.270 \\
\hline $\begin{array}{l}\text { Length of } \\
\text { stay }\end{array}$ & 8 & 8 & 11 & 11 & 11 & 12 & 12 & 12 & 12 \\
\hline $\begin{array}{l}\text { Average } \\
\text { expenditure } \\
\text { (US\$) }\end{array}$ & 163 & 173 & $\begin{array}{l}153^{1} \\
82^{2}\end{array}$ & $\begin{array}{l}153^{1} \\
82^{2}\end{array}$ & $\begin{array}{l}188^{1} \\
119^{2}\end{array}$ & $\begin{array}{l}155^{1} \\
125^{2}\end{array}$ & $\begin{array}{l}155^{1} \\
111^{2}\end{array}$ & $\begin{array}{l}284^{1} \\
132^{2}\end{array}$ & $\begin{array}{l}290^{1} \\
160^{2}\end{array}$ \\
\hline
\end{tabular}

Tourism in Tanzania is expected to generate US $\$ 1.35$ billion in 2009 and more than 820,000 international tourists are expected to arrive in the country. This growth can be attributed to several factors, a stable and peaceful environment with a democratically elected government and the constant improvement of the tourism industry.

Increased air access, with many carriers now flying direct to Tanzania, including KLM, Ethiopian Airlines, Condor, Kenya Airways, British Airways and Swissair, has contributed to the increase in international arrivals. New luxury camps, hotels and lodges both in the mainland and Zanzibar, including Singita and Kempinski developments; improved infrastructure and tarmac roads on safari circuits are also major factors contributing to tourism development in the country.

The improvements in tourism are the outcome of the diversification of tourist attractions and the existing appeal of Tanzania's unsurpassed wildlife, seven World Heritage Sites, the cultural richness and friendliness of Tanzania's people, miles of beautiful Indian Ocean coastline and the exotic spice islands of Zanzibar.

\subsection{Attractions in Tanzania}

Tanzania is blessed with a wealth of natural, cultural and human-made attractions in all parts of the country. Most of these resources are untapped from 
the standpoint of tourism development. They include a wide variety of world class tourism assets, some of which have been recognised internationally and are included in the list of World Heritage Sites (Ngorongoro Conservation Area, Serengeti National Park, Selous Game Reserve, Kilimanjaro National Park, Stone Town, Ruins of Kilwa Kisiwani and Ruins of Songo Mnara) and Biosphere Reserves (Serengeti-Ngorongoro, Lake Manyara and East Usambara) (UNESCO, 1998).

About 28 percent of the land in Tanzania, about the size of New Zealand, is under legal protection for conservation of the environment (Figure 4.2). Fifteen percent of the protected land is made up of 31 Game Reserves, eight percent of which is composed of 50 Game Controlled Areas. The 16 country-wide national parks contribute a total of four percent of all conserved areas, while the remaining one percent is the Ngorongoro Conservation Area. Tanzania's wildlife resources are considered among the finest in the world and have been widely known for many years (UNCTAD, 2008; World Economic Forum, 2008). Today the country is benefiting from its long history of conserving its natural resources and wildlife.

Tanzania has a rich heritage of archaeological sites such as Olduvai Gorge, and historical and rock painting sites, for example Kilwa and Kondoa. Along the Indian Ocean are the remains of ancient settlements. At Olduvai Gorge, in the interior Rift Valley, is the site of discoveries of traces of earliest human kind. At Kilwa are the impressive ruins of Husuni Kubwa, echoes of the town's importance and its magnificence in the $14^{\text {th }}$ century. At Kondoa there are marvellous historical rock paintings. To the tourist, Tanzania offers interesting culture and crafts, most notably the Maasai culture and art, and the Makonde sculptures and carving done in ebony.

As a destination with its diverse resource, Tanzania offers a number of tourist activities. They include bird watching, botanical tours, and tours of heritage and 
historical towns. Other activities are hunting tourism, wildlife safaris, and soft adventures like trekking and walking safaris. In its two marine parks Tanzania offers many activities including deep sea fishing, scuba diving, water-based activities like kayaking, and the island resorts on Mafia Island. In short, Tanzania has a rich variety of tourist attractions ranging from nature-based to cultural assets.

\section{Figure 4.2: National parks and Game reserves in}

\section{Tanzania}

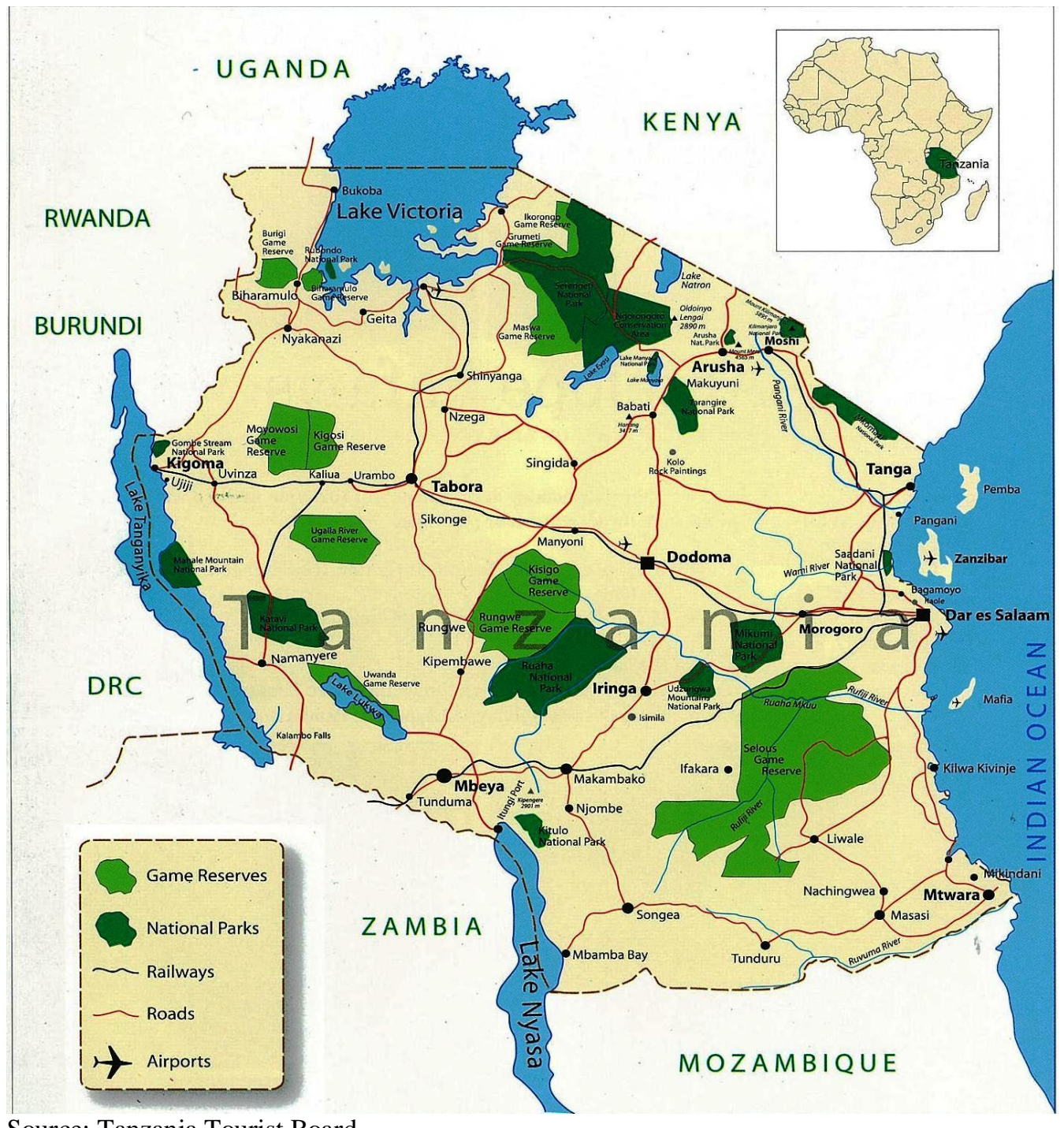

Source: Tanzania Tourist Board 


\subsection{Market demand for destination Tanzania}

A market survey to understand perceptions of Outbound Tour Operators about Tanzanian tourism products was conducted by the Irish consulting group CHL in 2001 in Europe and the United States. Fifty percent of tour operators in Europe reported an increase in demand for holidays in Tanzania. Tanzania and Kenya are the most popular destinations in East Africa, Kenya being ranked first and Tanzania second. In contrast to Europe, the survey in the United States showed that Tanzania was ranked the first in East Africa, followed by Kenya and Botswana. The main strengths of Tanzania are considered to be the abundance of wildlife, the unspoiled environment and the beautiful scenery, beaches with low tourist densities and the authenticity of a "unique African experience"(MNRT, 2004; Almagor, 1985). Other strengths of the destination were that it is considered to be a safer destination than competitors and to have friendly people and developed game areas and national parks. Tanzania outperforms rivals' destinations in terms of quality, quantity, diversity and visibility of wildlife (Eagles and Wade, 2006; MNRT, 2004). In 2008 the World Economic Forum ranked Tanzania the top destination in the world for the potential of its nature-based attractions (World Economic Forum, 2008).

European tourists are more interested in combined safari and beach holiday packages, and for them the main motivation to visit Tanzania is both wildlife and resort tourism. Unlike European tourists, Americans are fascinated with stand-alone safari packages and are motivated to visit Tanzania for the "wildlife safari, bush experience" that the destination offers. In both markets, the US and Europe, the potential growth of safari holidays and soft adventure like trekking is observed to be picking up (MNRT, 2004).

There are, however, some chronic downsides to Tanzania's tourism industry. The product is observed to be overpriced; there is inadequate international and internal access, and poor roads. Domestic access is also expensive. Italy is the 
only country that operates frequent charter flights to Zanzibar; and they occur three times a week. Other weaknesses in Tanzania's tourism industry are: a lack of quality accommodation, poor service and the increasing overcrowding in Serengeti National Park and Ngorongoro Conservation Area, the poor quality of guides in comparison with competitors and the low quality of tour operators (Eagles and Wade, 2006), and a weak marketing strategy.

Despite the problems with the industry in Tanzania, visitor numbers have been growing on average for the last nine years (2000-2008) (Table 4.3).

Table 4.3: International visitor arrivals 2000-2008

\begin{tabular}{|l|l|l|l|l|l|l|l|l|l|}
\hline Year & 2000 & 2001 & 2002 & 2003 & 2004 & 2005 & 2006 & 2007 & 2008 \\
\hline TOTAL & 501,669 & 525,122 & 575,296 & 576,198 & 582,807 & 612,754 & 644,124 & 719,031 & 770,376 \\
\hline AFRICA & 201,934 & 213,013 & 249,601 & 267,940 & 256,455 & 275,718 & 293,440 & 305,603 & 373,053 \\
\hline EUROPE & 157,470 & 162,225 & 191,982 & 191,025 & 221,865 & 220,255 & 229,048 & 274,964 & 245,873 \\
\hline AMERICAS & 49,001 & 45,544 & 59,077 & 49,781 & 53,437 & 61,604 & 71,278 & 80,554 & 87,835 \\
\hline $\begin{array}{l}\text { ASIA AND } \\
\text { THE } \\
\text { PACIFIC }\end{array}$ & 62,898 & 74,642 & 57,755 & 53,668 & 39,292 & 44,612 & 43,521 & 46,701 & 53,172 \\
\hline $\begin{array}{l}\text { MIDDLE } \\
\text { EAST }\end{array}$ & 30,339 & 29,675 & 16,682 & 13,742 & 11,594 & 10,528 & 6,815 & 11,180 & 10,377 \\
\hline
\end{tabular}

Source: MNRT, 2008

During the last decade the number of international tourists travelling in the world more than doubled to 922 million in 2008 (UNWTO, 2009). In Tanzania, the number of international arrivals has increased by 54\%, from 501,669 in 2000 to 770,376 in 2008 . This is equivalent to an annual growth rate of $2.74 \%$. The data in Table 4.3 indicate a substantial increase in international arrivals between 2000 and 2008 from the rest of Africa (85\%), the Americas (79\%), and Europe (56\%). Contrary to other regions, the number of international visitors from Asia and the Pacific, and the Middle East, has dropped by $15 \%$ and $66 \%$ respectively over the same time period. Africa is still leading in terms of total number of arrivals, followed by Europe and the Americas. 
Table 4.4: The top ten markets (countries) by arrivals

\begin{tabular}{|l|l|l|l|l|l|l|l|l|l|}
\hline Year & 2000 & 2001 & 2002 & 2003 & 2004 & 2005 & 2006 & 2007 & 2008 \\
\hline Kenya & 84,993 & 102,235 & 112,036 & 119,406 & 124,967 & 112,766 & 127,016 & 130,823 & 184,269 \\
\hline United States & 33,060 & 30,806 & 38,159 & 36,419 & 40,248 & 47,621 & 55,687 & 58,341 & 66,953 \\
\hline United Kingdom & 34,511 & 34,125 & 43,269 & 43,656 & 59,547 & 52,442 & 54,179 & 55,154 & 58,245 \\
\hline Italy & 5,768 & 8,035 & 23,459 & 24,675 & 44,045 & 49,829 & 50,287 & 54,194 & 45,950 \\
\hline Zambia & 6,349 & 9,577 & 13,096 & 10,670 & 25,405 & 29,120 & 31,132 & 34,669 & 37,682 \\
\hline Uganda & 21,035 & 25,330 & 28,618 & 34,664 & 24,253 & 25,373 & 35,521 & 30,385 & 31,682 \\
\hline South Africa & 14,977 & 17,568 & 22,916 & 35,071 & 25,849 & 28,922 & 28,961 & 28,394 & 28,721 \\
\hline Germany & 22,606 & 21,190 & 17,855 & 19,222 & 20,209 & 18,170 & 19,651 & 24,468 & 27,100 \\
\hline Malawi & 11,531 & 16,573 & 17,531 & 14,267 & 16,868 & 19,999 & 17,247 & 19,136 & 21,459 \\
\hline
\end{tabular}

Source: MNRT, 2008

Within Africa, Tanzania continued to receive many visitors from its neighbours: Kenya, Uganda, Zambia and Malawi (Table 4.4). South Africa has been among the potential and stable source markets within the continent throughout the last decade. In Europe, the United Kingdom has been the source of the largest number of visitors to Tanzania (Table 4.4) when compared to other European countries, followed by Italy and Germany. Italians are observed to be more fascinated by the beaches in Zanzibar than the wildlife safaris, while British tourists and Germans are both interested in wildlife safaris and beach holidays (MNRT, 2008). The United States by far leads other countries in the Americas as a tourism market for Tanzania. US arrivals rates have risen even more sharply than those of the United Kingdom and other European countries (MNRT, 2008).

For the past ten years, holidaymakers have continued to be the dominant group of international visitors to Tanzania, making up $90 \%$ of total international visitors in 2008 (Table 4.5). Unlike the holidaymakers, the number of business people and professionals visiting Tanzania has decreased by $71 \%$ in the last decade. The government is making some effort to boost the number of business people and professionals, for example by hosting conventions and building new 
conference centres. Other efforts include attracting investment in the private sector.

Table 4.5: Purpose of visit to Tanzania

\begin{tabular}{|l|l|l|l|l|l|l|l|l|l|}
\hline $\begin{array}{l}\text { PURPOSE OF } \\
\text { VISIT }\end{array}$ & $\mathbf{2 0 0 0}$ & $\mathbf{2 0 0 1}$ & $\mathbf{2 0 0 2}$ & $\mathbf{2 0 0 3}$ & $\mathbf{2 0 0 4}$ & $\mathbf{2 0 0 5}$ & $\mathbf{2 0 0 6}$ & $\mathbf{2 0 0 7}$ & $\mathbf{2 0 0 8}$ \\
\hline TOTAL & 501,669 & 525,122 & 575,296 & 576,198 & 582,807 & 612,754 & 644,124 & 719,031 & 770,376 \\
\hline $\begin{array}{l}\text { Leisure, recreation } \\
\text { and holidays }\end{array}$ & 339,596 & 341,329 & 358,000 & 337,000 & 458,679 & 478,024 & 523,966 & 625,674 & 696,683 \\
\hline $\begin{array}{l}\text { Business and } \\
\text { professionals }\end{array}$ & 130,201 & 152,285 & 115,000 & 133,000 & 83,415 & 84,924 & 70,940 & 57,374 & 36,847 \\
\hline \begin{tabular}{l} 
Other \\
\hline
\end{tabular} & 31,872 & 31,507 & 102,000 & 106,000 & 40,713 & 49,806 & 49,218 & 35,983 & 56,700 \\
\hline
\end{tabular}

Source: MNRT, 2008

The majority of holiday makers prefer package tours while business people are more interested in non-package tour arrangements (Table 4.6). Sixty Five percent of holiday and leisure visitors chose package tours, while only $20.5 \%$ of the business people came under package tour arrangements in 2008. This phenomenon is not unique to Tanzania; it is common for most long haul destinations that are developing countries (Rewtrakunphaiboon and Oppewal, 2003). Convenience and price considerations are some of the reasons why the majority of holidaymakers prefer package holidays. Consumers evaluate the value of a product easily and conveniently when it is in a bundle rather than when travel products are sold separately (Rewtrakunphaiboon and Oppewal, 2003). In practice, travel decisions are not single independent choices of separate elements such as destination, accommodation or transport, but rather a complex set of multifaceted decisions in which the choices for different elements are interrelated. 
Table 4.6: Visitors' travel arrangements

\begin{tabular}{|l|l|l|l|}
\hline & \multicolumn{3}{|l|}{ Purpose of visit by percentage } \\
\hline Travel Arrangement & Business \% & Leisure and holiday \% & VFR \% \\
\hline Package tour & 20.5 & 65.3 & 5.5 \\
\hline Non Package tour & 79.5 & 34.7 & 94.5 \\
\hline Total visitors & 100 & 100 & 100 \\
\hline
\end{tabular}

Source: MNRT, 2008

The majority of these international arrivals from outside Africa are aged between 18 and 55 years (Table 4.7). They make up an average of $83 \%$ of all visitors. Within this group those who are between the ages of 18-35 years outnumber those who are 36-55 years. Generally these two groups dominate international arrivals in terms of age. The groups are composed of visitors who are physically strong and eager to travel to different countries. The data in the table show that, in three surveys between 2004 and 2006, senior citizen visitors (those over 55 years of age), accounted for below $20 \%$ of all visitors. Senior citizens are a crucial market given that they have more disposable income and ample time for leisure. However, this group demands high standards of service mainly due to the physical challenges they face. Greater attention should be paid to them. This means that for the industry to capture this market segment, infrastructure like roads, railways and airports must be well-maintained to internationally accepted standards.

Table 4.7: Percentage of visitors by age group: 2004-2006

\begin{tabular}{|c|c|c|c|}
\hline \multirow{2}{*}{$\begin{array}{l}\text { Age } \\
\text { group }\end{array}$} & \multicolumn{4}{|c|}{ Percentage of total visitors } \\
\cline { 2 - 4 } & 2004 & 2005 & 2006 \\
\hline$<\mathbf{1 8}$ & 0.5 & 0.8 & 0.8 \\
\hline $\mathbf{1 8 - 3 5}$ & 41.6 & 49.2 & 45.8 \\
\hline $\mathbf{3 6 - 5 5}$ & 38.9 & 35.8 & 36.6 \\
\hline $\mathbf{5 5 +}$ & 19.0 & 14.2 & 16.8 \\
\hline Total & 100 & 100 & 100 \\
\hline
\end{tabular}

Source: MNRT 2006 
International visitors arrive mainly by air transport (57\%), road (41\%), railway $(1 \%)$ and water $(1 \%)$. The major arrival channels are through Dar es Salaam (Julius Nyerere International Airport-JNIA), Kilimanjaro International Airport (KIA), the Tanzania/Kenya border in Namanga close to Arusha, and through the border with Zambia in the small town of Tunduma. About $50 \%$ of international arrivals are through the two airports KIA and JNIA (Figure 4.5), ten percent of international arrivals are by road coming through Kenya. The remaining $10 \%$ arrive through both railway and road from Zambia through to Tunduma.

\section{Figure 4.5: Major tourist arrival routes}

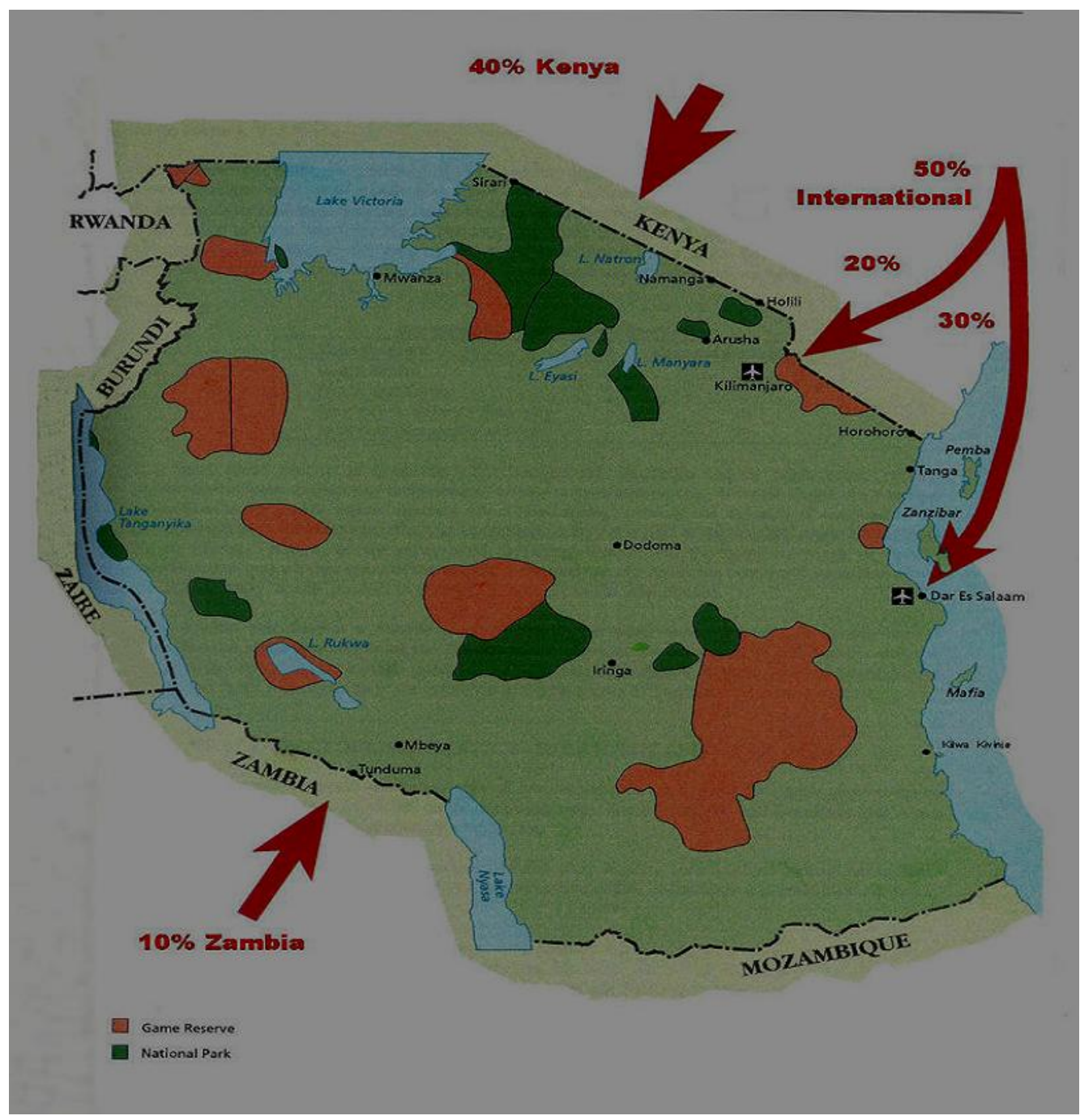

Source: MNRT, 2006 
The international airport in Dar es Salaam is the biggest in the country and receives more international flights compared to other airports for both passengers and cargo. Those visitors who come through Kenya are most likely to have landed at Nairobi (Jomo Kenyatta International Airport). In most cases such groups intend to visit both Kenya and Tanzania and they normally treat Tanzania as an add-on to their main Kenya destination (MNRT, 2006). The $10 \%$ of international arrivals through the border with Zambia is made up of a significant number of South Africans who drive all the way up from South Africa through a number of countries: Botswana, Namibia, Malawi, Zimbabwe and Zambia to Tanzania. A significant number of arrivals come through the TAZARA railway that connects Dar es Salaam (Tanzania) and Kapirimposhi (Zambia). These two channels, from Kenya and from Zambia, are also busy business routes for the neighbouring countries which suggest that there are a significant number of business visitors through the two channels.

Table 4.8 shows the overall increase in the number of arrivals by air and road transport, while the percentage of arrivals using railway and sea is low and decreasing. A number of possible reasons could explain this. For the last decade there has been significant improvement in roads all over the country. Railway transport is unfortunately getting worse, due to poor management, old engines and lack of regular maintenance of railways (Daily News-Tanzania, $20^{\text {th }}$ January 2010; $11^{\text {th }}$ November 2009). It also takes a longer time for someone travelling by train to get to the final destination, compared to the time spent by a person opting to travel by road to get to the same destination. These are among the factors that deter people from using the train and hence the shift to the use of roads. The recent decrease in the number of arrivals by sea is likely to be caused by safety issues in Somalia where pirates are hijacking ships that pass through the Eden Gulf (CNN, 12 ${ }^{\text {th }}$ January, 2010; Los Angles Times, $9^{\text {th }}$ April, 2009). 
Table 4.8: Modes of transport used by visitors

\begin{tabular}{|l|l|l|l|l|l|l|l|l|l|}
\hline $\begin{array}{l}\text { Transport } \\
\text { mode }\end{array}$ & $\mathbf{2 0 0 0}$ & $\mathbf{2 0 0 1}$ & $\mathbf{2 0 0 2}$ & $\mathbf{2 0 0 3}$ & $\mathbf{2 0 0 4}$ & $\mathbf{2 0 0 5}$ & $\mathbf{2 0 0 6}$ & $\mathbf{2 0 0 7}$ & $\mathbf{2 0 0 8}$ \\
\hline Total & 501,669 & 525,122 & 575,296 & 576,198 & 582,807 & 612,754 & 644,124 & 719,0301 & 770,376 \\
\hline Air & 311,612 & 315,073 & 316000 & 320,000 & 257,195 & 330,587 & 359,395 & 388,767 & 439,303 \\
\hline Road & 155,116 & 173,290 & 214,000 & 215,000 & 297,302 & 265,852 & 265,505 & 309,538 & 317,557 \\
\hline Sea & 15,081 & 21,005 & 20,000 & 25,000 & 23,681 & 10,315 & 14,171 & 16,153 & 8,660 \\
\hline Rail & 19,860 & 15,754 & 25,000 & 16,000 & 4,629 & 6,000 & 5,053 & 4,573 & 4,856 \\
\hline
\end{tabular}

Source: MNRT, 2008

\subsection{Seasonality}

The traditional pattern of visitor arrivals in Tanzania has led to three weakly distinct seasons. There are two low seasons: one from March to May and a second in November. June to October is considered the high season, and the peak season starts from December through February. In the low season there is a rainy period in March through May hence some of the sites in national parks are not accessible due to some roads being impassable. The low season in November is due to early short rains and tourists saving for the forthcoming Christmas and New Year holidays:

"You know at this time of year there are many big holidays, Christmas and New Year; every one celebrates these, all over the world. So these people [tourists] know this and so they save some money so that they can spend on the end of year holidays, that is another reason why we have few tourists in November" (Marketing Manager, Classic Tours).

However, it is this low season that is normally the best for bird watching and canoeing, especially in Lake Manyara and Rubondo National Parks. 
The high season runs from June to early November. This is the time when there are no rains in Tanzania's national parks, especially those located in the northern tourist circuit. Lush green vegetation dominates almost everywhere; both herbivores and carnivores are easily seen. The conditions for soft adventure such as short walks and hard adventures like mountain climbing are ideal at this time of the year. This is also the holiday time in the northern hemisphere, Europe and North America, which Tanzania depends on for much of its tourism industry. As the operations manager of Imagine Tanzania Safaris attests:

"This is the time of the year when everyone in the tourism industry is busy. Hotels are fully booked for almost six months. If you walk down the street, you will be amazed, you may think Arusha is one of the cities in US; streets are flooded by 'wazungu' (Swahili for white people). Everyone in the industry, small and big businesses, likes this season".

Tourists in this season are a mix of rich travellers and budget 'backpackers'.

The third season is the peak season. This starts in mid December up to February. It is the season in which there are no rains, and the annual migration of wildlife can be clearly viewed in the Serengeti. This is the season in which one should expect the highest prices for facilities and properties at least in the northern tourist circuit and particularly in Serengeti and Ngorongoro national parks. The majority of tourists in this period of the year are considered to be relatively well-off people:

"This is the time of the year in which we get many senior tourists, they have money and they like good things at any price. This is the season; you find most businesses make a lot of money per tourist. 
We also receive lots of honeymooners in these months" (Operations Manager, Akaro Tours).

There are just slight differences in the number of visitor arrivals between seasons and months (Table 4.9). For the last decade small differences in visitor arrivals have been observed between months. For example, more international arrivals were observed in July and August for the two years 2007 and 2008; this is possibly due to the increasing numbers of tourists who are interested in hunting activities. So, for the last two years, July and August were the peak season months. However, when comparing the visitor arrivals during these two months for the last two years, in 2008 there were fewer arrivals in comparison to 2007. The reasons for these differences are not known but are possibly due to the global economic crisis that started in 2008. Generally, Tanzania is fortunate in that the tourism season in the country is long.

Certain activities are seasonal in nature. Hunting safaris have two distinct seasons: hunting season and off-hunting season. The hunting season runs from July to December and off-hunting or the closed season is from January to June of each year. Due to hunting laws, hunting activities can be carried out only in the second half of each year (WCA, 2008). Some hunting companies use their hunting blocks for both hunting and photographic safaris; in this way the hunting block is used for hunting during the hunting season and for photographic safaris during the off-hunting season. Two business licences are required for a company to carry out both hunting and photographic safaris in a hunting block: one for hunting and the other for photographic safaris. 
Table 4.9: Visitor arrivals by month 2005-2008

\begin{tabular}{|c|c|c|c|c|}
\hline YEAR & 2005 & 2006 & 2007 & 2008 \\
\hline January & 50,297 & 62,643 & 57,614 & 65,819 \\
\hline February & 47,656 & 48,529 & 52,636 & 65,455 \\
\hline March & 50,319 & 47,865 & 51,539 & 60,338 \\
\hline $1^{\text {st }}$ quarter & 148,272 & 159,037 & 161,789 & 191,612 \\
\hline April & 34,957 & 38,134 & 41,824 & 47,482 \\
\hline May & 34,715 & 39,859 & 40,984 & 54,028 \\
\hline June & 46,396 & 49,602 & 60,473 & 61,458 \\
\hline $2^{\text {nd }}$ quarter & 116,068 & 127,595 & 143,281 & 162,968 \\
\hline July & 63,754 & 64,647 & 77,178 & 76,879 \\
\hline August & 70,398 & 63,383 & 81,247 & 76,678 \\
\hline September & 58,013 & 55,086 & 66,380 & 62,911 \\
\hline $3^{\text {rd }}$ quarter & 192,165 & 183,116 & 224,805 & 216,468 \\
\hline October & 49,662 & 62,969 & 64,372 & 70,565 \\
\hline November & 51,508 & 50,751 & 53,018 & 55,620 \\
\hline December & 55,079 & 60,656 & 71,766 & 73,143 \\
\hline $4^{\text {th }}$ quarter & 156,249 & 174,376 & 189,156 & 199,328 \\
\hline
\end{tabular}

Source: MNRT, 2008

In the hunting season; the majority of hunters prefer to come in the first three to four months of the season i.e. July, August, September and October. A few come in the remaining two months of November and December. As the operations manager of Tanzania Wildlife Company (TAWICO) says:

"The majority of hunters prefer to come in the first months; they want to come early so as to get animals easily before there are many hunters in the later months. This is generally the best time for 
hunting because the game are not afraid of bullets, but in later months, it is usually difficult to shoot animals as they get afraid of bullets and so hide most of the time. It can take two weeks to hunt a reasonable number of animals in the early months, but it will take four or five weeks to hunt the same number of animals in the later months".

The other reason that makes it difficult to get animals in the last months of the hunting season is the decreased number of animals due to most of them being already shot in the earlier months.

In backpackers accommodation seasonality is not so pronounced.

“We don't have seasons in backpackers; we are fully booked almost throughout the year; the backpacker has no seasonality. Backpackers are budget travellers, they may stay here three to six weeks, they are not interested in anything expensive and you know what, most of the things in their holidays they sort out themselves. Backpacker is a good market if you can get yourself well organised to tap [into] it, it is the growing market now" (Marketing Manager, Arusha Backpacker).

Seasonality in the northern tourist circuit is therefore observed in some businesses, mainly lodges and hotels, air charters, cultural and nature-based attractions. 


\subsection{Coping with seasonality}

In coping with the low season where clients are few, a number of strategies have been put in place. Annual leave for staff is common during this season across sectors in the industry. This is considered to be the appropriate time for maintenance of facilities and properties by different businesses.

"The main activities in this season is mobilization of camps, preparing roads and the camps which will be needed for use when the season [hunting] starts; maintaining a year-round presence in [our] concessions in the form of anti-poaching, community development, natural resources monitoring and population surveys. There is no such a thing as low season in terms of office administration. So the main activities during low season are a yearround presence in the concession area, conducting anti-poaching operations, maintenance of facilities and internal training" (Operations Manager, Tanzania Game Tracker Safaris).

In some businesses they attend international trade fairs at this time of year, as the marketing manager of Ahsante Tours attests:

"This is the time of the year in which major trade fairs in Europe and North America are taking place, so we attend those. This gives us opportunities to meet outbound operators, review contracts, to re-new and make new ones with new partners. It is also a time to present ourselves in the markets". 
For other businesses, particularly hotels and lodges and a few tour operators, low season is the best time for "fam visits" which basically means familiarization of products for the overseas partners.

"You know, we are very busy in high season, we do not have time to take our overseas partners for product familiarization. We therefore use this [low] season for that. We normally cover ground costs for them when they are here" (Statistician, Serena Hotels).

Some small businesses usually switch to other activities in the period of the low season, while some close down their operations.

"Low season is the hard time for business; you may not get a single client even for three weeks. There is no reason for us to work at that time; instead we just temporarily close business and do something else" (Manager, Tin Tin Tours).

Other businesses, however, are busy with office and administration work as this is the period during which they receive many bookings for the next high season.

“We don't have 'low season' in office work, the low season is just for field work; this is the time when we get a lot of inquiries and bookings for the coming high season, so we don't sleep: it is probably the most hectic time for us in terms of office administration” (Marketing Assistant, Abercrombie and Kent).

In the high season when there are many tourists, most businesses are very busy. Some companies get more clients than their handling capacity. A number of 
strategies are used in such situations; advance booking policies, prices rises, and extra clients are forwarded to other businesses on a commission basis, or the business hires part-time and temporary staff to handle the increased number of tourists who demand services. Accommodation properties commonly prefer the use of advance bookings, raise prices and referrals:

"We normally set price for our services on the basis of season, we have three different price categories; low season, high season and peak season prices. If we are fully booked, we bump extra clients to other properties with similar standards to ours" (Statistician, Serena Hotels).

Local transport providers, in addition to the use of increased prices, also hire more facilities and staff on a short term basis. Attraction providers, particularly nature-based attractions like national parks and game reserves, choose neither of the options as they believe carrying capacities are yet to be reached:

"We had never reached the carrying capacities in our parks; we still need more tourists to come. What we do in high season is to relocate some staff from the anti-poaching unit, the ecology department and out-reach departments to work with those in the tourism department so as to efficiently handle the increased number of tourists, especially in Serengeti National Park. After the high season every one returns to their departments" (Tourism Manager, TANAPA).

The main option adopted by these providers at this time of the year is the relocation of some staff from other departments to the tourism department. This shows that different businesses use different strategies depending on the nature, size and ownership of the business. 


\subsection{Marketing strategy}

In recognition of the importance of the tourism sector to the economy, the government, in collaboration with the private sector, has intensified promotional efforts in recent years. The Tanzania Tourist Board (TTB) is the body responsible for marketing and promoting destination Tanzania in and outside the country. The board was established by the Tanzania Tourist Board Act (1992) which amended the 1962 Tanganyika National Tourist Board Act. The Act establishes the functions of the TTB. The board's other duties are: to encourage the development of amenities enhancing the attractiveness of the country, to undertake research; to foster an understanding of the importance and economic benefit of tourism to the country, and to collect and disseminate tourism information. Promotion of destination Tanzania has included participation in international tourism fairs (Figure 4.4), conventions and road shows in Europe and North America.

\section{Figure 4.4: Participation of Tanzania in international trade fairs}

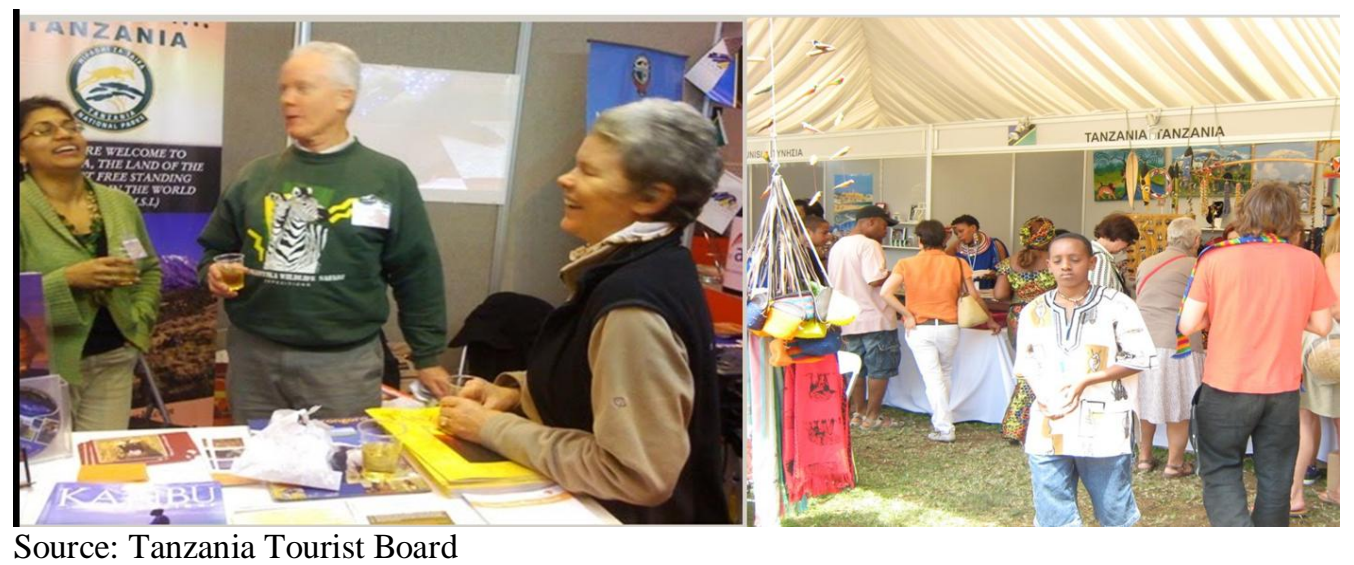

Other strategies that are used by the board include the launching of advertisements in internationally-renowned media such as $\mathrm{CNN}$ and $\mathrm{ABC}$ Television. In 2006 the newspaper USA Today named Serengeti National Park 
as the best natural site in the world. Moreover, Tanzanian embassies have been actively engaged in promoting tourism products that the country offers. For example, the Tanzanian embassy in the United Kingdom had a six month programme advertising destination Tanzania in London city buses (Figure 4.5) and at Heathrow Airport.

Figure 4.5: London city bus with advertisement of destination Tanzania

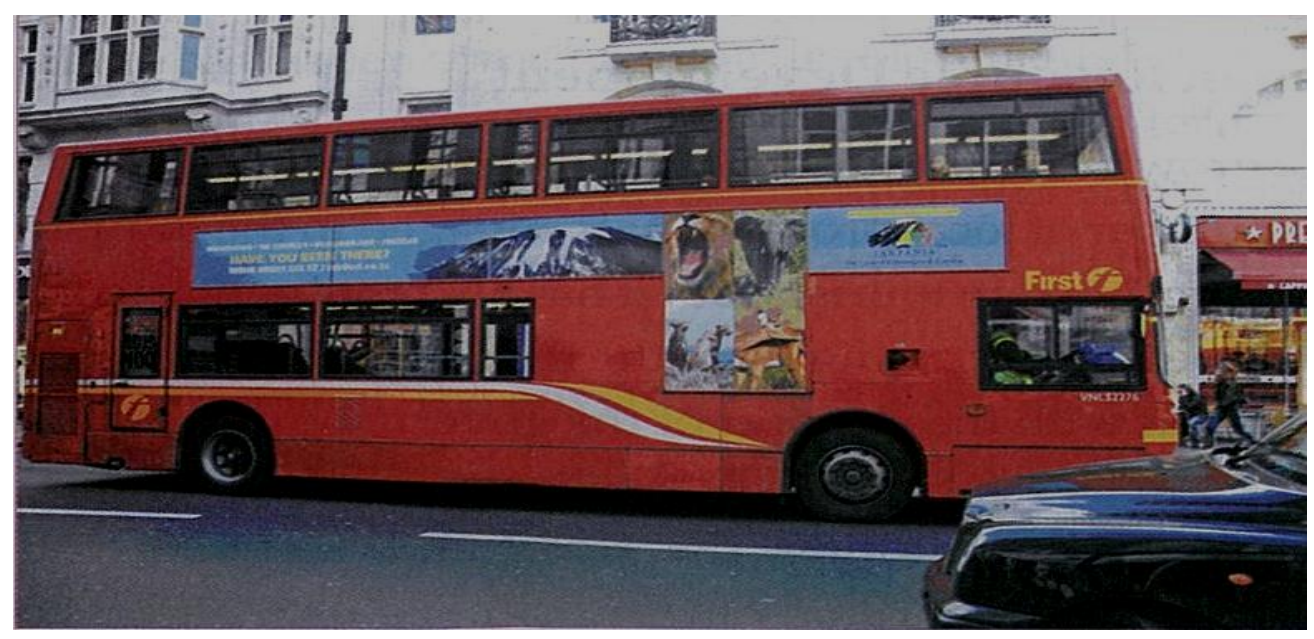

Source: MNRT 2006

The marketing strategy aims at creating awareness in main source markets that Tanzania is a stand-alone holiday destination. The primary tasks associated with this strategy are: to develop an image of Tanzania as the leading wildlife destination in conjunction with quality resort tourism and diverse cultural interests; to identify and define the target markets; to devise a cost-efficient means of communication and identify target market segments; to support the promotional activities of tour operators; to provide pre- and post-vacation services adequately, and with the quality image of the destination; and, to improve data collection and information for decision-making purposes (TTBA, 1992). It is the case, however, that some of these tasks have scarcely been implemented. 


\subsection{Safari tourism}

Safari tourism, wildlife safaris and game drives, are common terms used to describe the major tourism product offered in the Sub-Saharan destinations of Africa. Wildlife safaris are mainly made up of two types: photographic safaris and hunting safaris. The majority of destinations in this region are endowed with a rich diversity of wildlife resources. The available wildlife resources range from plants to animals; from small mammals to the 'big five' mammals (elephant, rhino, lion, leopard and buffalo) (Figure 4.6), and different species of insects, birds, reptiles and amphibians. A number of species, for example the black rhino, sanje mangbay, and cheetah, are naturally found nowhere in the world except in this region (TANAPA, 2006). All the Sub-Saharan countries have long histories of conserving these wildlife resources. The majority of the conserved wildlife is in wildlife-protected areas. It is the wildlife among other assets that attract many domestic and international tourists to these countries.

Figure 4.6: The big five mammals

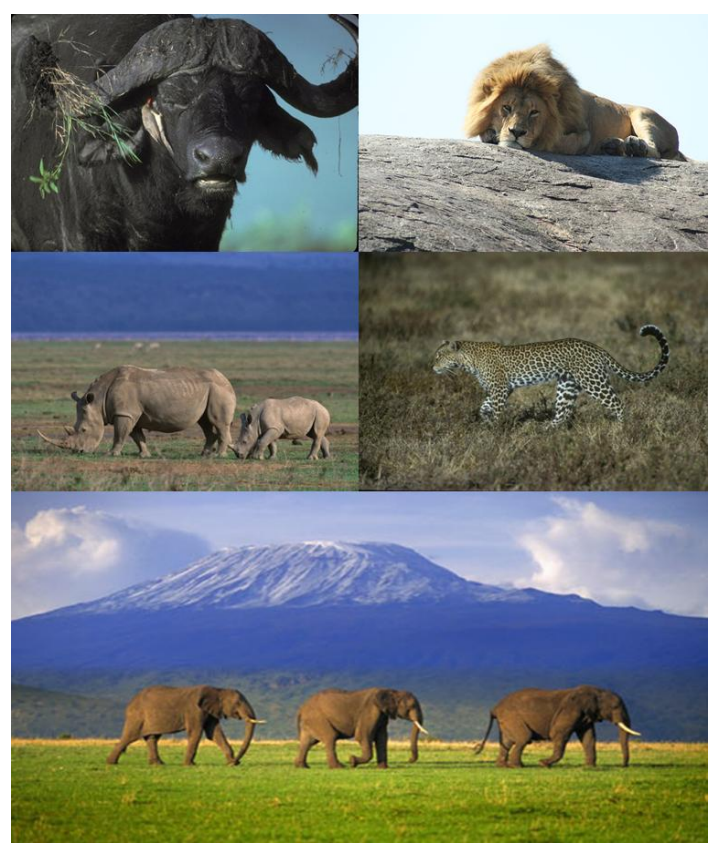

Source: Adapted from Ngorongoro Conservation Area/TANAPA. 
However, to get to where wild animals are located, one needs to have a vehicle. Walking is confined to small areas within the national parks. This is due to the danger posed by big carnivores like lions and leopards and other mammals, such as African elephants and African water buffaloes. So one can only enjoy the wildlife in African national parks by driving through in a car; hence the term 'wildlife safari'. Physical interactions between tourists and wild animals are highly discouraged, and in most cases prohibited.

The organization of wildlife safaris requires numerous arrangements. It becomes more complex, also, due to the long distance between destinations and markets. It needs pre-arrival arrangements with a number of businesses involved in a trip, ranging from the flight, accommodation, local transport and attraction providers, to mention but a few. Such arrangements are made easy and are readily available to consumers by tour operators at a charge. However, those travellers with ample time can sort out some of the arrangements by themselves.

\subsection{Tourism in the Northern Tourist Circuit of Tanzania}

The Northern Circuit, the focus of this thesis, is the heart of Tanzania tourism's industry. It extends from the Mara region on the eastern side of Lake Victoria to Lushoto, the western part of the Tanga region in the east (Figure 4.7). It is the northern tourist circuit where most tourism development has taken place. Arusha is in the central part of the circuit. The town is referred to as Tanzania's 'tourism capital'. Over $60 \%$ of tourism-related operators, activities and infrastructure are located and well-developed in the northern tourist circuit (MNRT, 2004). There are three major airports in this region, one being international, the Kilimanjaro International Airport. Tourism manifests itself and dominates in this zone. The northern tourism circuit has distinct groups of attractions. 
The first group of attractions is the well-established wildlife areas of the Serengeti, Lake Manyara and Tarangire National Parks, and the Ngorongoro Conservation Area including Olduvai Gorge, an archaeological site of great importance. This group of attractions has been the backbone of Tanzanian tourism over many years and represents the 'honey-pots' of the industry.

However, this zone has some shortfalls. The road system is not well designed for tourists to explore more of the area. There is only one all-weather road through this vast wildlife area: the road from Arusha to Lobo. Other roads are rough, not well maintained and thus hardly passable during the rainy season. The main road is a kind of "cul-de-sac" which in most cases leaves visitors with no option other than to backtrack along the same route. A well-maintained and more extensive road system providing at least one large circuit and a number of smaller circuits off it would be a key to using these assets more efficiently and productively without placing greater pressure on the environment.

The second group of attractions in this area comprises Kilimanjaro, Arusha and Mkomazi National Parks. These parks are particularly suited to satisfy those tourists who have an interest in mountain climbing and seeing wildlife. 
Figure 4.7: Northern Tourist Circuit

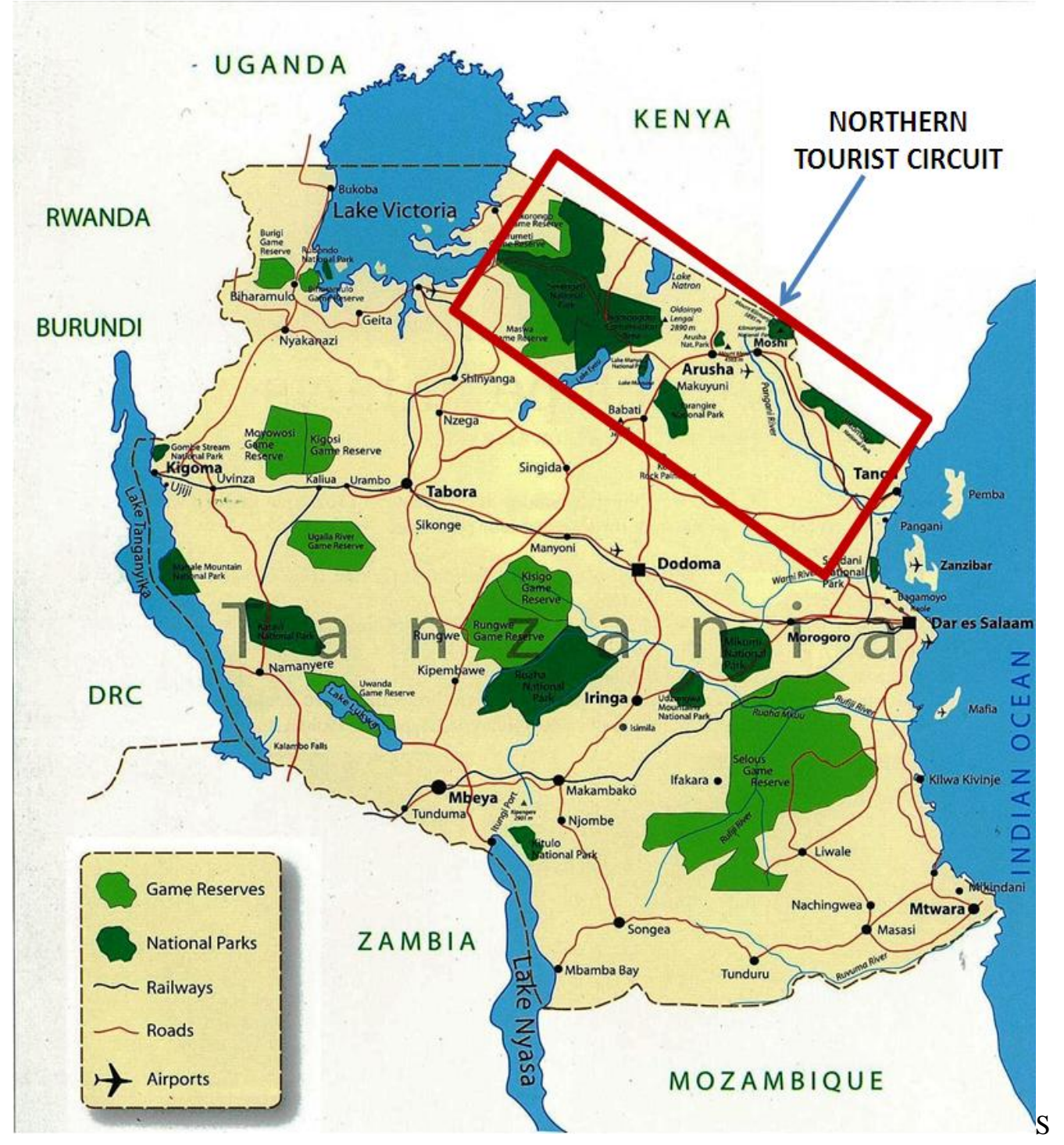

ource: Adapted from Tanzania Tourist Board

\subsection{Conclusion}

A viable tourism industry requires more than a range of natural and cultural attractions and a welcoming people. A well-developed infrastructure, together with facilities and amenities, are also needed. A sound promotional strategy is also an integral part of tourism businesses both at the national and international levels. In fact tourism is a diverse industry that requires many different 
components to be in place before there is a complete product to offer in the marketplace. This implies that a shortfall in one of the components will generally undermine the destination's appeal to potential tourists.

Due to increasing market demand it is clear that Tanzania is internationally recognized for possessing a superior wildlife product that offers a real, authentic African experience. The country has outstanding scenery, a wealth of cultural attractions, and friendly people. These are the 'core values' which must be protected and preserved as they confer a competitive advantage in the marketplace. All the specialness and authenticity of major attractions should also be protected at all costs. The nature-based tourism product offered by Tanzania needs both to be extended and to become more diversified. Resort tourism, special interest tourism and cultural tourism also need to be developed.

Investing in resort-based tourism will be essential to the long term development of areas with considerable potential because of their natural and cultural attractions, but do not have the 'drawing power' of the Serengeti and Ngorongoro "honey pots". The duration of tourist stays at the destination could be lengthened if resorts could offer diverse leisure facilities like tennis, golf, and range water sports, in addition, the possibilities of short trips and tramping to nearby parks, islands and cultural sites. Investment should also focus on large-scale enterprises as well as small and medium enterprises. Tourism plays a big role in Tanzania's economy. The country can benefit more from the industry by improving the current available resources, for example opening up new circuits in existing areas and upgrading access roads to hunting blocks and other national parks.

Tanzania still receives fewer international arrivals compared to Kenya, its neighbour and competitor. The reason for this is that in the market place, Tanzania offers a limited product, which is mainly the northern wildlife area. Tanzania has neither a competitively developed 'beach' product apart from 
Zanzibar nor an internationally- marketed cultural product. It confines itself to the promotion of the safari element, which is only one part of the tourism product demanded by tourists (MNRT, 2004). This has also accounted for the relatively short average length of stay. Kenya, on the other hand, by being able to sell the complete range of holiday combinations, gets a larger share of the market. The other reason for Kenya's popularity is the fact that it is well established in the market. This suggests the need for Tanzania to create a complementary 'beach' product as well as expanding the range and supply of its traditional products, together with a well-designed marketing strategy in order to compete more effectively in the marketplace.

General distribution strategies are part of broader marketing strategies. Distribution strategies exist in any business, although sometimes and probably often in developing countries, they may exist and are practiced by the business manager almost subconsciously. Tourism distribution in the northern tourist circuit, which is the study site, had never been studied before. However, investigation shows that the majority of suppliers in this region distribute their products both directly and indirectly. There are complex networks among suppliers in the destination, and with their counterparts in Kenya. As a result ground tour operators who put together individual components of different tour products into packages perform an important role. The packages are then sold to overseas agents or direct to tourists. As stated earlier, the majority of the businesses are small and family-owned. They rely mainly on informal channels of distribution and local marketing, using very traditional strategies such as brochure distribution. Lack of sufficient capital limits most businesses' participation in international trade fairs. International trade fairs are deemed to be important meeting places where marketing and travel agents meet suppliers of different products from different countries. Observations also show that local tourism operators (hoteliers, ground tour operators, cultural and nature-based attraction providers) are heavily dependent on overseas agents for most of their clients. 
Existing distribution channels in this region are analysed in detail in Chapters Five and Six. How channel members relate to each other, factors considered in choosing channels, performance of channels and the associated operational issues are all investigated. 


\section{Chapter Five: Distribution Structures in the Northern Tourist Circuit}

\subsection{Introduction}

In the previous chapter, the tourism characteristics of Tanzania were outlined. That background is important in order to understand the themes discussed in this chapter, and the following two chapters.

This chapter highlights channels of distribution for the main three activities in the northern tourist circuit: photographic safaris, mountain climbing and hunting safaris. As mentioned earlier, these are the primary attractions in the northern tourist circuit that attract the majority of tourists to visit Tanzania. Beach holidays are another attraction, but they take place in Zanzibar which is not part of the northern tourist circuit (Figure 4.6). Although the interviews were conducted with managers of different sectors in the northern tourist circuit, the explanation of the structure and nature of distribution focuses on how tourists access the destination and, eventually, individual businesses. This is thought to make the distribution channels used clearer, as there are many relationships, both formal and informal, amongst suppliers and from one stage to another on the channels that tourists follow. So the analysis extends to tracking en route arrangements and relationships between suppliers when tourists come to Tanzania through Kenya. This is deemed to be crucial as Kenya acts as the main hub for East African destinations and there are strong relationships between players in Tanzania and Kenya. There are also an increasing number of tourists who come to visit East Africa as a destination, partly due to the promotion efforts by the East African Community (EAC) that markets the whole bloc as a single destination. The regional bloc is made up of five countries: Tanzania, Kenya, Uganda, Rwanda and Burundi. 
Distribution in different sectors - accommodation, local transport, cultural and heritage sites are highlighted as well. Sectors and activities are very well connected and there are strong relationships that are worthy of discussion. This will also enable a picture to be drawn about the distribution mix for different suppliers in the northern tourist circuit. Within this chapter, different market segments are featured in the discussion together with the distribution channels used in reaching those segments.

Distribution channels used in the northern tourist circuit differ from activity to activity and across sectors. As highlighted in Chapter Four, visitors to Tanzania primarily come for photographic safaris, mountain climbing, hunting safaris and beach holidays. The major markets for Tanzania's tourism are in Europe and North America. The majority of suppliers in this region are largely dependent on indirect channels for distributing their products and services. There are close relationships among ground tour operators (photographic and mountaineering tour operators) in Tanzania with those in Kenya. When tourists finish their tours in Kenya, they are passed over to Tanzania's operators by the Kenyan operators. Commissions are paid in such relationships. The amount of commission depends on the agreement between the parties involved; it often ranges from $10 \%$ to $15 \%$ of total cost for local partners. Being located far from markets, and the destination being relatively less developed, are among the contributing factors to such dependency. A few businesses have permanent marketing offices overseas, which handle marketing and booking activities. Some businesses are entirely dependent on their overseas partners to channel down clients, while others depend on local partners. The overseas partners are equally dependent on ground operators to put together all the individual components of safaris (accommodation, park entry fees, local transports to, and between, national parks, and small activities).

The term 'distribution channels in tourism' was, unexpectedly, found to be new to almost all businesses interviewed. A manager of one the businesses 
thought tourism distribution channels are 'the ways in which tourists are distributed and channelled to different attractions in the destination'. This drew attention to the fact that these businesses practice different strategies of distribution almost unwittingly. No businesses amongst those interviewed had a written distribution strategy. Distribution strategies are practiced, but not written on paper. It is also found that the majority of the businesses interviewed were unable to distinguish between outbound tour operators and overseas travel agents. The two terms are used interchangeably by the suppliers in the northern tourist circuit. Consequently the term 'overseas travel agents' is used throughout the remaining chapters to mean the two groups (overseas travel agents and outbound operators). In addition, mountaineering, photographic and hunting safaris operators are collectively called ground tour operators, at least in the northern tourist circuit.

The sections at the end of this chapter discuss factors which influence the choice of channels, differences in the channels used by local and foreignowned businesses, and the relationships between channel members. It is important to note that the description of distribution channels differs, depending on who (supplier, intermediary or consumer) is being interviewed. Since this study involved suppliers and intermediaries at the destination (northern tourist circuit); it therefore presents a discussion of the distribution channels from their (suppliers and destination-based intermediaries) perspectives.

\subsection{Channels of distribution for photographic safaris}

Photographic safaris are probably the most popular activity for most tourists visiting Sub-Sahara African destinations, particularly Tanzania. They attract almost all market segments: package tourists, independent travellers, budget and wealthy tourists, young, middle-aged and senior tourists, domestic and international. Photographic safari operators are the main co-ordinators of 
safari arrangements in the destinations (Figure 5.1). In Tanzania, photographic safaris take place mainly in national parks and the Ngorongoro Conservation Area; but they also happen in some game reserves, for example Selous Game Reserve.

Channels used to access photographic safaris in the northern tourist circuit are both direct and indirect. The majority of visitors to national parks and conservation areas come through indirect channels, as shown by the arrows in Figure 5.1. As Figure 5.1 shows, the indirect channels used are composed of different channel members. Some channels involve few members while others involve many partners.

\section{Figure 5.1: Distribution channels for photographic safaris (International market)}

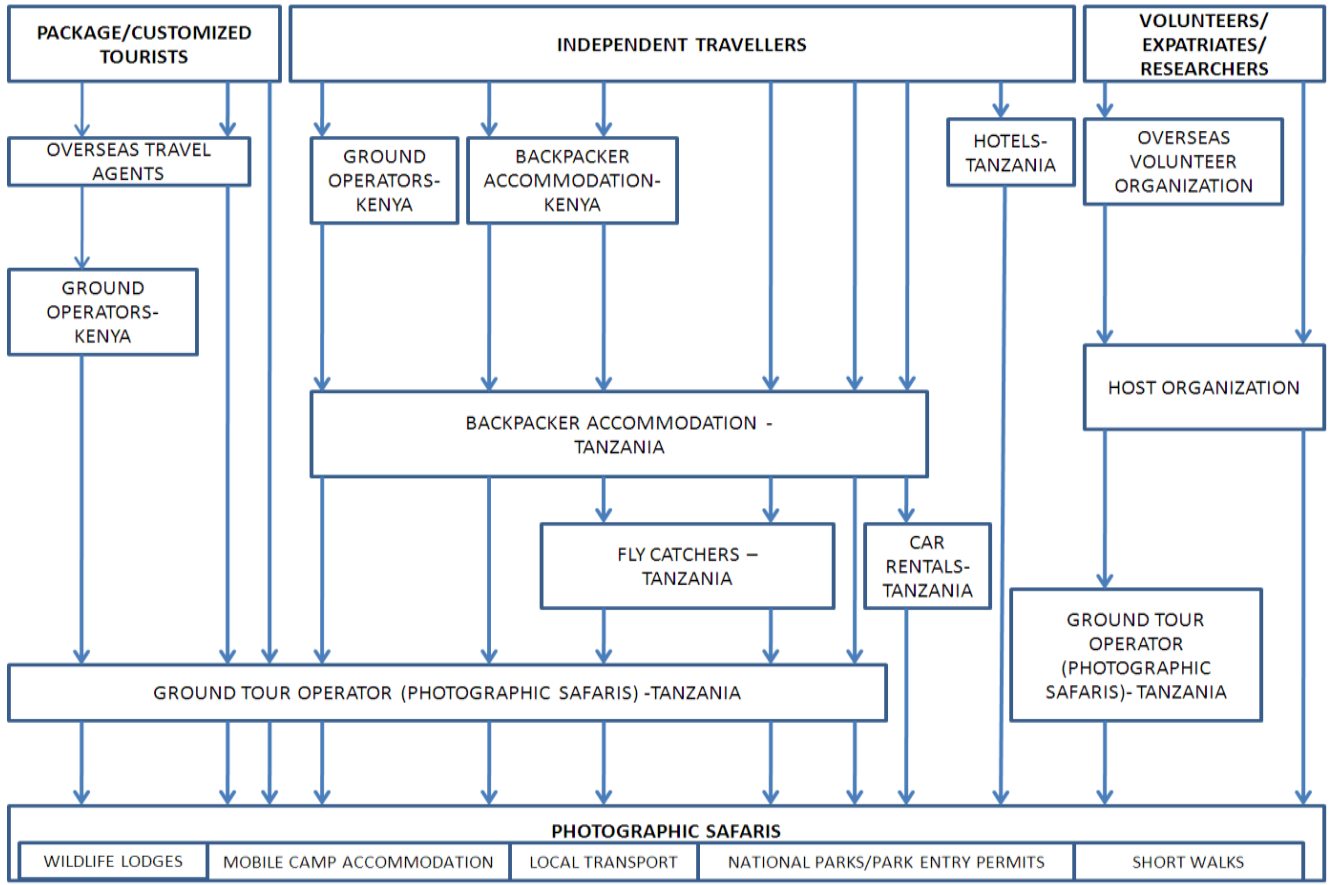




\subsubsection{International package tourists}

International tourists come in three main groups: as package tourists, customized tourists or independent travellers. Package tourists are those who buy the already designed packages, while customized tourists or tailor-made tourists usually want some components of the packages to be changed to meet their preferences. Statistics giving specific numbers of package and customised tours are scanty and hard to find; and the majority of businesses were unable to provide a clear distinction between the channels used for package and customized tourists, so the two groups are combined and treated as the same group, that is 'package tourists'. The majority of international tourists in Tanzania come as package or customized tourists in comparison to the number of independent travellers. As highlighted in Chapter Four, there are those tourists whose main purpose is to visit Tanzania, while some treat Tanzania as an add-on destination to their Kenyan main destination; and others come to both Kenya and Tanzania and regard the two as their main destinations.

\subsubsection{International package tourists direct to Tanzania}

Tourists who come to Tanzania as their main destination for photographic safaris come through different indirect channels. Based on businesses interviewed, an average of $70 \%$ of international tourists in Tanzania come through indirect channels:

"The majority of our clients come through agents in Europe and North America. About 70-85\% of our clients are coming through those agents" (Operations Manager, Kilimanjaro Crane Tours). 
"I get most of my business from the agents I am working with. Some are in Europe, Australia, Russia and in the United States. They do marketing all year round and so are in a good position to get many tourists. I don't have the actual statistics right here, but I can assure you [that] they account for more than $70 \%$ of my business" (Managing Director, Imagine Tanzania Tours).

Package tourists arrive in two different ways: through overseas tour agents or they can directly contact the ground tour companies (Figure 5.1). Those who come through overseas agents far outnumber those who contact ground operators directly. The majority of overseas agents have no branch companies at the destination; instead, they depend on local ground tour operators who they work with in a business partnership-type of relationship. Thus tourists who book their holidays through overseas tour agents are passed down to ground tour operators who handle the critical part of the business. As noted earlier, ground tour operators in Tanzania are also the main providers of local transport for tourists accessing the national parks, so all aspects on the ground are coordinated by them (the ground tour operators). The aspects include accommodation to local transport and activities. Some ground operators own accommodation properties in addition to their tour-operation businesses. Tourists who book their holidays direct with ground tour operators are handled in the same way as those who book through overseas tour agents. The only difference is where the bookings were initially channelled and priced. Those who book with overseas tour agents are charged more than those who book direct with the ground tour operators. It is also observed that the majority of those who book directly with ground tour operators prefer customized tour packages: 
"We have our tour packages and they are all on our website including prices for each package, but there are still those who contact you, and they want different combinations depending on their interests; some combinations are quite hard to tailor, but we do it for them or sometimes we refer them to different companies" (Manager, Chagga Tours).

\subsubsection{International package tourists through Kenya}

Package tourists who come through Kenya book their holidays through overseas travel agents mainly in Europe and North America; these agents have links with ground operators based in Kenya. The ground operators in Kenya have well- established business relations with their counterparts in Tanzania; so once international tourists have finished their holiday in Kenya, they are easily transferred to the ground tour operators in Tanzania to continue their holiday. In almost all cases, holidays are bought in a single purchase. In Tanzania, it is the local ground operators who organise and handle everything for the tourists, starting from pre-arrival arrangements, the booking of accommodation and activities indicated in the package. Occasionally the overseas agents may book and pay direct for some properties themselves:

"We have our partners in Kenya; they do similar business to ours. If they have clients who want to come to Tanzania they pass them to us, so we handle the arrangements in Tanzania. But sometimes, clients may book a holiday with overseas agents who [agents] occasionally book and pay themselves to individual properties and business that are included in the itinerary, or they [the agents] may leave everything in a destination country to be sorted by a partner company in that country, which is us in this case" (Managing Director, Hoopoe Adventure). 
In most cases, it is again the ground operators in Tanzania who make sure the tourists finish their holidays satisfied.

\subsubsection{International independent travellers}

Independent travellers are a fast-growing market on the northern tourist circuit. The majority of travellers in this group are budget travellers who want to see and experience the destination the most, but at the lowest cost possible. As with the case of package tourists, there are those independent travellers who go directly to Tanzania, and those who come through Kenya.

\subsubsection{International independent travellers direct to Tanzania}

For independent travellers who come to Tanzania their first stop points are budget accommodations in Arusha or Moshi. They then explore all possible options, sorting and arranging some parts of the activities in which they are interested. Access to the national parks will depend on the interest of the tourists themselves: by using a ground tour operator or hiring vehicles themselves.

When walking down the street exploring available options these travellers bump into a lot of people who sell souvenirs on the streets, commonly known as "fly catchers". Fly catchers know the locations of different ground tour operators' offices. Locating the offices of ground tour operators is usually somewhat challenging for tourists; this is due to the poorly-marked sign posts on streets. So fly catchers are often used [to help direct tourists to the ground tour operators in addition to running their souvenir businesses. They get 
commissions for walking clients to ground tour operators and some businesses entirely rely on fly catchers for 'marketing':

"I am the only business that pays high [commission] rates to fly catchers, they know me and they also know where my office is. I encourage them to bring tourists into my office. I never do any other kind of marketing, why should I incur all those costs for marketing while there are a lot of fly catchers on the streets just one step from my door? I don't want those rich tourists, I want budget ones and I can easily get them by using fly catchers" (Managing Director, Imagine Tanzania Tours).

Although tourists can access national parks using their own or hired vehicles, the majority use ground tour operators. Some independent travellers, mainly from Southern Africa and particularly South Africans, prefer to drive up from their countries to Tanzania and then on to the destination they are interested in within the country.

\subsubsection{International independent travellers through Kenya}

Independent travellers who come through Kenya have a number of options; they may contact ground operators in Kenya directly or they may come to Kenya and go directly to backpacker accommodation. While at backpacker accommodation, the independent travellers explore all possible options and sort out parts of their holiday by themselves. After their holidays in Kenya, these travellers then come to Tanzania. Once they get to Tanzania (in Arusha), usually through the Tanzania/Kenya border in Namanga, the first point, like those who come direct to Tanzania, is backpacker accommodation. From there, everything is explored and arranged such as access to the national parks; 
these travellers either rent a car or get it done through ground operators. The ground tour operators in Tanzania are the ones who provide transport to access national parks and other conservation areas. However, tourists are not obliged to use the ground operators' cars. They can also hire from car rentals as long as they are confident driving on Tanzania's rough roads which are, in some parts, not clearly marked. Going to the majority of national parks does not require advance booking, but if visitation will involve camping within the park, then booking for campsites is required in advance. Contrary to package/customised tourists, independent travellers do make multiple purchases of tourism products and services at different points on their routes.

\subsubsection{Expatriates and volunteers}

Expatriates and volunteers access Tanzania through their organizations. These tourists are considered to be coming to the destination for other purposes, and tourism is a secondary purpose. There are those who come through overseas organizations and are passed down to the host organizations, and those whose arrangements are handled direct by host organizations (Figure 5.1). While attending to the main duties which brought them to Tanzania, they take the opportunity to visit different attractions. Commonly, they may arrange within the host organization and visit the attraction, or they may decide to use ground operators to arrange all or part of their holidays.

\subsubsection{Domestic tourists}

Domestic tourists to national parks in Tanzania include groups of students from different institutions, and some middle class workers (Figure 5.2). They access national parks by arranging everything, transport and accommodation, by themselves. If it is a group, normally a team leader and a few people are chosen from group members, and it is these people who follow up different arrangements for the group. In this case, multiple purchases are common. 
Unlike domestic tourists, expatriates, including international volunteers, opt to organise part of their arrangements, and the rest is left to ground tour operators. The majority leave transport and part of their accommodation to be sorted out and arranged by ground tour operators. The accommodation part that is left for the ground tour operator to sort out is that in remote rural areas, where these tourists are less aware how things work. Part of the transport that is arranged by ground tour operators for these tourists is that which starts from operators' premises or any pick-up points to the national parks. Transport from the tourist's origin is organised by the tourist themselves.

Figure 5.2: Distribution channels for photographic safaris (Domestic market)

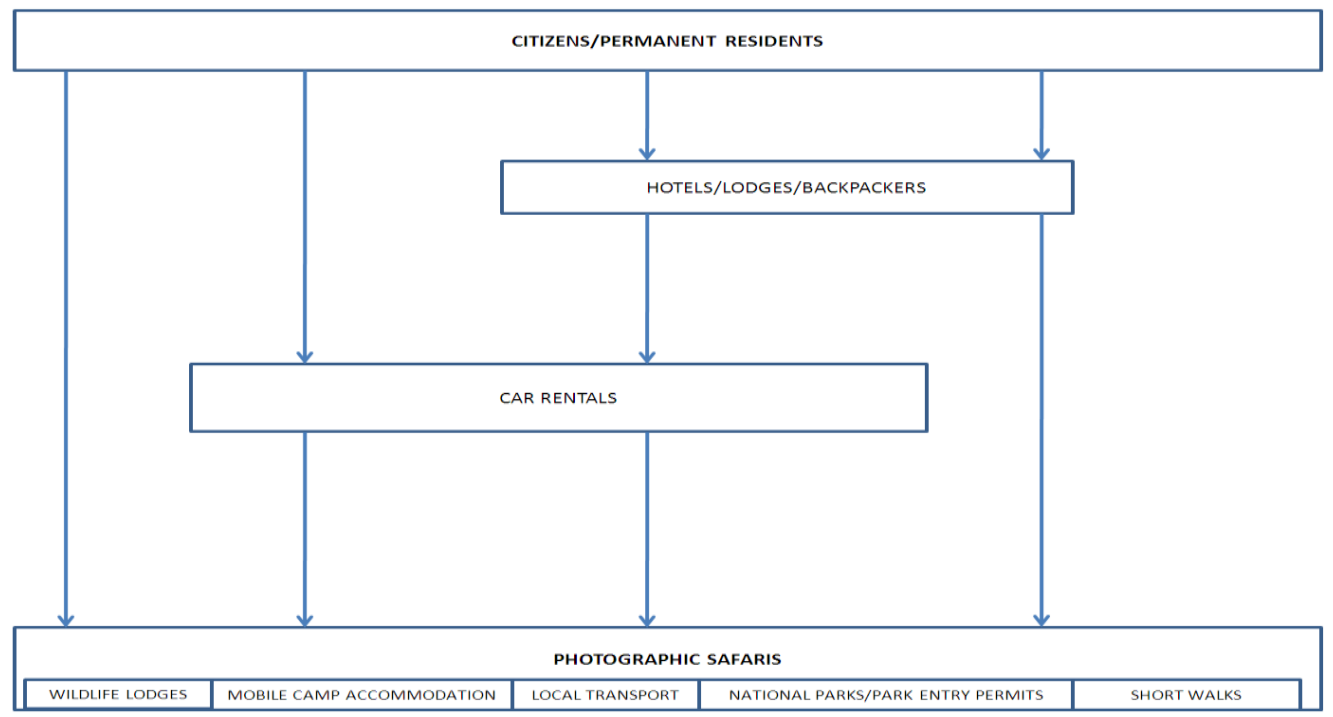

\subsection{Channels of distribution for mountain climbing}

Tourists who come to Tanzania for adventure are primarily interested in Mount Kilimanjaro and Mount Meru (Figures 5.3 and 5.4), at least in the northern tourist circuit. All these mountains are within the national parks, namely Kilimanjaro and Arusha National Parks respectively. They are therefore on state-owned lands. 


\section{Figure 5.3: Mount Kilimanjaro}

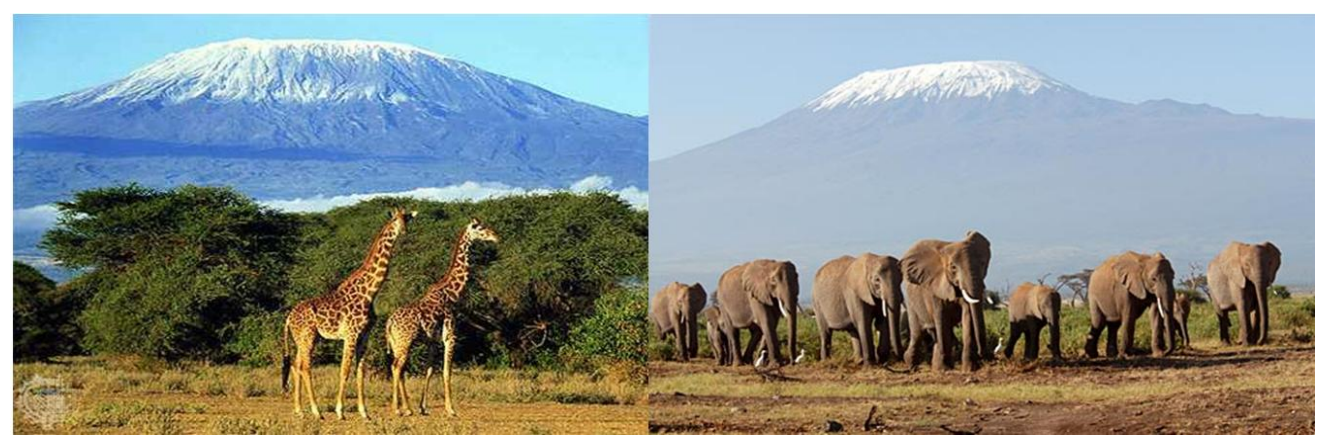

Source: Ahsante Tours

\section{Figure 5.4: Mount Meru}

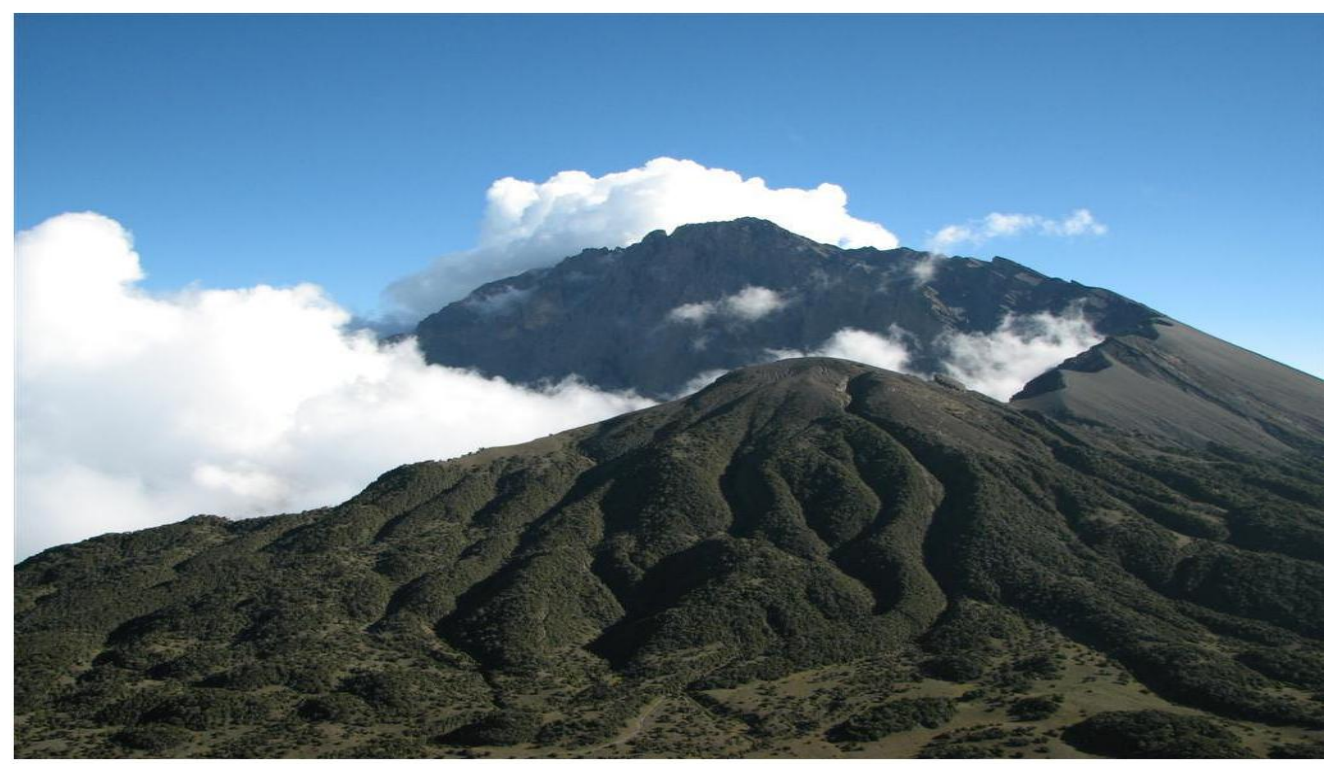

Source: King of Kilimanjaro Tours

These mountains attract tourists who are interested in tramping and hiking and who are physically fit. The nature of the activity automatically limits other types of tourists like young and some senior tourists. There are five routes in climbing Mt Kilimanjaro namely, Marangu route, Umbwe route, Machame route, Lemosho route and Rongai route. Of all these routes, the most common and easiest is the Marangu route, dubbed the "Coca Cola route". The most challenging and difficult is the Machame route or "whisky route". The Marangu route takes five days to climb the mountain for physically fit climbers; ascending takes three days and descending two days. Climbing the 
Machame route may take up to ten days. However, all routes offer the rewarding and memorable adventure experience of being at the highest point in Africa and being on top of world's highest free standing point (Figure 5.5).

Figure 5.5: The peak of Mount Kilimanjaro

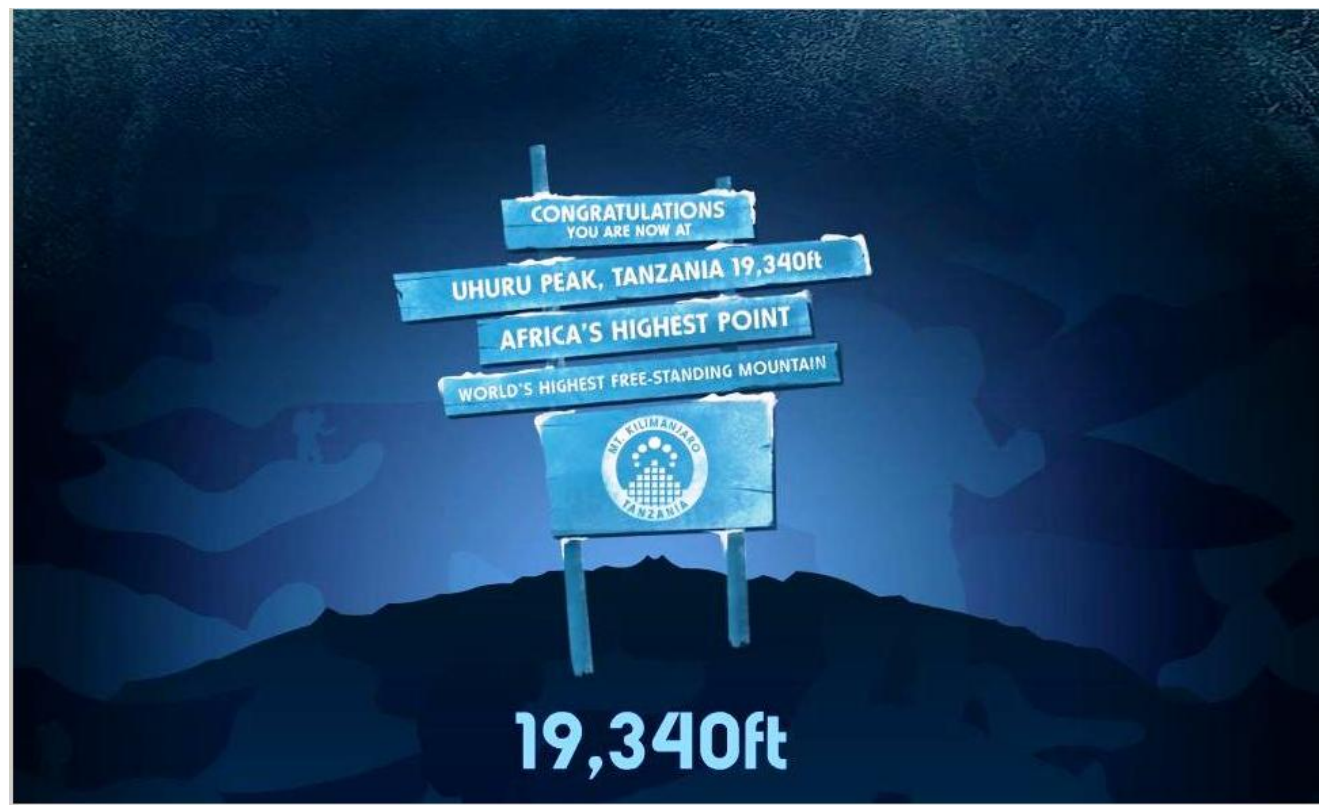

Source: Tanzania Tourist Board

Adventures in these mountains are distributed both directly and indirectly. With regard to international tourists, products are indirectly distributed through overseas travel agents (Figure 5.6). Ground operators (mountaineering and photographic safaris) also distribute the product. Although local operators play a big role in the whole process of adventure distribution, one would hardly find a single brochure from the TANAPA about Mount Kilimanjaro or Mount Meru in the operators' office. This was also observed to be the similar case even for other national parks that are used for photographic safaris in which you cannot find TANAPA's brochure about the parks in ground operators' office. The majority of the brochures in ground operators' offices are produced by the operators themselves to advertise their business. But, because they depend on the adventure providers, particularly TANAPA, they therefore feature adventure attractions in those brochures. Many of the 
brochures produced by TANAPA for Mount Kilimanjaro, Mount Meru and other National Parks are used for international marketing. Few are placed in the information centres at their premises. International marketing is done through participating in tourism and trade fairs:

\begin{abstract}
"We normally attend up to 10 international trade fairs, we participate in road shows and probably you have heard we launched advertisements on CNN and London buses. We are planning to participate in more trade fairs and to use popular television stations across Europe and North America” (Tourism Manager, TANAPA).
\end{abstract}

There are no overseas permanent offices for marketing throughout the year. Instead, marketing activities are left to overseas travel agents (Figure 5.6) who sell package holidays for different destinations. The marketing done by these agents is solely for their own businesses; there are no signed contracts between adventure providers and these agents. The agents feature Tanzania's adventure holidays as part of the wide range of packages they sell for holiday-makers. The majority of tour operators in Kenya feature Mount Kilimanjaro in the tour packages they design:

"If you look on the websites of Kenyan tour operators, you will find all of them feature Kilimanjaro in their packages. By doing so they are helping us to market Kilimanjaro” (Marketing Manager, Tanzania Tourist Board). 


\subsubsection{International package tourists}

This section describes the channels used by international tourists in accessing the adventure products offered in the two mountains of Kilimanjaro and Meru. As with photographic safaris, several type of mountain climbers can also be identified. They all come through different channels. There are those who come through Kenya for the main purpose of visiting the two destinations (Kenya and Tanzania) and those who come purposely to Tanzania because it is their main destination. For these tourists, the same is happening as for photographic safari tourists (Figure 5.6). The main difference between photographic safari tourists and their fellow mountain climbers is that most of their arrangements, like local transport and accommodation choices and booking, are handled by the mountaineering operators. There are also tourists who come mainly for hunting but also do mountain adventures, often after their hunting safaris. A large part of their holiday arrangements is coordinated and handled by hunting operators. They are then transferred to mountaineering operators for the mountain adventure part of their itinerary.

Figure 5.6: Distribution channels for mountain climbing (International market)

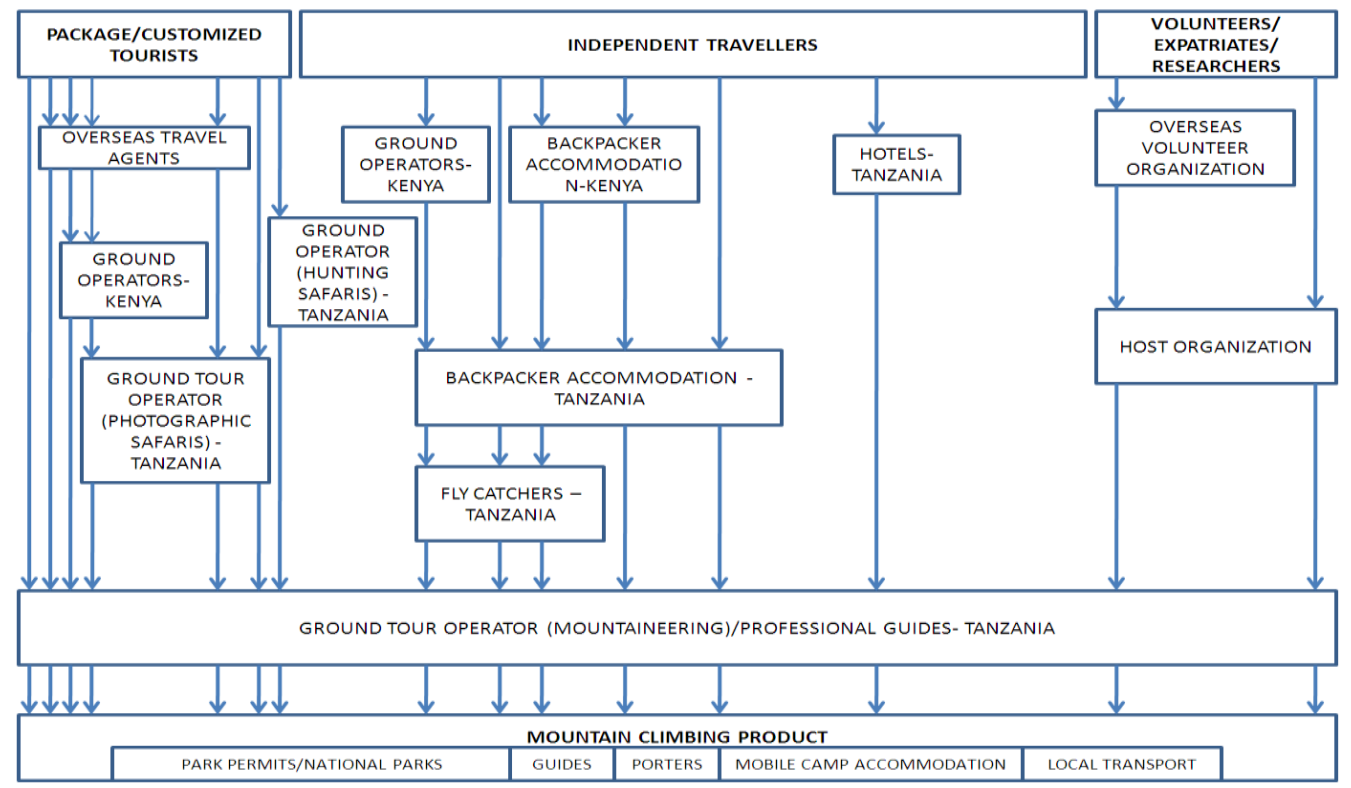


For those package tourists who come through Kenya, the Kenyan operators transfer them to their counterpart operators in Tanzania. As observed in wildlife safaris, these partnerships between Kenyan and Tanzanian operators are on a commission basis. In situations where these tourists, who come through Kenya, have more than one interest in Tanzania for example, they want to do a wildlife safari, climb Kilimanjaro and have beach holiday in Zanzibar, they may be passed on from one operator to another:

\begin{abstract}
"Once they get here from Kenya, we handle all their wildlife safari arrangements. If, on their itineraries, Kilimanjaro is included, we will pass them to mountaineering operators as we don't do mountain climbing. After the Kilimanjaro these tourists will be passed on to resort operators in Zanzibar" (Tourism Manager, Ranger Safaris).
\end{abstract}

The same is observed for tourists who book their holidays direct with Tanzania- based operators. Depending on their interests, there are those who are interested in both wildlife safaris and climbing mountains, and those who are only keen on climbing the mountains. The former will normally book their holidays with ground tour operators (mountaineering companies) or ground tour operators (photographic safari companies). The proportion of those who book with mountaineering companies compared with photographic safari companies is unknown:

"We don't have any statistic for how many book with photographic safari companies and how many book their holidays with mountaineering companies. But I think most international tourists book with photographic safari companies” (Managing Director, Mem Tours). 
The majority of mountaineering operators also do photographic safaris, they handle both mountain climbing and photographic safari arrangements for the tourists. But only a few photographic companies do mountain climbing activities as well. For those photographic companies which specialize in doing only safaris, like Ranger Safaris, the mountain climbing part of the itinerary is referred to mountaineering companies under certain agreements between the two.

\subsubsection{Expatriates and volunteers}

The initial arrangements of expatriates and international volunteers are pretty much the same as in photographic safaris, where the sorting out is handled by overseas organizations in collaboration with the host organization (Figure 5.6). Climbing mountains is then organized either by a professional guide or a mountaineering operator, depending on the particular interest of the climbers.

\subsubsection{International independent travellers and domestic tourists}

Independent travellers may book their adventure while they are at their origin or at the destination. Again, the proportion of those who book while in the market, and those who prefer booking at the destination, is unknown. As with photographic safaris, once they arrive at the destination the first point for independent travellers is backpacker accommodations. Other arrangements are sorted out later. Climbing Mount Kilimanjaro, by law, requires one to be accompanied by a registered professional guide and a minimum of two porters; tourist safety being one of the reasons for that requirement. Therefore, whether they are independent or package tourists, those who want to climb Mount Kilimanjaro, are required to have a guide along. For package tourists, these arrangements are sorted by their operators. For independent travellers, 
the two options are either to book the adventure through a mountaineering operator, or, if they want to climb the mountain, to get a professional guide for climbing the mountain.

Distribution and marketing to domestic tourists is done very informally and there are no well-organised programs. Usually, people who are interested in climbing Mount Kilimanjaro or Mount Meru have to go to the management offices, ring or consult nearby tour operators to get detailed information. When a Tanzania citizen or a permanent resident wishes to climb Mount Kilimanjaro or Meru, they book the adventure through a mountaineering operator or get a professional guide (Figure 5.7). It also should be known that climbing Mount Kilimanjaro requires advanced booking prior to the climbing dates. Putting together the individual components of the adventure product requires an experienced person, especially when the park huts along the tracks are fully booked. This is where mobile camp accommodation will need to be mobilized, and require the presence of professional guide or operator; these are important in bundling together all the components for the adventure. Most of the adventure sales for the two mountains, Kilimanjaro and Meru, come through indirect channels.

Figure 5.7: Distribution channels for mountain climbing (Domestic market)

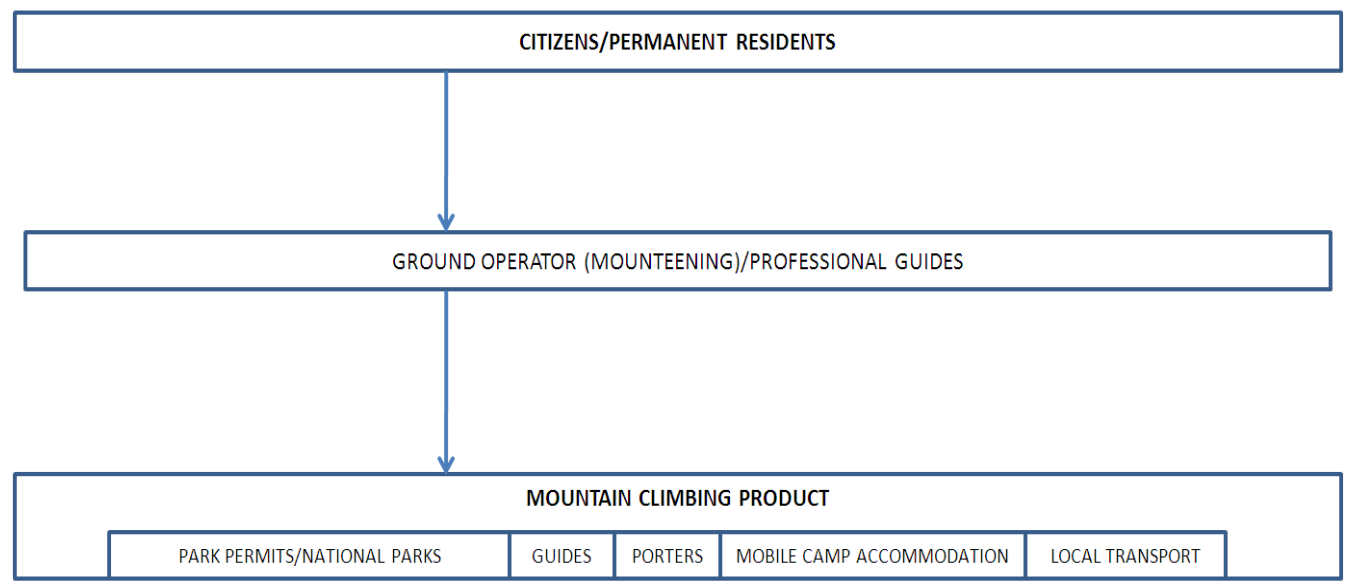




\subsection{Channels of distribution for hunting safaris}

Hunting safaris, commonly referred to as tourist hunting, are a very distinct adventure-kind of safari, at least in Tanzania. The do not attract many tourists, but the few who are attracted are very rich and spend a lot of money:

"Hunting Safari is a sport for those very rich people from the US. Ordinary Americans cannot afford it. It is a very expensive sport and experience. Just think, a hunter spends a minimum of US\$50,000 on a 14-day hunting safari. This is a lot of money a normal person like me, you, or even a medium-income American cannot really afford." (Reservations Manager, Tanzania Big Game Safaris).

"Tourist hunting is very different from normal photographic safaris. First of all it is a much more personalised experience; very often the groups are much smaller, so the interaction between the clients and the professional hunter is much closer than on a photographic safari ..." (Operations Manager, Tanzania Game Tracker Safaris).

Hunting blocks where hunting safaris are taking place are owned by the government. Concessions are given to private businesses (hunting companies) for defined periods of time. The concessionaires manage business-related activities within the block, and the government, through the Wildlife Division, manages the conservation-related activities. However, due to a lack of sufficient funds for efficient management, and insufficient staff in the Wildlife Division, hunting companies often carry out conservation management in their 
concessions. Conservation management includes activities such as ecological and habitat monitoring, and anti-poaching operations.

Unlike sport hunting, subsistence hunting is only allowed in wildlife open and game controlled areas. These are areas rich in wild animals but are neither named as hunting blocks or national parks, nor are they conservation areas. Tourist hunting and subsistence hunting takes place in different areas. Tourist hunting (hunting safaris) can only take place in hunting blocks within game reserves, while subsistence hunting takes place in wildlife open areas and game controlled areas. Permits for subsistence hunting are issued only to citizens and permanent residents. Tourist hunting and subsistence hunting are the same activities, but are done for different purposes, different areas and by different people. Slight differences in regulations also apply; for example, a subsistence hunter does not need to be accompanied by a professional hunter.

Marketing for hunting safaris is mainly done in two ways: attending hunting conventions and the use of marketing agents. Hunting conventions are similar to tourism trade fairs. Most of these conventions are held in North America, the popular ones being the Texas and Houston Safari Club conventions. Similar hunting conventions are also organised in Europe, particularly in Spain, Italy and Germany.

A professional hunter is a person who has attended hunting courses and is knowledgeable enough to identify different species of wild animals including their sex and an accurate estimation of their age. Such a person is also trained in the use of firearms and ammunition. A professional hunter is essentially a hunting guide and is considered to be amongst the top, if not the best-paid people in the tourism industry in Tanzania. Payment per day ranges from US\$ 500 to US\$ 800. According to the hunting laws of Tanzania, a tourist hunter must be accompanied by a professional hunter in hunting safaris. The tourist pays all costs associated with the hunting adventure, including the payments 
for the professional hunter. Some professional hunters are also marketing agents. They guide hunters during the hunting season and do marketing during the off season. $70 \%-95 \%$ of hunting safaris are booked through indirect channels and professional hunters play a crucial role in this (Figure 5.8). Only $10 \%-30 \%$ of hunting safaris are sold directly. An estimated 35\%-65\% of bookings come through professional hunters.

"A lot of our bookings come through our professional hunters; they have very large following up, they area very important source of our clients, because clients like to return on safari with the same guide they hunted with" (Operations Manager, Tandala Expedition).

"Very often the client will contact the professional hunter in the off season, and will ask the professional hunter to arrange a safari for them; then the professional hunter deals with the company booking and getting the itinerary together"'(Reservations Manager, Tanzania Big Game Safaris).

Tourists who come for hunting are either package tourists or customised tourists. There is no such thing as international independent hunters. Tourist hunting is considered to be a well-off tourist sport. Independent hunters are only domestic tourists (local inhabitants and permanent residents) who practice subsistence hunting. 
Figure 5.8: Distribution channels for hunting safaris

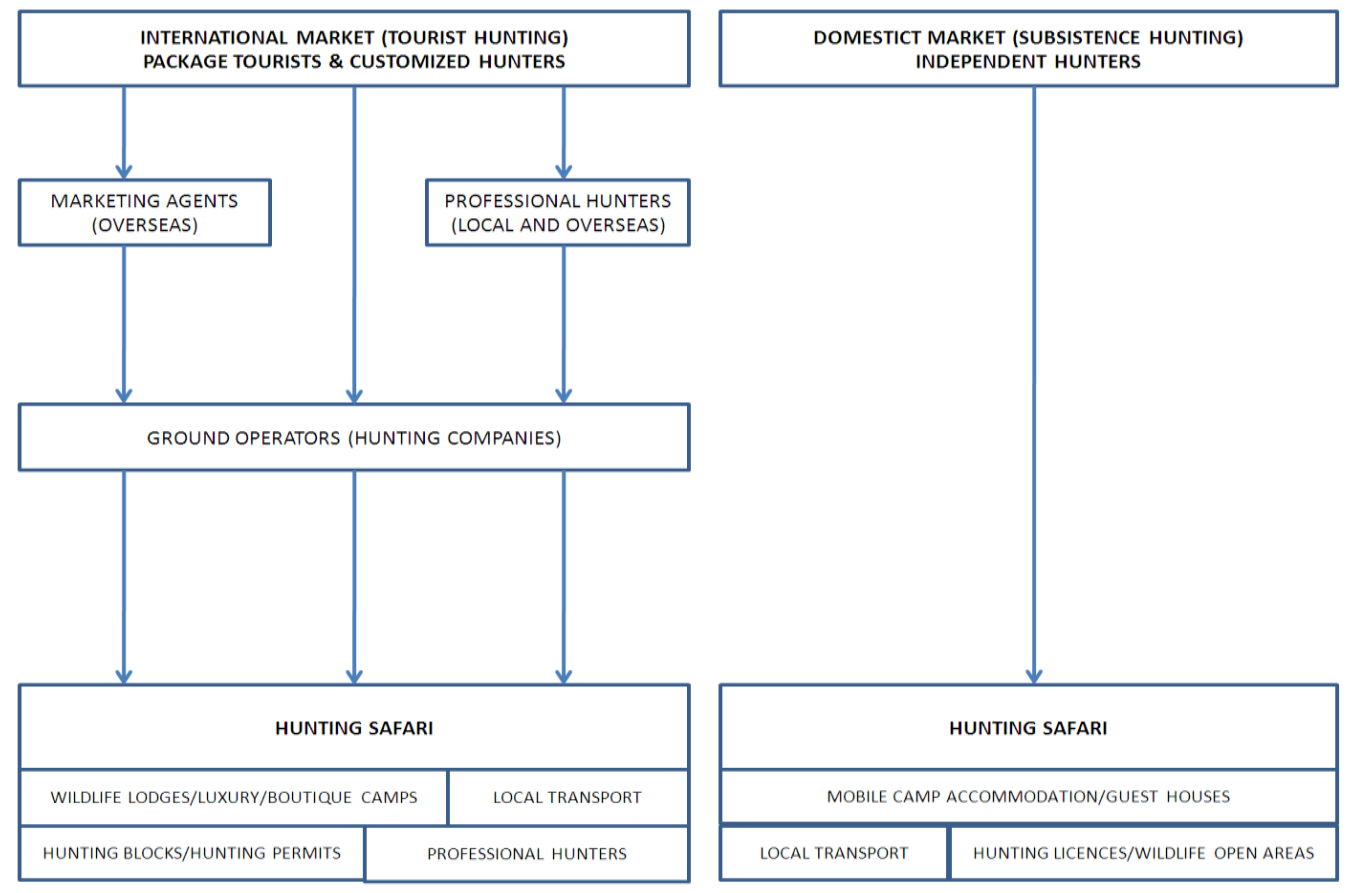

\subsection{Distribution channels for cultural and heritage sites}

Tanzania is blessed with a very wide range of cultures. There are more than 120 tribes, all speaking different languages. Of all tribes, the Maasai people are known for their traditional ways of living. Interviews were conducted with leaders of Maasai Cultural Bomas in Ngorongoro Conservation Area. Bomas are the Maasai family villages (Figure 5.9).

Figure 5.9: Maasai bomas in Ngorongoro Conservation Area

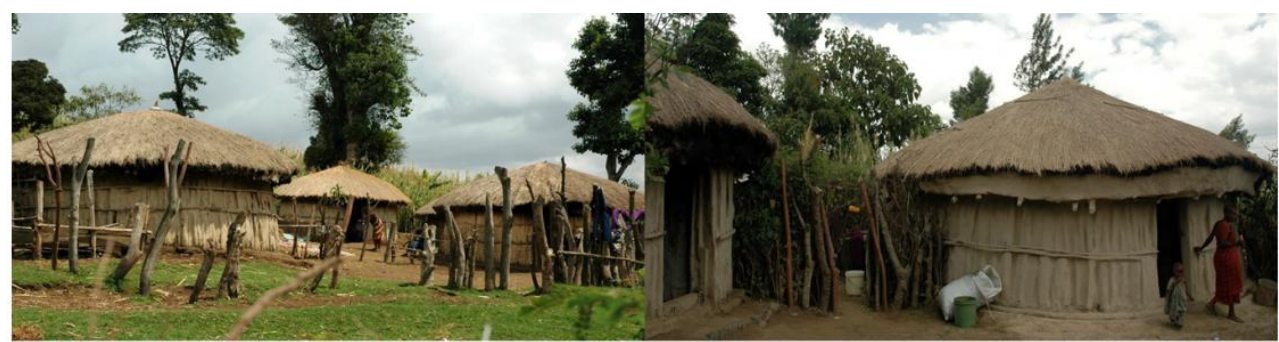

Author's own photographs 
Direct sales in the bomas take the form of on-site selling where tourists are charged prior to entry (Figure 5.10). However, due to their remote location, these bomas are entirely dependent on the tour operators who bring in tourists on game drives in the conservation area. There are some arrangements between these bomas and some tour operators, where the latter take tourists to the bomas on their way to national parks or while doing a game drive in the conservation area. Tour drivers are often given TSh 10,000 (10US\$) as an incentive for stopping at these sites so that tourists can have a look at them (Figure 5.10).

Figure 5.10: Distribution channels for cultural and heritage sites

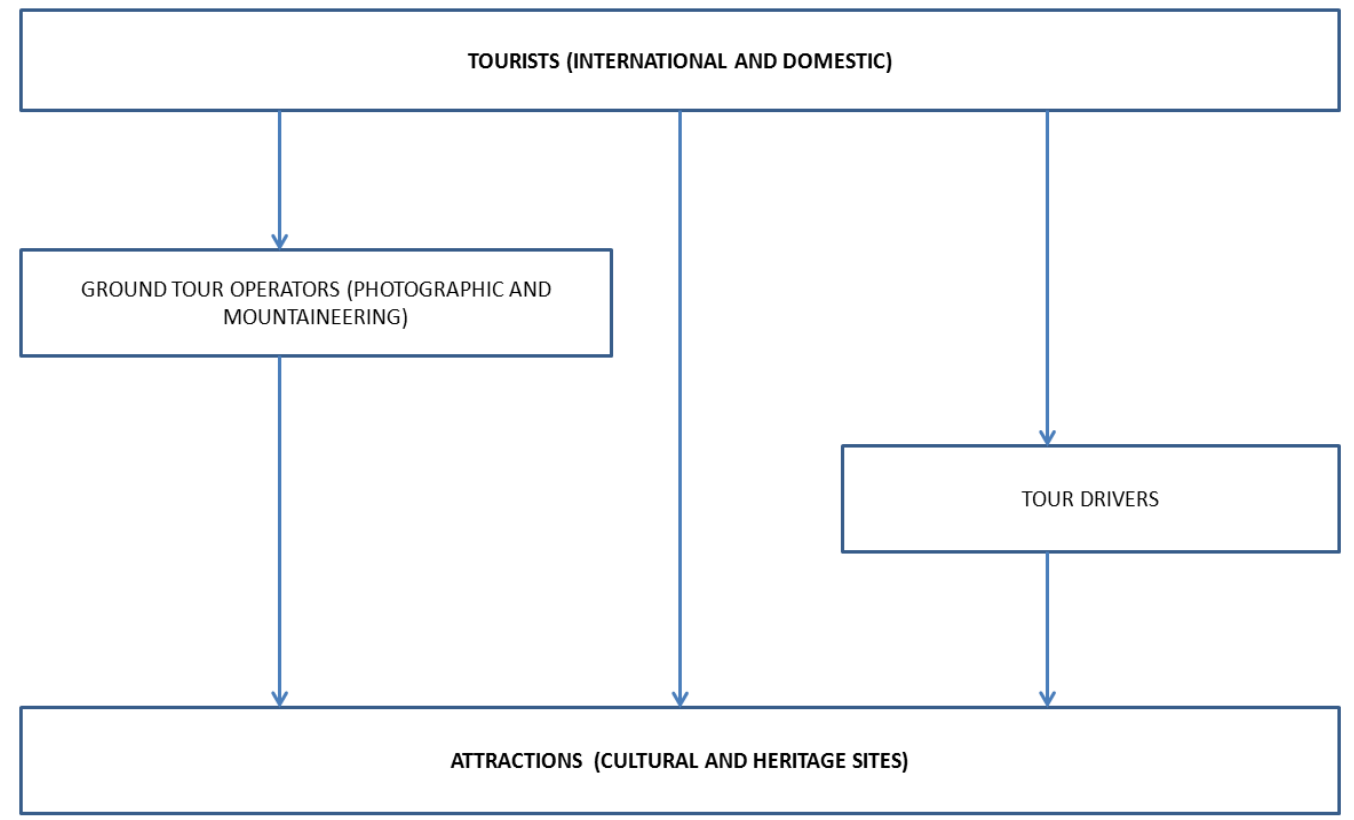

Unfortunately cultural and heritage attractions are often not included in the packages due to their 'weak draw power' when compared to wildlife. They are therefore treated as add-on attractions. Marketing is largely done at the destination to generate awareness once visitors have arrived in Arusha and Moshi. As expressed by the head of one Boma: 
"People come to Tanzania because they want to see wildlife, not Maasai culture; if there are, very few then and probably just for social studies or research. The drawing power of wildlife is much stronger than anything else. But we take advantage of that, once they get to Arusha, they see the brochures we put at the Ngorongoro information centre in Arusha. Even if we do international marketing, people will never come to Tanzania just for the cultural attractions, these are just nyongeza (nyongeza is Swahili for add-ons).

Cultural tourism is therefore reliant on "at destination" distribution simply because it is seen as a secondary attraction to wildlife-based tourism, at least in the northern tourist circuit.

\subsection{Distribution channels by sectors}

As mentioned earlier, the following sections provide descriptions of the distribution channels used in the different sectors of accommodation and local transport, so as to get the whole picture of the distribution complex in the northern tourist circuit.

\subsubsection{Accommodation}

Distribution channels used by accommodation providers differ depending on the location of the facility, targeted market segment, and level of services offered. Clear differences in distribution channels and marketing strategies were noted between backpacker accommodation, hotels and wildlife lodges. 


\subsubsection{Backpacker accommodation}

Backpackers target budget travellers; they sell the majority of their products directly where a client may book in advance for a bed or just pop in anytime if there are vacancies. This kind of distribution happens for both those travellers who come directly to Tanzania and those who come through Kenya (Figure 5.11). The latter may book for the bed night while in Kenya, or they may wait until they get to Tanzania and physically approach the properties. Backpackers put their advertisements in the travel guides like Lonely Planet, commonly referred to as the "Traveller's Bible":

“We market ourselves in travellers' guide books, as we target budget travellers, these are ideal ways of getting our ads across and it really works. A lot of our clients have known about us through guide books and by word of mouth from previous clients" (Manager, Meru Tourist Inn).

This is considered to be the most important venue for their marketing. Of all the businesses interviewed, not even one attends trade fairs. It was also observed that the majority of backpackers in the northern tourist circuit target international budget travellers. This is partly why they do not even do domestic marketing, or perhaps because there are no domestic receipts they do not do any domestic marketing. 


\section{Figure 5.11: Distribution channels for backpacker accommodation}

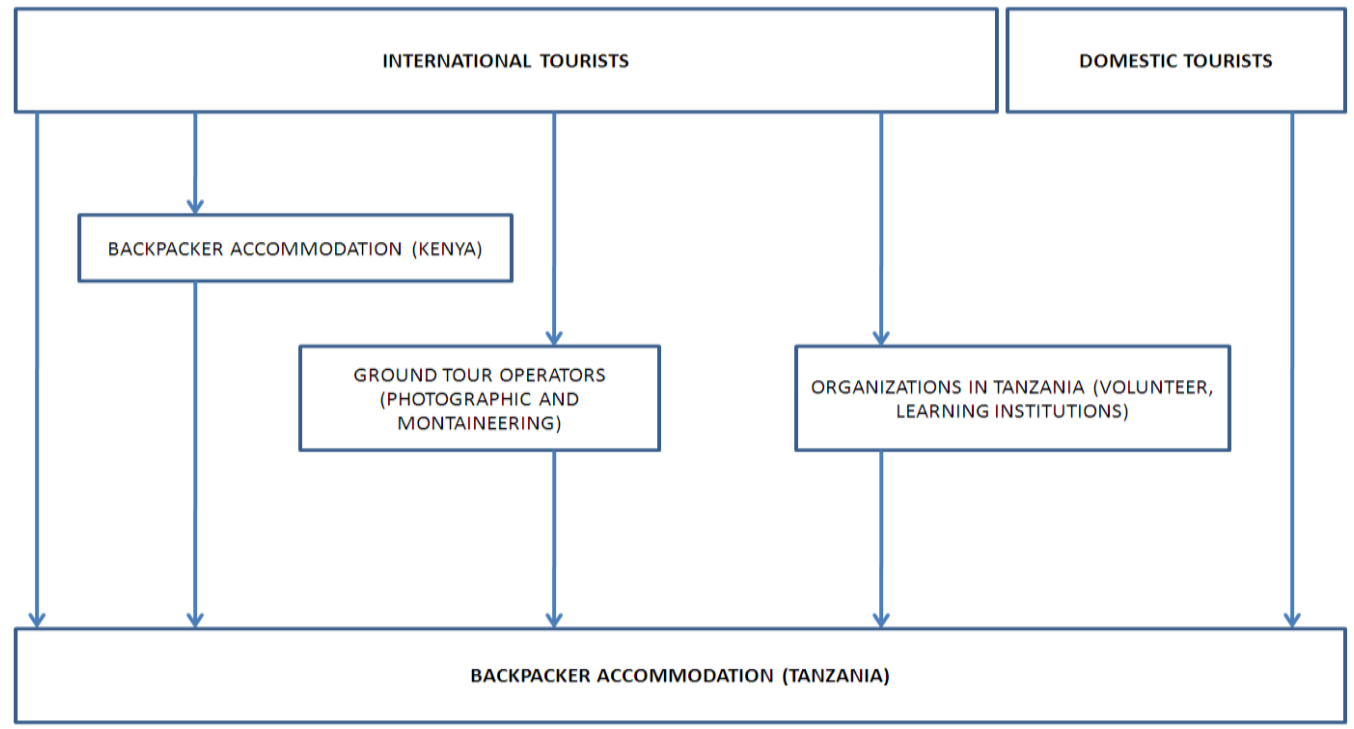

The majority of domestic tourists prefer to use guest houses, but if they happen to want backpacker accommodation they normally just approach the properties. The reasons why most domestic tourists use guest houses are not known, but it is probably due to the fact that some guest houses are relatively cheaper than backpackers accommodation. Occasionally, backpackers get their services sold through ground tour operators (Figure 5.11). Over $80 \%$ of backpacker services are sold directly. The remaining $20 \%$ of sales come through indirect channels. These channels include volunteering organizations, learning institutions and ground tour operators. While some organizations may demand commissions, some do not:

"We get our clients from different organizations too, some of these organizations want to be paid a commission for doing that; we are not sure whether the organizations demand this [commission] or [whether] it is just the interest [in asking a commission is] of the in-charge person; I'm sure you know how things work here. But some of the organizations don't demand to be given commissions. Tour operators are business people; you definitely have to get prepared to give 
commissions if they bring you clients" (Marketing Manager, Arusha Backpackers).

\subsubsection{Hotels}

In hotels, distribution channels used are approximately 50\% direct and 50\% indirect. These hotels in the towns of Arusha and Moshi serve both tourists and non-tourists. The main clients for these hotels are corporate workers, government officials, business people, conference organizers and ground tour operators (photographic, hunting, mountaineering and hunting operators). Services for corporate and government officials and business people, including conference attendees, are often directly distributed (Figure 5.12) but are sometimes channelled through the organizations, government departments or conference organizers. Services to international leisure tourists are often sold through ground operators (wildlife, hunting and mountaineering operators). Again, tourists who come through Kenya, are passed to ground operators in Tanzania (for package tourists) or book the hotel accommodation by themselves (for independent travellers) (Figure 5.12). Most volunteers and expatriates access hotels through their host organizations which organize most of their arrangements in Tanzania. 
Figure 5.12: Distribution channels for hotels

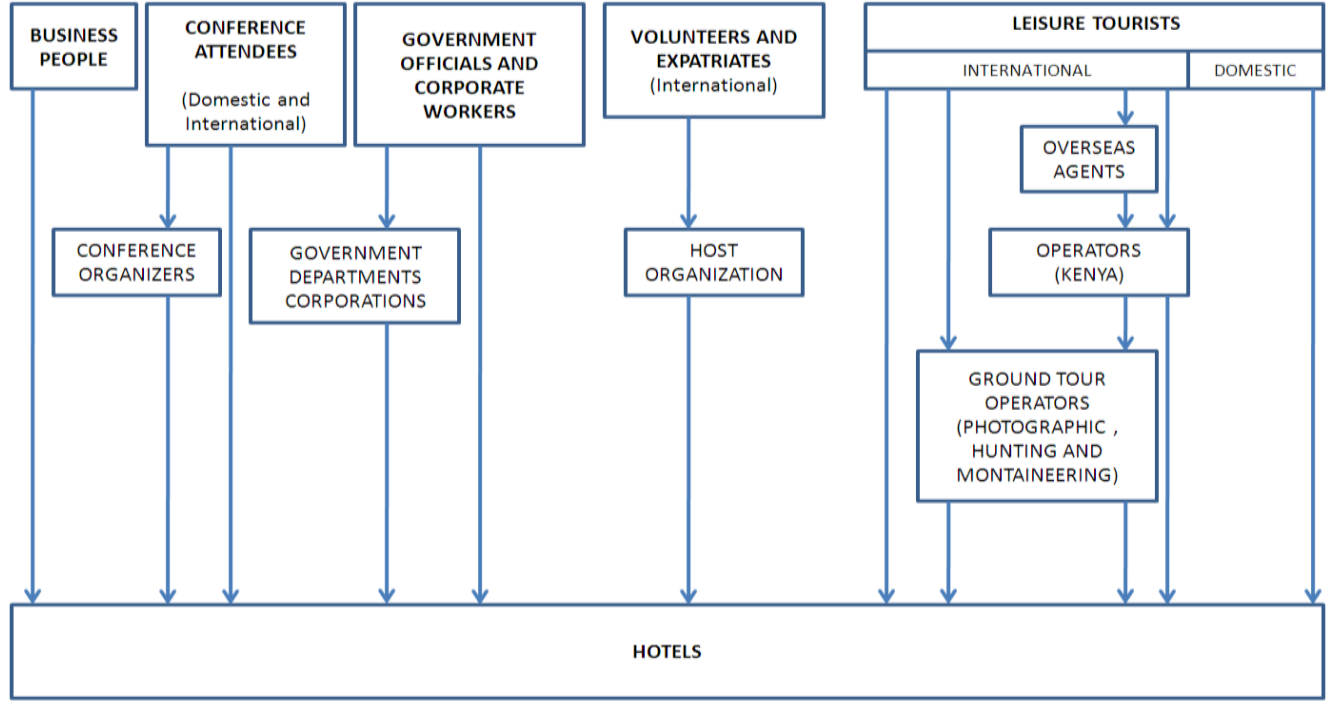

The majority of hotels are located in towns and some of them have conference halls that make them ideal for tourists and other businesses. International tourists who book directly with the hotels are mainly those from South Africa and neighbouring countries. Marketing for the majority of hotels is done through brochures, attending trade fairs and physically approaching different corporate and government offices for creating awareness and promotion offers to these clients.

\subsubsection{Wildlife lodges}

Wildlife lodges are strategically located in and around national parks and target visitors to the parks. These lodges have organized management systems and well trained staff in almost all sections. Wildlife lodges target a more well-to-do market. Services are offered to tourists but their clients are mainly operators (photographic, hunting and mountaineering operators). These lodges are entirely dependent on indirect distribution. Bed nights are sold as part of package tours or tailor made packages by either overseas travel agents or local operators. Some operators do block booking for these lodges. Block booking 
essentially means you book and pay for a number of bed nights for a certain period of time. This is done by ground tour operators usually for the whole period of high and peak seasons so as to guarantee space availability for their clients. This enables the operators to have higher bargaining power and thus get good deals for prices as they purchase in bulk quantities using economies of scale. As noted by the director of Victoria Expedition Tours:

"Well, the way the industry works is that the more business you provide to them the bigger the discount or the lower net rates they can give you",

Block booking seems to be posing a risk for businesses as the block is booked without being sure if they are actually going to use the entire booked quota or not. But this is sometimes done so as to out-compete other business rivals as there is less supply than demand of accommodation in and around national parks. If it happens that the company has more clients than booked bed nights, it has to buy more bed nights from the other operators with excess booked bed nights. In this case business is done between two operators; the lodge management may not even be aware of this. When buying bed nights from operators, as in this case, one gets charged relatively higher rates than when buying directly from the lodge. Regardless of whether the block booker gets enough clients or not, they still stand a better position to make business by selling the booked bed nights to other operators.

Indirect distribution is the most common distribution system in lodges and mostly comes through operators. This is because operators have well established names in the markets and so they are often the first points of contact. Usually tourists leave everything to operators to sort out for them. This leaves lodges with little power and they are totally dependent on operators. One would expect, since there is high demand for bed nights in wildlife lodges, this would give them more power than ground operators. 
Surprisingly this is not the case. Ground operators are still more powerful than other suppliers in the destination. In a customised package, a tourist may suggest a certain lodge, but all the payments will be made to the agent or tour operators, who will then purchase the bed nights on behalf of the tourist.

\subsubsection{Local transport}

Means of local transport that were included in the interviews are air charters and land transport, namely car-hire companies and tour operators. As mentioned earlier, tour operators, apart from their main business of sorting and coordinating arrangements, are also the main providers of local transport, especially for accessing national parks. This is often included in package tours or even customized packages, since to do a game drive (photographic and hunting safaris) requires one to have a vehicle. It is estimated that over $90 \%$ of this local transport is directly distributed. The remaining $10 \%$ is distributed indirectly through other operators who may run out of vehicles to accommodate clients at a particular time. There is no formal marketing for this service. However, ground tour operators are generally the most active stakeholders at destination for attending domestic and international trade fairs. The main purpose for attending these trade fairs is to meet potential partners such as travel agents from different corners of the world, who will work with them in coming seasons. Some ground operators only target budget travellers, so they are less active in attending trade fairs which are considered to be an important meeting place for overseas agents and local suppliers. Such ground operators use guidebooks like Lonely Planet to get their business advertisements across. They also use fly catchers to get more clients. Fly catchers are often paid fixed commissions which range from Tanzanian Shilling (TSh) 10,000 (US\$ 10) to TSh 20,000 for each client they bring. Brochures are also put in budget accommodation. 


\title{
5.6.2.1 Car rentals
}

Car hire companies provide services to anybody who is in need, regardless of them being tourists or not. However, the main clients are conference organisers, business people and a few tourists. As with tour operators, direct distribution is dominant in car hire as well. Marketing in such companies is done through websites, brochures, and a physical approach to different offices. The size of the business and customers targeted are the main reasons for the marketing strategies and distribution style adopted. Most of these businesses are family owned. The main targeted market is domestic - which is why attention is not paid to international marketing. As the marketing officer in Serena Car Hire noted:

\begin{abstract}
"Look, my target clients are people who are here, conference organizers and some corporate workers when [they] are in workshops. They all know my company, why should I do international marketing which is way too costly?"
\end{abstract}

\subsubsection{Air charters}

An air charter is another easy means to get into national parks. All parks and game reserves have air strips. The interviewed companies are purely air charters; they have no scheduled flights. The main clients are operators but services are provided to tourists. Indirect distribution dominates this sector. Services are indirectly sold as part of customized packages to tourists by local tour operators and overseas travel agents. Air charter companies market themselves through the use of websites and by physically approaching potential clients which, in this case, are ground tour operators. Competition among air charters is intense due to a small number of tourists who are interested in this service. 


\subsubsection{Local travel agents}

Travel agents in the northern tourist circuit perform a very small role when compared to their counterparts in developed countries. They are basically booking offices for flights (airlines), and that is all they do. They never sell holiday packages, nor do they have catalogues for holidays, even for locals. They also do not design travel packages for the domestic market. Very few brochures about resorts in Zanzibar were found in one of the travel agents interviewed, and that agent, when asked, did not know anything about the details of the resorts.

All of the sales by travel agents are made directly. The clients are all people who want to fly to different parts of the country or overseas. The majority are business people, corporate workers and expatriates. Marketing is done through distribution of brochures to offices where potential customers are thought to come.

\subsection{Factors influencing the channel structures}

A number of factors influence the structure of distribution channels in the northern tourist circuit; and the influence of other tourism sectors is among them. Other tourism sectors such as tour operations have well-established names, and it is tour operators especially who coordinate most of the arrangements in the destination and are considered to be the most knowledgeable about different aspects. In most cases these are the sectors that tourists, especially international ones, prefer to contact first in the destination: 
"Tourists prefer to make all their arrangements with agents and tour operators; they never ring us ... However, we don't coordinate travel arrangements" (Tourism Manager, TANAPA).

It is largely ground operators who coordinate most day-to-day tourism activities in the northern tourist circuit. So individual components in photographic safaris rely on ground operators in distributing the safaris; thus indirect distribution channels are more popular with international tourists than direct channels.

Risks associated with sending money to a third world country are another factor. The majority of tourists prefer to book their holiday through overseas tour agents in their countries of origin. Some tourists do not want to risk sending their money to businesses which they do not know and are not sure whether they exist or not. So instead of buying their holidays directly from suppliers, they buy from overseas agents:

"And also they are very suspicious about sending money to Africa, not only Africa but [to the] third world, ('Is our money safe'?) To a company they don't know. But the agents trust us [African companies]. They would not use us if there was no trust and performance. So there is trust and security, if something goes wrong there is law that protects them [clients]" (Managing Director, Hoopoe Adventure).

Little and less reliable information about the destination in the markets also plays a part in influencing which channels are used by tourists to come to Tanzania. The "on and off" style of marketing affects the decision as to which channels are used by tourists. A style of marketing - "showing up and going 
away" - that lacks year-round sustained momentum, limits the level and extent of information about the destination at the markets. There are no permanent information centres dedicated to the destination in many major markets for Tanzania tourism. Such information centres are important for providing information about the destination year-round in the markets. Most of the marketing activities are seasonal and take place only during the tourism trade fairs in Europe and North America.

"We have two marketing agents; one in the US and another one in Spain. We pay them on a part-time basis. They normally get paid about 10-15 hours a week for doing that" (Information Officer, Tanzania Tourist Board).

This affects suppliers indirectly, as prospective tourists get most of the information they are seeking from overseas agents who work year-round in marketing:

"I have been involved in tourism business for more than seven years. I have attended a number of international trade fairs in US, Europe and Africa. What I observed is that Tanzania does not represent itself enough in the markets as [our] competitors do. There are no year-round centres for specific information about Tanzania. We are far from markets that we depend on; we need to have permanent information centres in all our big markets or we will be defeated by our competitors (Kenya). In my opinion, the majority of tourists book their holidays through agents because they don't know who to contact direct in Tanzania and due to the distance as we are located in a different world"(Marketing Manager, Ahsante Tours). 
This has a potential impact in influencing tourists' decisions on who to book with. Little information that is available in the markets, and that makes it difficult for tourists to shop direct. A lesser-known destination, combined with distance, influences tourists' decisions to buy their holidays through agents, thus indirectly.

Ownership and lack of competition among national parks within the country are affecting how active attraction providers are. All national parks and conservation areas are state-owned and there are fixed entrance fees regardless of the channel a tourist uses to access the national park. This makes the national parks relax and wait for the visitors to come, thus not getting very much involved in designing which distribution strategies, direct or indirect, are to use. The other reason is that wildlife in national parks is among the main attractions that draw tourists to the destination. No matter how tourists get to the destination, they must visit one or two national parks; these are seen as "must visit" attractions.

Existing laws partly influence the structure of distribution channels, especially in adventure packages. The condition that a climber has to be accompanied by a professional guide makes most climbers buy adventures through mountaineering operators or professional guides.

Tourist hunting is a personalised experience. The groups of tourists (hunters) are relatively small in comparison to photographic safaris, where a group is often made up of one or two people, a couple or father and son. The hunting activity itself takes place in very remote areas, where interaction with other tourists is very rare. Professional hunters can create strong relationship bonds with tourists. Their relationships involve camaraderie, so when the tourist 
wants to come again for a hunting safari he will contact the professional hunter first:

“...in hunting [safaris] you often find groups are much smaller than in photographic safaris, very often one client to one guide, or one to two so the interaction is much closer. Normally by the end of the safari you have created a relationship with that client. The client trusts you, he has had a good opportunity in the period that you had been together in the remote area, he has trusted you for with his life, he has trusted you with ensuring that everything is going smoothly in his safari, he has trusted the professional hunter to make sure that he got what he paid for, I am not talking about the number of animals that he shot, but the overall experience and therefore very often there is a bond that is created and you know the clients afterwards; they want to deal directly with the professional hunter and the professional hunter is in the best position to make sure that when he designs the itinerary and puts together the details of holiday he does it to meet the best requirements of the client because he knows how the client behaves what he likes, his fitness level, what he can do and what he can't, what does he like, he likes heat or does he like colder weather, you know all these sort of things so it is only natural that bond is created ... the client feels that he communicates his needs, his requirements and his wishes much better with the professional hunter with whom they have spent time together, in very close environments with no other people to distract you; so you have the full undivided attention of your professional hunter for the entire period that you are there, and they just feel that if he allows the professional hunter to design his itinerary, the professional hunter will know this client will not enjoy Maswa Game Reserve but he will enjoy 
Selous Game Reserve, so that's how it works" (Operations Manager, Tanzania Game Tracker Safari).

Contrary to tourists with other interests, hunters are particularly special in doing hunting safaris. Every year, about $70 \%-95 \%$ of international hunters in Tanzania are on repeat visits. The hunting experience is sometimes being passed on from one generation to another in the same family. For instance, if a father is a hunter, the chances are very high that his sons will be future hunters and so on, from generation to generation. Basically, the relationships with professional hunters influence the decisions of hunters as to how they buy their hunting safaris and so tourists' preferences play a big role here.

It also seems that even the hunting companies themselves prefer professional hunters to design itineraries for their clients. Often direct clients are referred to professional hunters before their itineraries are designed. Professional hunters design the itineraries and quote a price to the clients:

"If a client contacts us and they want to go for a hunting safari, we normally refer them to a professional hunter. You know, professional hunters know all the difficulties associated with hunting in different parts of the country, they know the problems associated with physical fitness, and they also know where to find different species of animals and the best time to hunt. So we normally want the hunter to discuss all these issues with a professional hunter; the professional hunter stands a better chance of providing more practical and relevant advice to hunters. Hunting is not only fun or a sport, it is sometimes very risky, a person my get killed by an animal. We apply the strictest ethics when it comes to hunting itself. We want these to be clear well in advance to the hunter" (Operations Manager, Rungwa Hunting Safaris). 
If a client is satisfied with the itinerary, they may book their safari either with the company or with the professional hunter who then passes on the payments to the hunting companies.

\subsection{Differences in distribution channels between local and foreign owned companies}

There is a very slight difference between distribution channels used by local and foreign owned companies. Foreign investors dominate in the sectors of wildlife lodges, ground operators (hunting companies) and air charters. Locals run the majority of hotels, backpackers, mountaineering and photographic operations. Foreign-owned companies tend to focus on middle to high-end tourists, while local companies target the budget and middle class market. Both largely depend on the indirect distribution of products. The majority of foreign-owned companies invest more in marketing, especially attending international trade fairs, while just a few locally-owned businesses do so. Local companies also have wide networks with other local businesses where 'at destination' referrals of clients are common among these companies. However, most of these relationships are just informal agreements. For the foreign-owned businesses, it is observed that they receive a relatively higher percentage of clients from their country of origin; a Dutch owned company receives more Dutch tourists as compared to tourists from other countries.

\subsection{Relationships among channel members}

As shown in Figures 5.1-5.12, there are complex relationships among members in different channels. The more activities the tourists are interested in doing, the more members are involved and the more complex the distribution channels become. Ground operators, particularly those dealing 
with photographic safaris and mountain climbing, may deal with many overseas travel agents ranging from 20 to over 100 . The majority of their overseas travel agents partners are in North America and Europe with few in Asia and the Pacific.

Arrangements for relationships vary a lot between partners and from one relationship to another. Some partnerships involve signed contracts between partners but some are purely informal or just agreements, as expressed by the managing director of Hoopoe Adventure in these terms:

"We don't have permanent written contracts with agents, but each time we sell a safari there are terms and conditions for clients. We have written contacts with hotels and lodges which are reviewed on an annual basis".

This is true both between local partners and between local and international partners. No particular reasons appear to guide the formality of partnerships. If both partners are satisfied to work without having a written contract, then the relationship will just be like that. But if one partner is keen to have a signed contract, then the contract will be drafted by one partner and discussed by both before it gets signed. The signed contracts are generally reviewed annually by both parties. Ground operators are observed to be very flexible in having either very formal or informal relationships. While some overseas travel agents are relatively less flexible. As mentioned above, a ground operator may be dealing with more than 50 partners in a mixed variety of relationships; some are formal and others are just informal agreements. The majority of agreements are between local partners, for example between photographic safari operators and mountaineering operators. 
Partnerships between members in a channel involve commissions which range from $20-30 \%$ of the total package quoted. However, observation shows that in some formal contracts the overseas agent does not disclose how much they charge clients. This remains unknown to ground operators; even worse, they are not allowed to ask the clients how much they paid for their holidays; it is treated as confidential and is clearly stipulated in the contracts.

The general principle is that whoever brings business or clients has more power than the other party. The overseas travel agents who bring the majority of tourists to ground operators are the most powerful in the distribution channels. But, as mentioned earlier, ground tour operators coordinate all arrangements at the destination and in most cases they are the one who decide which services (accommodation or local transport) to use. They are the most powerful at the destination, as by principle, they have relatively higher bargaining power on properties than other stakeholders at the destination. As an operations manager of Tanzania Game Tracker Safaris revealed:

“Well, it's not a question of being happy or not, that is just the way the industry works: the more business you provide to them, the bigger the discount or the lower net rates they can give you”.

This point of view was substantiated by the managing director of Hoopoe Adventure:

"Most properties protect us, they give us good commissions and we normally speak to them, we tell them you must protect us, you must give us better rates than anyone outside, you protect us, we will use you, you don't protect us, we will use someone else." 
Tour operators also coerce the accommodation providers to charge higher rates to other stakeholders so as to discourage them (other stakeholders), particularly overseas travel agents, from booking directly with hotels and lodges. Ground tour operators have gained such strong power at the destination to the extent of discouraging the overseas travel agents from doing any arrangements rather than consulting the ground operators first.

"What we do for the agents, we book all lodges, internal flights and all attractions, occasionally agents may book these properties these days [themselves] and pay directly but we discourage that; we say. 'Look, our rates are good, and we have better rates than you do for the lodges and we know these properties better. If you are going to book these properties yourself you will have to employ another person. And very simply put, how much will it cost you to employ one person in England compared to how much it costs here [Tanzania]'. There is a big difference. So we say, 'You let us do the whole work, we will make a small margin on it'; we will do all the work, and generally that is a good formula which most agents agree with...” (Managing Director, King of Kilimanjaro Tours).

However, the power of ground operators at the destination does not apply to state-owned attractions like national parks, game reserves, conservation areas and mountains. These have fixed entrance fees. It does not matter how many clients you bring, just the same fee applies and there are no commissions paid for that. 


\subsection{Conclusion}

The distribution mix of the northern tourist circuit of Tanzania is complex. It is a mixture of direct and indirect channels and there are a lot of en-route referrals from Kenya to Tanzania, and 'at destination', referrals of tourists between businesses. Such relationships between businesses are on a commission basis. Some relationships are formal with signed contracts but others are just informal agreements. Indirect distribution channels are more popular than direct channels. Small event activities and cultural and heritage attractions are solely dependent on direct distribution channels. This is due to their weak drawing-power compared to wildlife, and thus they are only occasionally included in package tours. The size of the business, market knowledge and preference of tourists are the factors that influence decisions about the choice of channels to be used.

To have a formal or informal relationship will depend on the interests of partners themselves. If they are both satisfied with having informal relationships, then they will just have that one. While local businesses are flexible and are open to any kind of relationship, formal or informal, their overseas partners prefer formal contracts. Ground operators deal with many overseas travel agents, up to over 100 . This helps them to extend their market coverage.

Marketing is done mainly using websites, attending trade fairs and producing brochures. Information technology is limited in providing information on-line and for receiving enquires from possible clients in the future. Payments are made through banks in most cases and $25-30 \%$ of the total price is to be sent in advance. The majority of websites are in the English language; a few have either one or two other languages, for example Dutch, Italian, French, Spanish, German, Russian and Japanese. 
There are slight differences in distribution channels between those that are locally owned and those owned by foreigners. While the latter have more links and networks with many overseas travel agents and have participated in many international trade fairs, companies that are owned by locals have many networks at the destination and with international partners. Foreigners, in particular, prefer to invest mainly in wildlife lodges, hunting companies and air charters.

As seen in the above sections, there are some differences in the distribution channels used across different activities and sectors; there are also many commonalities amongst and between them. Almost all businesses are heavily dependent on indirect channels of distribution and therefore maintaining relationships with other players is of great importance. It also appears that ground operators are the main clients for other businesses such as accommodation providers and air charters at the destination, and therefore other suppliers are dependent on them; they are also generally the most powerful players. Across all businesses that are privately owned there is significant variation in terms of how formal the relationships are among players. A business may be dealing with many other businesses under the whole bunch of different agreements and contracts. It mainly depends on the preference of the other partners.

Distribution channels in hunting safaris are especially different compared to other businesses. Up to $30 \%$ of bookings are made in the hunting conventions, while in other businesses, trade fairs are mainly used for, although not limited to, meeting suppliers and wholesalers. Bookings may be made in the trade fairs, but the majority of the businesses do not expect much from that. Somewhat more attention is paid to getting partners to work with in the coming seasons. While a range of other sectors get tourists through Kenyan operators, there are no such arrangements in hunting safaris. 
The degree of specialization varies a lot as well. A high level of specialization is evident in air charter operations and attraction providers (photographic safaris, adventures and cultural attractions) where the players in these sectors perform mainly one activity. Other players, businesses, particularly the ground operators, engage in more than one business. Some, in addition to their tour operation activity, run accommodation properties and provide local transport, and others co-ordinate both photographic safaris and mountaineering adventures. It is also observed that operators of hunting safaris are planning to diversify into photographic safaris, while some hoteliers plan to get involved in tour operations in the areas of photographic safaris and mountaineering adventures.

A partner who brings clients to another partner is found to be more powerful. In the northern tourist circuit, ground operators (photographic, mountaineering and hunting) are the most powerful players. By being powerful they get good deals from different properties. This in turn discourages overseas agents from booking for some properties direct, as they are often charged higher rates than those charged to ground operators.

The next chapter builds on the discussion from this chapter by highlighting the operational aspects related to distribution channels. It specifically looks at how channel partners are chosen, operational characteristics of channels, application of information technology and how the channels of distribution are evaluated; the chapter also looks at the booking behaviour of visitors. 


\section{Chapter Six: Operational Aspects of Distribution Channels}

\subsection{Introduction}

The distribution mix has been highlighted in the previous chapter. This chapter focuses on operational issues relating to distribution channels in the northern tourist circuit of Tanzania, specifically, how channel members are chosen. As we saw in Chapter Five, different businesses deal with many other businesses in the distribution channels, but how are all the channel members involved actually chosen, and what are the roles of each channel member? What operational characteristics are involved in maintaining all of the channels? What are the challenges faced by members in a channel? How are packages designed, and by whom? Which channels perform better than others, and what criteria are used to evaluate them? This chapter attempts to unravel, and to find answers to, these operational questions. General visitors' booking behaviour and the application of information technology are also canvassed.

This chapter, then, highlights in particular the operational aspects of existing distribution channels. It builds on the distribution structures described in the previous chapter, bringing out the internal features within the channels. As a whole, this thesis is expected to make the distribution channels in the northern tourist circuit clearer by presenting both the external structures and the internal features of distribution channels in this region.

The majority of studies in tourism distribution channels focus on the structures of distribution channels and ignore the operational characteristics in the channel used. The operational characteristics of distribution channel are the internal features that largely govern the everyday channels activities including the relationships among channel members. These are among the important things that managers would in the industry would want to know and compare 
their own channel operational routine with others in different activities or different destinations. These aspects are investigated in the northern tourist circuit as well.

\subsection{Roles of different channel members}

Dealing with a number of partners in distribution channels requires a clear understanding of the roles of each partner. This is particularly important when the partnership involves written contracts, demands for a high standard of service, and distant partners. It also requires some investigation in order to unveil the different roles. Different members in distribution channels play some common roles, and some are slightly different.

Overseas' agents play important marketing roles as they are located in the market-generating countries. This simplifies things for small businesses at the destination that are unable to do international marketing. These overseas' agents are also the booking points for holidays, making it easier for travellers, especially package tourists, to shop. Packaging of holiday tours is also done by these agents, who often consult ground tour operators.

Ground tour operators in Kenya play a key role coordinating and handling holiday packages in Kenyan destinations. They act as intermediaries, linking travellers with other intermediaries and suppliers in East African destinations; they also carry out 'passive' marketing for their partners in other destinations within the regional bloc. Similar to their counterparts in Kenya, ground tour operators in Tanzania are responsible for coordinating and handling tourism activities at the destination. They are, essentially, co-ordinators of the day-today operations of a package and responsible for bringing together core elements of travel packages such as local transport and accommodation, and arranging various tourism activities at the destination. Ground tour operators 
are also expected to monitor quality on behalf of their overseas partners; they do this by carefully selecting the properties that they distribute clients to like hotels, air charters and other local transport. Through brochures they produce, ground tour operators often feature attractions and thus play a marketing role, advertising different attractions in the destination, for example like national parks, culture and beaches. The role of ground tour operators in designing different tour packages is crucial to overseas agents, who often consult them given that they are considered to be the most knowledgeable stakeholders at the destination. Familiarisation visits by agents are commonly coordinated by ground tour operators, in collaboration with accommodation providers.

Accommodation providers - backpackers, hotels and wildlife lodges - are the providers of the hospitality service components of holidays. Some wildlife lodges design and offer short walks in the neighbouring environment and visits to local communities. These lodges help market destination attractions through their websites and host overseas agents during 'fam' visits, a role also played by hotels.

Providers of local transport, for example of rental vehicles and air charters, are actively involved in facilitating the movement of tourists from one attraction to another; this is particularly the case in national parks due to the very nature of safari holidays where the use of vehicles is inevitable.

National parks, conservation areas, and cultural attractions usually form the core components of different tourism products. Most of these components, especially national parks, are state- owned and often form an integral part of promotions and marketing strategies by the Tanzania Tourist Board. These attractions form the corner stone of the whole destination on which other players depend. 
Generally, all members in the distribution channels play crucial roles in the overall development of the tourism industry in the northern tourist circuit. If one these players fail to perform their roles, it may spoil the whole experience for a tourist.

\title{
6.3 Choice of channel members
}

A fundamental function of distribution is to access markets and sell products or services. As seen in the previous chapter, different businesses at the destination work together with a number of other businesses in a channel. Channel members are chosen according to different criteria. In this study the majority of local companies were observed to be flexible in choosing overseas partners. They ready to work with any overseas partner who shows interest:

\begin{abstract}
"We work with any overseas agent that expresses their interest to work with us. Why should we say no, while we depend on them? Most of our clients book their safaris through agents. If you have many agents you have a wide coverage, you should expect to get more clients as well", (Manager, Mauly Tours and Safaris).
\end{abstract}

This flexibility is partly because most local companies are small and cannot afford the cost of international marketing. As highlighted earlier, international marketing is done in various ways, and trade fairs are well set up for this purpose. Trade fairs are where overseas agents meet local tour operators and other suppliers:

"The place where you can meet many agents is at trade fairs that are the places where even them [overseas agents] come 
to hunt for operators, particularly those new agents. But they sometimes write you an email and ask if you could work together" (Manager, Chagga Tours).

However, many of the local tour operators are small businesses and cannot afford to attend these fairs, especially those in Europe and North America. They therefore use any opportunity available to them to access overseas agents. It should also be remembered that over $70 \%$ of all international sales in photographic safaris, and over $35 \%$ in hunting safaris are made indirectly. The bookings are made through overseas agents, so for a local business to obtain enough clients they must make every effort possible to ensure they have as many overseas partners as possible to work with. They are therefore not particular when it comes to who to work with from overseas:

"I work with more than 50 agents; I never choose who to work with; anyone who is ready, we work together" (Managing Director, Imagine Tanzania Tours)

\footnotetext{
"As I mentioned earlier, the majority of our clients (tourists) book their holidays through overseas agents. About $80 \%$ of our business, and probably for the majority of other [local] operators, we get from agents; so how can I say no to agents who want to work with me? You also have to know, the more agents you have the wider your distribution coverage” (Manager, Akaro Tours).
}

However, a few of the companies with sufficient resources, and who attend most of these trade fairs, are very fussy in choosing their partners. This is expressed by the Tourism Manager of Ranger Safaris: 
"We don't deal with just any agents, we are very keen when it comes to choosing and deciding who to work with, we don't want to have a long list of unproductive agents, it's better to have a few [agents] who produce well".

Companies such as this one have freedom of choice; they can meet many agents when attending overseas trade fairs and promotions. However, sometimes even these large companies tend to take all available opportunities to extend their distribution coverage:

"We look for well known agents, but sometimes we take chances, sometimes we take companies that find us" (Managing Director, Hoopoe Adventure).

Other companies choose overseas partners by considering the level of product knowledge the company has about Tanzania:

"[We] would prefer to deal with a company that had been in Tanzania, they at least have a rough knowledge of how the product looks, rather than dealing with complete productblind agents. We generally prefer those with at least some rough knowledge about tourism in Tanzania" (Managing Director, Evans Tours).

Smooth payment is among factors considered by other businesses; the company that pays promptly is preferred: 
"We normally go for agents that do quick money transfer, and we insist this should be clearly stated in the contract. Some agents take months to send money, we don't like such agents, we never work with them, they are hassles to us" (Marketing Assistant, Crown Eagle Tours).

The above observations are found to apply when local operators are looking for partnerships with overseas agents and mainly when looking for those partners who bring business to the company. When it comes to local business, for example the ground tour operator who coordinates and distributes clients to other businesses, different criteria are used to choose potential channel partners:

"I normally look for hotels and lodges with standard
services not just a hotel. It is very important to book a hotel
with good services or clients will complain. I rarely go for
friends' businesses" (Managing Director, King of
Kilimanjaro Tours).

Air charters, hotels and lodges are not particular about who they work with. Their main interest is to obtain clients; whoever comes is welcomed:

"We provide accommodation services to everybody, but we have different rates for different clients. For example we have rates for individual clients, for corporate workers, and tour operators' rates” (Marketing Manager, East African Hotel).

A similar observation was made for air charters: 
"Most of our clients are tour operators, but we work with any clients; we don't have any particular segment that we are targeting; we provide services to everybody who needs them, even you” (Accountant, Regional Air).

In general, the main factors considered by other businesses are the quality of the services offered, the commission rates, and the general cost of services. These factors are usually considered, even by overseas agents hunting for ground tour operators to work with:

"Some of the agents come here to look for partners to work with; some may email you, introduce themselves and ask whether we work together. Experienced agents know most of the businesses and they are well known. It is easy for them to get partners as you know many businesses want to work with them, they have well-established names in the market and so most tourists book their holidays with them. These agents are hard to win and they apply strict criteria when looking for partners. They demand high quality services and professionalism” (Manager, Sunny Adventure).

A similar view was also expressed in different terms by the Marketing Manager of Ahsante Tours:

"Normally agents hunt us, it is not us who choose which agents to work with. The major criteria they use in choosing ground tour operators is whether you are a responsible tour operator. Responsible tour operator means you care for 
your employees in terms of their rights, if not they won't work with you. They also look on the quality of services that you offer and quality of facilities for climbing the mountain".

Some businesses have marketing offices in Europe and North America which do all the marketing activities and make bookings. Confirmed bookings are sent down to the ground tour operators in Tanzania for handling and coordinating different aspects of the itineraries:

"We have a permanent marketing office in the United States which is also the headquarters of our company. All bookings are channelled there, and once confirmed are passed down to us. We never do booking from here; we forward all the enquiries to the head office in the United States. All the payments for different properties like hotels and lodges are paid direct by the office in US. We never make any decision who to work with from this office, pretty much everything is decided from the head office. They often seek some recommendations from us for different properties. So your question about how do we choose partners would probably be correctly answered by our office in the US, what I only know is that they normally ask us for recommendations almost every year and some of the hotels and lodges that we do recommend are the ones we are working with today, so this tells us they do consider our suggestions too in deciding who to work with" (Operations Coordinator, Tusker Trails).

"Our marketing office in London handles everything relating to marketing and booking. The main office is here, but the marketing and bookings are done through the 
London office; it is a year round office. I'm sure there are a number of other agents who they work with, how they choose those partners, I don't know much" (Tourism Manager, Ranger Safaris).

When Kenyan operators are looking for partners in Tanzania, they are very flexible and normally they do not have strict conditions about who to partner with. They prefer to work with companies that have been established for a while, and are sometimes looking for friends' companies or recommendations from other partners and friends:

\footnotetext{
"Operators from Kenya, are easy and flexible but it is sometimes hard to win them as there is too much personal relationships involved in their deals" (Manager, Tin Tin Tours).
}

The initiative to find a partner (who starts) does not have a particular pattern; it depends on whose needs are. A company which needs partners will always start the search. The search process involves asking friends, looking for websites, attending trade fairs, and contacting relevant tourism boards in the country partners are sought.

\subsection{Operational characteristics of channels}

In daily operations involving the distribution of products and services, slightly different approaches are used by different businesses. When an individual client wants to shop directly, they are required to send an enquiry to ground tour operators: 
"An enquiry has to be made, then a quote will be sent back, negotiation and bargains may happen in between before the sale is confirmed. Before it gets confirmed, the bargains may take up to a week [with this] all happening through emails", (Marketing Manager, Ahsante Tours).

The enquiry describes what services are sought, the time available for the holiday; other client interests are included, or the enquiry may match one the package tours offered. A quote is then sent back to the enquirer as a response from the tour operator. It normally contains the "included and excluded" list of services and activities on the trip. If the client is satisfied with the quote, the booking is made, and a deposit (often $20-40 \%$ of the total price) is paid 'up front' to confirm. Payments are made via bank transfers. Once the deposit is received, other arrangements, such as bookings for accommodation and local transport as indicated on the itinerary, are organised and put together by the tour operator. The balance is normally paid once the tourist arrives at the destination:

\begin{abstract}
"We normally want tourist to send $25 \%$ of the total cost of a safari to confirm their booking which is just a small amount, and there are cancellation conditions that apply, in case a client wish to cancel their holidays. Normally the rest of the amount is paid once they get here, and it has to be done before any activity commence" (Manager, Victoria Expedition).
\end{abstract}

Some companies, however, demand final payment a certain period before arrival of a tourist: 
"Our payment policy is that 20\% non-refundable deposit has to be paid at the time of reservation. Final payment is due 60 days prior to arrival. This enables us to book other properties well in advance" (Operations Assistant, Zara Tours).

If bookings have been made through an overseas agent, the itinerary is passed to the partner ground tour operator. Depending on the agreements between the ground tour operator and the agent, an agreement may require a certain percentage of the total price to be sent as a deposit for booking other facilities, while the remaining amount might be sent later. In some companies, no deposits are sent until the tourist finishes their holiday; in other companies the total cost of the holiday is sent 'up front'. Different methods of payment are mainly based on the kinds of agreements between partners. A business might have several different methods of payment with the different agents and partners it works with:

"As I said earlier, we are working with lots of agents from different parts of the world. We have different contracts with all these agents. Some pay 50\% deposit, while others pay us on a monthly basis based on the number of clients they gave us on that month. But there are a few agents who pay after the holiday, we don't prefer this kind of policy but sometimes we have to accept it as you may find the agent is a good producer so you can't afford to let them go, you will lose large volume of clients. For new agents we normally want them to follow our policies, you know they are new in the market and they have no big names so their production is not that good. So there are a lot of different arrangements with agents. Some follow our policies and we also follow some of the agents' policies. All we want is business and to get paid" (Manager, Victoria Expedition). 
When a holiday that involves two destinations, Kenya and Tanzania, is sold through overseas agents, the agent may pay direct to the individual businesses involved, or may allow payment to be handled by one partner business in each country. When a client who books their holiday with Kenya-based operators also wants to visit Tanzania, the Kenyan operator may decide either to pay for individual properties or leave this to their partner in Tanzania to do.

"When you form a part of package that involves Kenya and Tanzania attractions, the agent may pay each of you directly or may leave it to you to organize all arrangements in Tanzania for him. It really depends on the agent” (Managing Director, Hoopoe Adventure).

For independent travellers, particularly budget travellers, everything about a safari is discussed at the ground office when the tourist first approaches the company. The tourist describes what they want to do, or which parks they want to visit; the quote is prepared for them and, if they agree, all payments are made at the office. Payments are made either in cash or by credit card.

Unlike the majority of tour operators (photographic and mountaineering), hunting companies demand $100 \%$ of the total indicated on the quotes to be paid during a period ranging from one to three months before the arrival dates. Depending on who they contact, hunters can make their payments through overseas agents; professional hunters pay directly to the hunting companies. However the payment is made, the hunting company co-ordinates and handles all arrangements for the holiday but not for the professional hunters. As mentioned earlier, hunting companies also own boutique campsites in their hunting blocks. They are essentially operators and providers of both accommodation and local transport (mainly vehicles) in the hunting blocks. 
Some, however, such as Tanzania Game Tracker Safaris, a hunting company, has its own planes which operate as Northern Air.

"The majority of bookings are done during the annual tourist hunting conventions that we attend, they are just like trade fairs but they are specific to tourist hunting, they bring tourist hunting agencies and tourist hunting operators and clients for example Safari Club International, and Houston Safari Club in the USA, and the Vinatoria - Spain. This is the place you meet different marketing agencies. You visit and attend those shows and you market your products. Potential clients come to the conventions and book their safari; we are also associated with marketing agencies that do marketing all year round. A lot of our bookings come through our professional hunters, they have very large following, they are very important source of our clients, because clients like to return on safari with the same guide who they hunted with. Very often the client will contact the professional hunter in the off-season, and will ask professional hunter to arrange a safari for them so then the professional hunter deals with the company in booking and getting the itinerary together. Once we have decided on the itinerary, the client is quoted; $30 \%$ deposit has to be paid so as to confirm the booking and this can be done through a professional hunter account or it may be channelled down to us, as I mentioned earlier some professional hunters run marketing firms. The closer it gets to dates of the safari the client is required to top up their deposit and between 60-90 days prior to the dates of safari the clients are required to make full payment. This is simply because there are expenses that we incur: mobilization of camps, special requests, for example beverages that we need to import and obtaining all the necessary permits from the government in order to hunt, 
import the client's firearms and ammunitions" (Operations manager, Tanzania Game Tracker Safaris).

It is generally a good idea to book accommodation in advance so as to secure space: the demand for accommodation exceeds supply. Hotels, lodges and air charters have specific arrangements with partners they work within the channels. There are different arrangements with different partners. Some partners, mainly ground tour operators, prefer to block-book bed nights while others choose to purchase depending on availability of clients. Ways of payment vary also, depending on the agreements between partners. An interesting comment came from one of the hotels interviewed:

"I usually deal direct with the overseas agents, they are western people, they know how to do business; you can't compare them with the local operators which often frustrate you. To be honest I don't understand them [ground tour operators]" (Manager, Meru Tourist Inn).

Visiting a national park does not require one to book in advance, although early booking is encouraged. Entrance fees are paid through bank deposits or at the gate when entering the park. Usually tourists pay all the cost to the operators who then pay each property like accommodation and entrance fees in the parks.

\subsection{Arranging and designing packages}

Tour packages are often arranged by the ground tour operators. Most of these packages do not involve international flights. The organization process does involve other properties' managers, although not always: 
"We normally discuss with them, but in most times, we are the ones who take all the headache of arranging, sorting and coordinating the package; because we have well-established networks with other suppliers, it is a lot easier for us to arrange that than them" (Manager, Kilimanjaro Crown Birds Tours and Safaris).

Sometimes overseas agents design tour packages by themselves, especially those who have been in business for a long time. The main factors considered when designing tour packages are: the type of attractions included; the cost of different services and properties; and the location of different components in the package. The knowledge about what previous visitors were interested in, for example, the activities and national parks they liked, are also taken into consideration in the process of designing tour packages. Frequently, overseas agents seek advice about different packages from the ground tour operators:

"You know, when designing packages you need to have knowledge of different properties and their prices. You also have to know what tourists are interested to see and visit, they are the consumers we are targeting at; so you really have to know what they like and what they don't like. Even agents know this: before they design a package they will ask you to recommend; they also come roughly once a year to have knowledge of the destination" (Managing Director, Imagine Tanzania Tours).

"Frequently, agents rely on the local operators to produce a variety of travel options when consulted by possible consumers" (Managing Director, 
Imagine Tanzania Tours).

An operator who prefers group clients from agents had the following comment:

\author{
"When they bring us a group of clients, it is a less hassle to \\ co-ordinate and arrange their packages so you actually save \\ time of dealing with individual clients in that group" \\ (Operations Assistant, Zara Tours).
}

\begin{abstract}
After tourists finish their holiday, ground tour operators are required to write a short report to overseas agents about how the whole holiday went. These arrangements are not practiced by all overseas agents: as mentioned earlier, arrangements vary from partner to partner. Such a report gives a brief of all that happened at the destination, how the tourists behaved, the level of satisfaction, and any difficulties that arose.
\end{abstract}

\title{
6.6 Performance of channels and perceived issues
}

Distribution is increasingly being recognized as a critical source of competitive advantage in the marketing mix (Pearce and Taniguchi, 2007). Thus evaluation systems assessing channels' performance are very important; at least a few businesses in the northern tourist circuit of Tanzania practice it. In this region, channel performance is evaluated using mainly two criteria: the business volume the channel produces, and the profit margin made in each channel of distribution. As commented by different businesses during the interviews: 
"In terms of profit per client, direct channels perform better, but in terms of volume of business I would say indirect channels are better" (Marketing Manager, Ahsante Tours).

"When you get a client from somebody else, you pay them commissions; but if clients approach you direct you don't pay commission to any one, so direct sales generate more profit per tourist. The main problem is that you don't get many clients who book direct with you, so you will be dependent on indirect channels to get more clients. They are not as profitable as direct ones per client but the total profit you get from the whole volume of clients you served is much bigger than what you get from direct channels. So, I would say indirect channels produce larger total profit than direct ones, and I would definitely say they perform better" (Statistician, Serena Hotels).

"Direct clients are more profitable because we don't give any commissions to agents, but you have to know how to reach more direct clients; you have to spend more money on marketing; you have to market yourself to get that. Better to use agents, because they use all their resources to market so they reach more people and if is a good agent, they have a name, clients trust them. The main downside with agents sometimes is product knowledge; sometimes it's a little lacking” (Managing Director, Hoopoe Adventure).

In order to address this: 
"We bring them over; cover the ground costs for them, so that they have product knowledge" (Tourism Manager, Ranger Safaris).

Normally the costs for 'fam' visits of overseas agents are divided in such a way that the agent covers the international flights themselves; ground tour operators offer local transport; and the lodges and hotels provide accommodation. Such 'fam' visits are commonly done once a year. They are done to familiarise the agents with the products offered, and they are expected to enhance their knowledge about the destination.

Some companies consider getting the business's name to the market:

“... by dealing direct with client we get our name up, it gets its way to the market and in most cases, things are booked well in advance, except for those few who come to your door; this allows us to get prepared ahead, before clients arrive. Secondly, dealing with them direct, you cut out the middlemen, so your commissions that you would otherwise give out, are kept for the company and thus your net return is higher in comparison with when sourcing from middlemen" (Managing Director, Mem Tours).

Among major issues of concern, and one coming especially from the ground tour operators, is the issue of profit distribution with partners in a channel. Overseas agents are complained about for using their powers to bully small operators at the destination. Overseas agents get a large share of the profit for each sale. They pose some oppressive conditions in contracts which limit the growth of local operators. For example, ground tour operators are in most cases not allowed to ask clients how much they actually paid for their 
holidays. Some agents also force the ground tour operators to remove their company [the ground tour operators'] stickers from their vehicles and replace them with the agent's sticker when handling clients from that agent:

"Working with some agents is very frustrating. You don't know how much the agent charges the client and they don't want you to ask the client how much they paid. They charge the client higher prices but what they give you is just a peanut. Worse, some market themselves in Europe that they have branch companies on the ground. You know what they do, they will tell you to take out stickers of your company and put theirs so that when clients get here they see a sticker of the agent they booked with, so they believe that is a branch company but it is in fact not. We handle everything about clients but a good word that is being spread by clients is not about our business, it is the agent's name because clients didn't know that the company which handled them at the destination is different. So our effort to get our business name known in the market is all troubled. Agents brand themselves using our business and you sometimes can't say no as you depend on them to get business" (Managing Director, King of Kilimanjaro Tours).

In this situation, the agents usually brand themselves using ground tour operators by telling visitors those (ground tour operators) are their branch companies that operate on the ground. This is done to fool visitors into thinking that the ground tour operator company is actually a branch company of the agent they booked their holiday with. Ground tour operators are also required not to mix clients who booked their holidays through agents with those clients who booked directly with the operators, as they have paid very different rates. This is so that the ground tour operator does not get to know how much tourist paid. It is the case that there is an enormous difference 
between the price paid by clients who book their holidays directly and those who book through agents. Sometimes agents charge clients up to five times the normal price but ground tour operators end up getting less than $30 \%$ of that:

"A few years ago, we were working with a certain agent in Europe. He charged five clients a total of $€ 12,000$ for a fiveday safari tour; he gave us only $€ 3,500$. But the clients were very unsatisfied with the services we provided to them and they were complaining saying 'we paid $€ 12,000$, this is not service that is worth our money'. That is where we realised how much they paid. You know we have to provide service depending on how much we are paid for that. We just decided to terminate the contract as it was spoiling our business name” (Marketing Manager, Classic Tours).

Separating direct clients and indirect ones, especially those who climb mountains, is observed to be a challenge for operators to manage. Climbing tourists actually speak to each other and they may ask each other about the amount of money they paid. This result in visitors being unsatisfied with the level of service received when compared to the price they paid to the agents. Their dis-satisfaction is sometimes exacerbated when they realise other visitors have paid far less than them, but that they are all getting the same level of service. Ground tour operators have to be extra careful in managing that:

“They don't want us to mix independent and package tourists, but this is a bit challenging because we sometimes get independent travellers who are looking for groups to join so that they can reduce cost. So you have to form a group for independent travellers which sometimes may take a bit longer to get the full group. The more time it takes to get a 
full group, the more likely you are to lose the client as they may be taken by other companies, something which no one would like to happen. You have to ask other partner companies if they have group-waiting clients so that they can pass them to you and form the whole group; you pay commission to them if they give you clients" (Manager, Mauly Tours and Safaris).

Dealing with independent visitors also poses challenges. These visitors shop around while at their origin. They are said to be hard to win as they do window shopping at a number of companies, hence gaining a relatively high level of market knowledge; they know who offers what, and at what price. It is a competition with unknown competitors:

"We like to get more and more independent travellers, but it is very hard to win them, they shop around, they send e-mail to more than ten different companies, you find yourself competing with companies and you don't know what are their strengths and weaknesses" (Managing Director, Hoopoe Adventure).

Early response to enquiries has been observed to be an important technique in winning these clients. Time differences (12 hours) with North America and the Pacific require the company to have a person available 24 hours a day to respond to enquiries received from potential clients. 


\subsection{General visitors' booking behaviour}

Based on the perceptions of different players at the destination (suppliers and intermediaries), booking behaviours for international visitors have been observed to be changing over the last four decades. In the early 1970s, significant numbers of visitors were booking their safaris direct with the ground tour operators, although at that time it was taking longer time to communicate and the associated costs were relatively high. Unfortunately, most ground tour operators during those years were unreliable; some did not even exist. Back then, some people who booked their holidays direct never got to meet ground tour operators at the airports as agreed in the communications and itineraries, as the ground tour operators were fake:

"The problem is that, in those years there were many fake companies, they were taking the monies and then you didn't hear from them anymore. I would say that is probably among the reasons why we see most of our clients book their holidays through overseas agents" (Manager, Mauly Tours and Safaris).

As a result, in the 1980s through to the 1990s, the majority of people from international markets started booking their safaris with overseas agents. This has continued to be the case: $70-90 \%$ of international bookings are now made through overseas agents. Peace of mind and the guarantee of a refund in case anything goes wrong at the destination are among the reasons why most international visitors book their holidays through overseas agents, although it is far more expensive compared to direct booking. 
International independent travellers and domestic travellers have been observed to purchase their holidays directly from suppliers of individual components of holidays or through ground tour operators, and the number of international travellers who shop direct with suppliers or intermediaries located in the destination is increasing.

\subsection{Application of information technology}

Advances in communication technology have had little effect on distribution in the northern tourist circuit when compared to other parts of the world. Over 99\% of all interviewed businesses have websites for on-line marketing. Information found on the website is fairly similar across sectors in the industry. The basic information found on the websites can include: background about the business; services offered, which includes tour packages, where the company is located, attractions found in Tanzania, and some tips for tourists about the destination accompanied with pictures. Some websites show rates for different services and have links with other channel partners. Only a few websites are translated into different languages, the majority are available only in English.

None of the websites of all the businesses interviewed have a section where purchases may be made online; rather, they are mainly for enquiries and email communication. Communication with overseas agents is mostly done by e-mail, and occasionally by 'phone:

"If it's so urgent, they may ring you up and say hey have got one hour left give me an answer on the phone if you can" (Manager, Evans Tours). 
Most businesses which are well established have noted an increase in the number of enquiries through websites from possible future clients; direct booking is increasing as well. As observed by the marketing manager of Chagga Tours:

"Since we developed our own website, we have been receiving a lot of enquiries from people who might be our clients in the future. The number of people who book direct is also increasing but not much. We hope in future we will be receiving many direct bookings through our website."

\subsection{Conclusion}

In the northern tourist circuit, stakeholders work with each other in business partnerships. The partnership networks include overseas agents in Europe and North America. Different factors are taken into consideration when choosing partners in a channel. While most local ground tour operators are flexible in choosing who to work with in terms of overseas agents, their overseas partners are less flexible. Sectors such as local transport, accommodation and attraction providers work with every stakeholder and have no conditions as to who they will partner.

For package tours, bookings generally need to be made well in advance through overseas agents or directly with a ground tour operator. Visiting a national park does not require a booking unless the visit involves camping in the park. For other attractions and activities, entrance fees are paid at the gate; they do not require one to book ahead. Although bookings are not necessary for attractions and activities, visitors are encouraged to book in advance. 
Tour packages are often designed by ground tour operators or sometimes by overseas agents, who frequently seek advice from the ground tour operators. The reason is ground tour operators are at the destination and thus are expected to have better product knowledge; also, with their established networks with suppliers, they are able to obtain better product rates. Different factors are taken into consideration when designing packages: accommodation, activities and attractions, and local transport are the main factors considered. Packages designed by ground tour operators do not include international flights; they are made up of ground components.

Profit generated from a channel and the volume of business the channel produces are the main factors used to evaluate channel performance. Direct channels produce more profit per client while indirect channels, although producing less profit, produce a large volume of clients. However, the total profit gained from all indirect channels exceeds that from direct channels.

Most international visitors prefer to buy their safari holidays through overseas agents. Although this is relatively expensive, buying through overseas agents brings peace of mind to tourists; in case anything should go wrong at the destination, tourists have legal protection. The proportion of tourists who booked their safari holidays direct with ground tour operators in the 1970s was observed to have been decreased in following two decades. Fake ground tour operators are said to be among the main reasons for such observations.

Information technology, particularly the internet (website), is largely used as a marketing tool for creating awareness worldwide, and for communication purposes. Advances in information technology for on-line payments have not yet reached the northern tourist circuit. 
The next chapter provides detailed discussion of the study's general findings. In particular, the findings are linked to the general literature on tourism distribution channels. Implications of the findings for different businesses are discussed. General conclusions and recommendations are presented; and avenues for future research are proposed. 


\section{Chapter Seven: Conclusions and recommendations}

\subsection{Introduction}

This thesis has investigated tourism distribution channels in the northern tourist circuit, the existing structures, factors influencing those distribution structures and the operational characteristics of channels of distribution. As we have seen, the main purpose of distribution channels is to link suppliers and consumers. But also in this era of increasing competition among businesses it has been observed that it is too difficult for a business to maintain its competitive advantage just by relying on price, product and promotion. So distribution strategies are increasingly being recognised as a critical component in the marketing mix (Smith, 2007; Pearce and Taniguchi, 2007) not only for businesses but also for countries like Tanzania which seek to develop their tourism sectors.

As seen in Chapter Two, Tanzania is a developing country and also a peripheral destination with reference to the major tourism markets it depends on. However, the northern tourist circuit, within the country and the overall East African region, is a core rather than a peripheral destination. As seen in Chapter Four, the circuit is considered to be the heart of Tanzania's tourism sector. It receives the majority of tourists who visit the country. The northern tourist circuit is basically a core destination within a peripheral country.

This chapter presents the conclusions of this study. It brings together all the findings and links them to the existing literature on tourism distribution channels. As this is a destination based study, the findings are therefore from the suppliers' perspective. The chapter also discusses the implications of this study for both business managers and for the government as well. The recommendations are intended to provide some ways in which businesses can improve their marketing strategies. This is of critical importance considering that Tanzania is putting together its effort to develop its tourism industry. Finally, avenues for future research are offered at the end. 


\subsection{The structures of tourism distribution channels in the northern tourist circuit}

The structures of the distribution channels used by different sectors vary depending on the size of the business, nature of the activity, needs and requirements of travellers from different market segments (Sharda and Pearce, 2006). Photographic safaris and mountain adventures are mostly sold to international clients through overseas agents and ground tour operators in Kenya; they play a crucial role as channel partners (Figures 5.1 and 5.6). Hunting safaris are distributed in roughly equal proportions between direct channels, through marketing agents and professional hunters (Figure 5.8). Professional hunters in hunting safaris are well recognised for their crucial role in the distribution processes. The distribution of accommodation varies depending on the status of the property, location, and the market segment targeted. The majority of hotels are located in towns serving different clients: tourists, conference attendees, business people, and corporate and government workers. Hotel rooms are distributed directly and indirectly through ground tour operators, conference organizers, government and corporate organizations (Figure 5.12). Wildlife lodges are clearly targeting tourists who visit national parks. Bed nights in these establishments are largely distributed through ground tour operators. Backpacker hostels target budget and independent travellers. Dorms in these hostels are mainly distributed directly to the consumers. Like lodges, air charters largely depend on ground tour operators for the majority of their clients. Attraction providers like national parks receive most of their visitors through ground tour operators. While the latter have connections with all other suppliers at the destination, some suppliers have very limited connections with other suppliers. However, all businesses observed use a combination of direct and indirect distribution strategies for their international and domestic markets. The use of multiple channels is common across sectors. 
Figure 7.1 is a simplified diagram that summarises the relationships among the main members of the channels. The continuous arrows show the relationship between two members and the arrow direction indicates where the tourists are distributed or supplied to.

\section{Figure 7.1: Simplified diagram showing relationships among major members of channels}

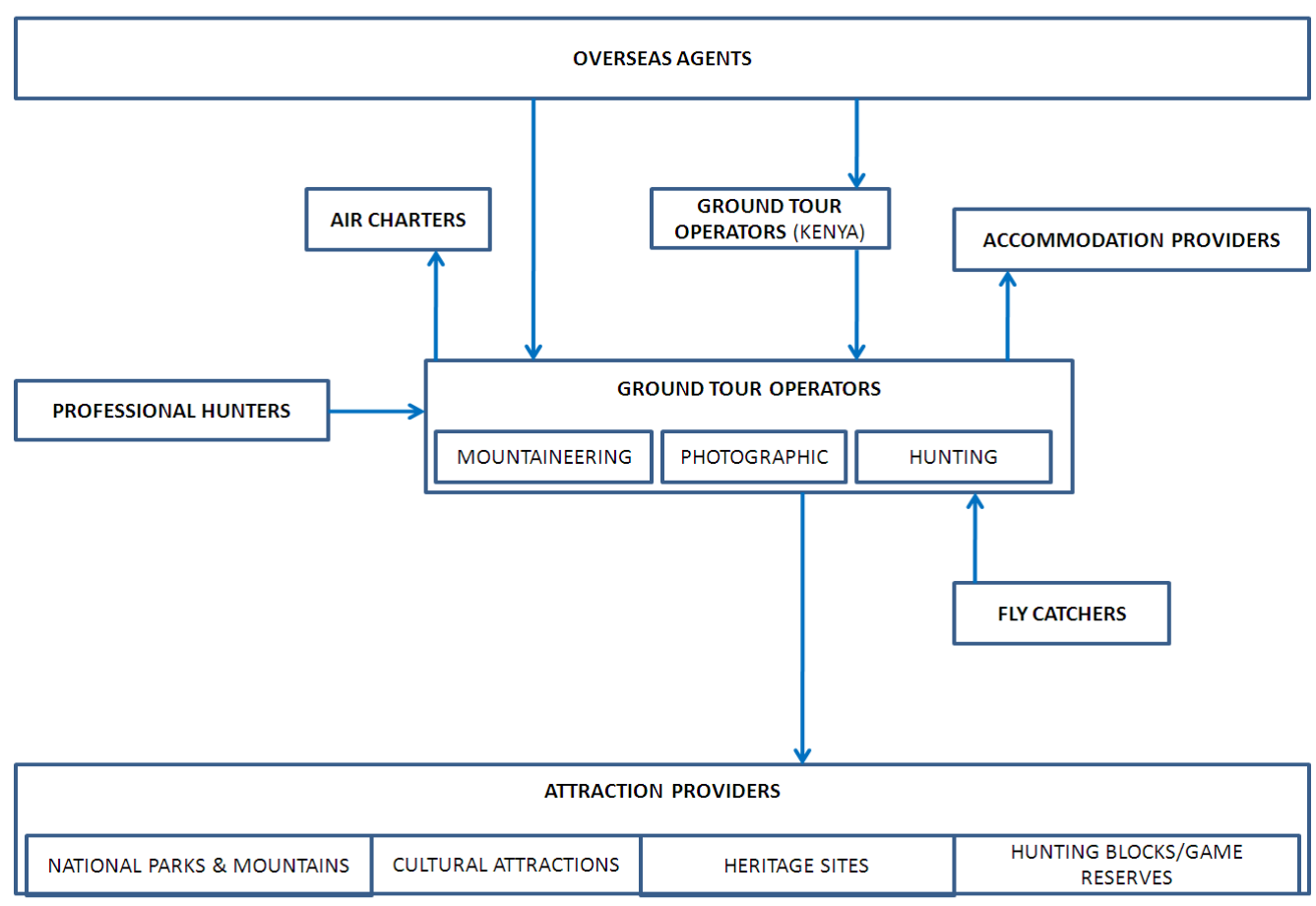

As seen in Chapters Five and Six, ground tour operators are the most linked members with other channel members due to their main role of bundling packages and coordinating safaris. Ground tour operators commonly referred to as inbound operators (Buhalis, 2000; Pearce, 2007), are unfortunately observed to be the least studied channel members in tourism distribution studies (Buhalis, 2001; Tan, 2002). Their importance increases with the increase in distance between the markets and the destination. As they are considered to be knowledgeable enough about different aspects at the destination like local customs and cultures (Wynne et al., 2001), ground tour operators are therefore seen as the convenient access points in the tourism 
industry in a foreign country (Pearce, Morrison and Rutledge, 1998). For this case, Tanzania depends largely on distant European and North America markets. So having ground operators makes it easier not only for overseas agents but also for independent travellers who sort parts of their travel arrangements and need assistance in organizing other parts. Ground operators in the northern tourist circuit are particularly important in putting together individual components for safari products, thus making them readily available for consumption. Sharda (2005) and Sharda and Pearce (2006) observe that the factor of long distance between markets and the destination makes distribution systems more complex and thus the demand for intermediaries is unavoidable in many cases. Ground operators are often responsible for negotiating, contracting and reserving tourism products with the suppliers at the destination on behalf of the overseas agents (Tan, 2002; Morrison, 1992). Consumers are not only package tourists but also independent tourists; they find it easier to consume products if the components are bundled. This role of ground operators has enabled them to build strong relationships with other key players (Smith, 2007) and hence expose them to more opportunities.

\subsection{Factors influencing channel structures}

Factors influencing channel structures in the northern tourist circuit are mainly similar to other peripheral destinations (Stuart, Pearce, and Weaver, 2005) and developing countries. Being located far from markets forces the majority of businesses in the destination to use other intermediaries within the country or overseas agents as booking points. This makes it easier for these small and medium sized enterprises which lack enough capital to get their services and products to the market they target. Lack of marketing knowledge is another factor that hinders the majority of the businesses in the northern tourist circuit to distribute their products directly to the consumers. Most businesses in this circuit, with the exception of attraction providers like national parks, are family owned and run. Just a few of the people in these businesses acquired formal businesses knowledge from schools, the majority are self-taught, acquiring that knowledge from friends, family members or through practice. 
Another factor that influences the structure of the distribution channels in the northern tourist circuit is the well developed Jomo Kenyatta International Airport in Nairobi which has many direct flight connections with Europe and North America. This makes the ground operators in Kenya important channel members as a significant number of clients come to Tanzania through there or after visiting Kenyan destinations.

As seen in previous distribution studies (Cooper et al, 1993), intermediaries and suppliers work together in ways that make sure the consumer is satisfied with the services and products they receive in exchange for money. Considering that a business cannot handle all the functions of distribution channels alone, this underscores the importance of developing businesses relationships (Rosenbloom, Larsen and Smith, 2004) with other channel members and hence increase interdependence among channel members and therefore indirect distribution becomes more common.

"These relationships take on a particular significance in the tourism sector where many tourism products involve the bundling together and sale of a variety of different components from a range of suppliers using the services of one or more intermediaries (e.g., tour wholesalers, inbound operators and travel agents)" (Pearce, 2007, p.58).

Tourism activities like cultural tourism in the northern tourist circuit are dependent on 'at destination' distribution strategies. This is largely due to the nature of the activity and its appeal in comparison with wildlife resources in which cultural attractions are less strong in attracting visitors. The majority of tourists to the northern tourist circuit are primarily attracted by the wildlife resources; cultural attractions are perceived as just add-ons. This, therefore, makes providers of cultural attractions reliant on 'at destination' distribution.

The nature of the activity has also been observed to influence the structure of distribution channels in hunting safaris. Hunting safaris are very unique products that attract rich tourists. The hunting tourists access the destination 
roughly in equal proportions through direct channels, professional hunters and through overseas marketing agents. In these safaris, professional hunters have a high influence due to the camaraderie relationships that they develop with tourists on their hunting safaris.

Generally, distribution costs are observed in other studies to be on the increase (Green, 2005; Middleton and Clarke, 2001; Dev and Olsen, 2000). This is one of the factors that hinders small businesses in peripheral destinations and developing countries like those observed in the northern tourist circuit from accessing international markets directly due to the high costs that the majority of the businesses cannot afford. Distribution can contribute up to a quarter of business operating costs (Pearce and Taniguchi, 2007). Use of internet distribution has so far shown success in cutting distribution costs in hotels and airlines (Choi and Kimes, 2002). Again, the challenge for the cost of promotion and staff still remains largely unsolved (Noone and Griffin, 1997; Morrison and Harrison, 1998; Green, 2005; Sanchez and Satir, 2005).

Visitors' preference is among the factors that influence the distribution structures. The majority of the visitors to the northern tourist circuit prefer to book their holidays through overseas agents and only a few shop directly. This then strengthens the use of indirect distribution channels.

\subsection{Operational aspects and measuring channel performance}

\subsubsection{Choice of channel members}

Criteria used to choose channel members in the northern tourist circuit do not vary much across the sectors. Two main patterns are observed in the northern tourist circuit. When a local business is looking for a channel member who it will be getting clients from, much flexibility is observed in reaching such a decision. For the majority of businesses there are no strict procedures on this. If the business distributes clients to other properties, the main criteria used to decide who to work with are quality of services and prices. Usually properties 
with high quality of services but low price are preferred. Other studies have found some other factors which are being considered in deciding who to work with: "price-value dimension, the financial security of the company, high levels of service, level of know-how and reliability" (Lumsdon and Swift, 1999), "partners having excellent resources" and "the potential for a mutually beneficial relationship" (Chen and Tseng, 2005) and "...those related to products (including market fit, market demand and product quality), to people (the attributes of the suppliers themselves) and to pricing" (Pearce, 2007).

\subsubsection{Designing of tour packages}

Tour packages are largely designed by ground tour operators. They involve consulting different properties that form the package or product. Overseas agents also sometimes design packages, but often by first consulting ground tour operators for recommendations. As mentioned earlier on, this is because ground tour operators have links with other suppliers at the destination and are considered to be the most knowledgeable about different aspects in the destination. They are the destination experts (Sharda, 2005). They also have expert knowledge about the customs and cultures of the destination (Wynne et al., 2001). They can negotiate, contracting and reserving tourism products with the suppliers at the destination on behalf of the overseas agents (Tan, 2002). They are therefore convenient points of access for tour arrangements in a foreign country (Pearce, Morrison and Rutledge, 1998).

\subsubsection{Evaluation of channel performance}

Evaluation of which channel performs better than others is a very complicated process that even in the broader literature on tourism distribution channels, with the exception of Pearce and Taniguchi (2007) and Yilmaz and Bititci (2006), has not been receiving much attention from researchers. In the northern tourist circuit, channel performance is plainly measured using two main criteria: profit generated from the channel and the number of visitors received from different channels. Based on those two criteria, direct channels 
are observed to perform better in terms of profit generation per visitor while collectively indirect channels produce larger volumes of clients than direct channels, with the exception of backpacker hostels and cultural sites which receive the majority of their clients directly. This observation partly supports the findings by Pearce and Taniguchi (2007) who measured channel performance in New Zealand suppliers using the criteria of net revenue, where direct channels were generally observed to perform better. However, Stuart, Pearce, and Weaver (2005) and Pearce and Tan (2006) question whether managers have a comprehensive picture of the performance of the different channels they use and are able to evaluate systematically their distribution mix is a different matter. It is important to develop a systematic measurement of channel performance and a better understanding of the factors that influence this, especially cost structures and revenues and how these vary from channel to channel and a more balanced approach including cost and revenue in places where use of multiple channels is common (Pearce and Taniguchi, 2007). However, Pearce and Taniguchi attest that measuring cost structures across multiple distribution channels presents many methodological challenges, and admit that "Certainly there are challenges involved in compiling and analysing the necessary data, but with care reliable and robust data can be generated" ( $p$. $11)$.

\subsection{Relationship between channel members and interdependence}

This study observes the high interdependency among channels members; specifically, the majority of members at the destination are heavily dependent on ground tour operators (photographic, hunting and mountaineering tour operators). As shown in Figure 7.1, overseas agents supply tourists to different ground tour operators and are more powerful (as perceived by the ground tour operators) in their relationships. As shown in the Figure 7.1, Kenyan ground tour operators pass on clients to the ground tour operators in Tanzania. The two groups of channels members are observed to be comfortable in their arrangements and therefore no issues were raised by the ground operators in Tanzania. However, there are some minor issues between ground operators in 
Tanzania and the overseas agents, where the former seem to be unhappy with some arrangements including profit margins between the two parties. Buhalis (2000) observed that consumers have a certain, often fixed, budget for their holidays and therefore channel members compete directly with their partners for a larger share.

Accommodation providers, particularly those located in and around national parks, depend on ground tour operators for the majority of their customers. Due to this, regardless of the high demand for accommodation in and around national parks, ground operators have continued to be more powerful than accommodation providers (Figure 7.1). This is an important area for further studies: to find out the reasons as to why accommodation providers are less powerful than ground tour operators.

Car rentals and ground operators have relationships in the way that the latter hire vehicles from the former when they run out of them. It seems that both sides are comfortable with the arrangements in which the rental rates are known and often the room for negotiation or bargaining is narrow. Rosenbloom (1999) recognised this (rental rates) as an important component in the relationships between members in a channel of distribution. One would expect that ground tour operators would be more powerful than attraction providers as they are the main suppliers of visitors to these sites, but it is not the case; they are both observed to be almost equal, although some attraction providers might have more power simply because they belong to the government. The entry fees are determined by government and therefore ground operators are less likely to have potential influence on such decisions.

So, generally, the complexity of distribution systems in the northern tourist circuit is largely contributing to the necessity of different suppliers and intermediaries to come together and interact with each other (Cooper and Lewis, 2001) so as to accomplish their business goals. Through such cooperation that is being coordinated by ground tour operators, among different members of the channels (Cooper et al, 1993), the task to bundle individual safari goods and services is made possible and therefore, as 
succinctly put by Hill, O'Sullivan and O'Sullivan (2003), facilitating organizations' offerings available to customers when and where required.

The interdependence of firms in the northern tourist circuit forms wider networks extending to Kenya. However, comparatively little of the work on tourism distributions explicitly recognizes such networks of interdependent firms that are part of larger distribution systems (Pearce, 2009).

\subsection{Implications for businesses}

From the findings of this study, it appears that the majority of the businesses interviewed did not have a written distribution strategy, but implement it subconsciously. This study is expected to make them aware of the importance of having an effective distribution strategy (Pearce and Taniguchi, 2007; Buhalis, 2000). This will allow business managers to design a clear strategic plan for distributing their product and services effectively.

The diversity of channels identified highlights the need for businesses to use a number of channels to access the different market segments they target. However, there is a need to understand and take into consideration that the majority of visitors are increasingly choosing and using multiple channels on the basis of what they see to be the easiest way of arranging their holidays (Pearce \& Schott, 2005). The observed multichannel systems used by various businesses involve a mix of direct and indirect channels which are not uncommon in tourism businesses (Ujma 2001; Daff 2006; Pavlides 2006; Pearce and Tan 2006). They are important in extending coverage, responding to the preferences of different market segments, reducing costs, and taking advantage of technological advances. Managers are also advised to critically evaluate the performance of different channels to find the costs and profit variations across channels used and to identify factors that cause any variation (Pearce and Taniguchi, 2007). 
The plans for many businesses, particularly hotels, lodges and ground tour operators, in the northern tourist circuit will have an impact on the current distribution systems. A significant number of managers of hotels and lodges have plans to diversify into ground tour operation activities. This implies that they will be handling a large component of the tourists themselves by bypassing the current ground tour operators. In addition some photographic and mountaineering ground tour operators have huge plans to establish their own hotels and lodges so that they can use those properties for their increasing numbers of tourists. Again this will have enormous impacts on the accommodation providers at large. Such plans to diversify do not end with those channel members. Hunting ground operators will also be engaging in photographic safaris as a strategy to siphon all the disposable income from their heavy spenders, hunting clients. This might be largely influenced by the fact that the majority of these businesses are unable to do overseas marketing through out the year and so decide to expand their services at the destination so as to tap as large a profit as possible from their clients rather than letting part of it go to other providers. It is difficult to predict what is going to happen but possibly the competition will intensify among channel members; there is the high possibility of providing poor services and conflicts (Buhalis, 2000) among members may emerge. A typical characteristic of an emerging destination in a developing country is that one would expect as the destination matures, the specialization of businesses would increase (Stuart, Pearce and Weaver, 2005); contrary to that, in the northern tourist circuit, as the destination matures businesses plan to diversify and hence reduce the specialization. In other words, there is a trend for more integration.

The ongoing marketing of East Africa as a single destination will also influence some changes in the current distribution systems, not only in the northern tourist circuit but in the whole region. This impact is made more serious with the coming free trade, labour movements between countries in the bloc and the issuance of a single tourist visa for the whole region (East African Community, 2010). It is likely that these policies will benefit ground tour operators in Kenya more due to the fact that Jomo Kenyatta International Airport in Nairobi (Kenya) is the most well developed international airport in 
the region and has many international direct flights. Morever, the fact that Kenya has a better established name in the markets means it will be favoured more than other countries. This will mean that Kenyan ground tour operators will be allowed to operate in the whole region and therefore those clients that were passed down to Tanzania's ground tour operators from Kenya will no longer be available for ground operators in Tanzania. For the ground tour operators in Tanzania to benefit from the scenario, they would have to open offices in Kenya and probably in other countries in the region. It is important at this stage that ground operators, particularly for mountaineering and photographic safaris, start thinking about forming strategic alliances and working together rather that diversifying individually, which will spread their effort and thus make them weaker instead of strengthening them. In this case collaboration will be important and probably necessary rather than working solitarily. Strengthening relationships will be a crucial strategy rather than weakening them. As Stuart, Pearce and Weaver (2005) observed that for the small and medium sized enterprises to gain power and to access big markets, linking together to form alliances is a more promising strategy.

\subsection{Implications for the government}

Indirect distribution systems to a great extent dominate the tourism industry in the northern tourist circuit. About $70 \%$ of all international visitors to the northern tourist circuit make their arrangements indirectly through overseas agents. From the interview responses, it appear that overseas agents are getting a large part of the "cake" leaving the ground operators with only the left overs. It appears that there is serious leakage in this industry. If this is not looked at properly it will have huge short and long term impacts. This might also limit the growth of local investors due to the small profits they get in the businesses. The long term impacts include holding back industry growth; resulting in the government losing income that would otherwise be saved for other development purposes. 
Promotion of East Africa as a single destination could make things worse. The majority of tourists will be flying direct to Kenya. It is likely that Kenyan ground operators will dominate the industry at the destination. The future of ground tour operators in Tanzania is in balance. Increased burden of unemployment might be one of the impacts anticipated.

\subsection{Overall conclusion}

Tanzania represents one of the developing countries in Sub-Saharan African that offers unique safari tourism. The country is blessed with vast wildlife resources which are the main attractions in the safari products. Although the country has relatively undeveloped infrastructure, nevertheless it has been attracting and receiving many international visitors (MNRT, 2009). The main safari products offered in the country are photographic and hunting safaris. Mount Kilimanjaro, being in Tanzania, adds another product that attracts many tourists as well. The country is rich in the diversity of culture and the pleasant beaches of Zanzibar. The northern tourist circuit is the heart of the country's tourism sector. World renowned attractions like Serengeti National Park and Ngorongoro Conservation Area are all part of this circuit.

Distribution of safari products in the northern tourist circuit is a mix of direct and indirect channels and variations in channel structures. In the northern tourist circuit, indirect channels are more common and produce large volumes of tourists as opposed to direct channels. The majority of the businesses in this circuit heavily rely on distributing their services through other channels members. For example, most of the lodge rooms are sold by ground tour operators and the majority of clients that come to ground tour operators are passed down to them by overseas agents. In the northern tourist circuit there is a high level of business dependency on each other. Due to being small and lacking access to capital, the majority of the ground operators form relationships with many overseas agents. Other factors for having many 
relationships with offshore intermediaries are the fact that the destination is located far from the markets it depends on. Forming many relationships is therefore a strategy to spread their presence in a wider market and hence, as observed by Stuart, Pearce and Weaver (2005) and Stuart (2004), increases the chance of getting more clients. Arrangements in relationships differ depending on the preferences of parties. Some of the relationships are formal and involve signed contracts between channel partners. Informal relationships and 'at destination' referrals are very common between businesses in the destination. Such relationships between and among intermediaries are of vital importance as Christopher (1992) attests. Intermediaries help to bridge gaps in time, space, quantity, variety and communications between supplier and consumer. Intermediaries in this circuit work together as part of a large distribution system; they are therefore crucial components and nodes in networks. Such relationships between intermediaries in the northern tourist circuit, are on the basis of commissions which vary depending on the agreements between parties, often ranging from $20 \%$ to $40 \%$.

Generally, in the channels, members who bring clients are more powerful than those who receive with the exception of attraction providers like national parks and game reserves to whom such power relations are not pronounced. As the main suppliers of clients to the destination, overseas agents are considered to be by far the most powerful of all channel members in the northern tourist circuit. Such powers are used to marginalise the small enterprises at the destination, thus to some extent creating a slight hostility among channel members towards these overseas agents (Britton, 1982; Frazier, 1983; Buhalis, 2000). Ground tour operators are dominant among channel members in the northern tourist circuit; they are linked to all other channel members (Figure 7.1) and they are the "destination experts" (Sharda, 2005).

Unlike in the Mediterranean destinations where there are intensive conflicts between hoteliers and tour operators (Buhalis, 2000), in the northern tourist circuit, the situation has not yet reached serious conflict between ground tour operators and hoteliers although hoteliers are slightly unhappy about being 
less powerful in comparison to ground tour operators. However, there are still opportunities for the accommodation providers, particularly those in and around national parks, to gain power in their channels due to the fact that there is higher demand for accommodation in these areas than the actual supply. The two market forces: demand and supply, if they are used strategically would really lift the lodges up on negotiations with other channels members. The challenge will remain that the ground tour operators can use economies of scale in their purchases and the strong connections they have established with overseas agents so as to maintain their power over accommodation providers. Normally the attempts by channel members to protect and advance their own interests and the power they exert over their partners is said to be one of the issues between channels members in the general literature on distribution channels (Buhalis, 2000).

Closer collaboration and the efficient utilisation of information technology would enable small and medium sized enterprises to expand their distribution mix and to enhance their position in the distribution channels (Buhalis, 2000; Stuart, 2004).

Use of information technology as a means of distribution seems to be in its infancy in the northern tourist circuit. All the businesses which participated in this study have websites. The websites are mainly used to create awareness among the general public if one is looking for related information like safaris. Receiving enquiries is another use of these websites. If used properly, the internet has potential not only to create awareness but also to generate online bookings and sales (Stuart, 2004). The internet can also be used to gain market intelligence, to determine what others are doing and offer services at what prices. Businesses in the northern tourist circuit have observed dramatic decrease in the communication costs between businesses within and outside the country; similar observations are made by Middleton (2001), Wynne et al (2001), Choi and Kimes (2002) and Dev and Olsen (2000). However, the question of whether tourists will be willing to buy their holidays to the northern tourist circuit online needs further studies that are visitor-focused it has to be understood that due to many variables involved and thus the 
complexity of distribution channels (Buhalis, 2001) generalization of distribution structures and functioning is not an easy task.

\subsection{Recommendations}

Recommendations based on the findings of this study are offered both to the businesses in the northern tourist circuit and the government. In order for the businesses to improve their practices and increase their competitive advantage.

Businesses are advised to unite and form a few larger companies rather than continue working alone. This will enable them to gain bargaining power and will expand the capital base and thus enabling them to market themselves overseas. Marketing costs will be highly reduced as instead of each business marketing itself, there will be a few big businesses with enough capital and budget for different operational activities. Briefly, uniting will improve brands, will reduce marketing costs, improve efficiency and reach potential markets at low costs.

Anticipated promotion of a single destination, East Africa, and issuance of a single tourist visa for the whole region needs to be looked at as well. As discussed above, this may heavily impact suppliers and operators in Tanzania as they will be bypassed. Kenyan operators might not pass down clients anymore. Opening marketing offices in Kenya is inevitable if the business intends to stay competitive in the industry. Again, if the current small and medium sized enterprises in the northern tourist circuit are united, they will be able to withstand any shock that may results.

Budget accommodations like backpacker hostels could be established near the national parks. This would make it easier for budget travellers who are unable 
to afford the high rates charged in the wildlife lodges. This might also extend their length of stays in the destination.

Businesses should keep records to the different channels they use for the purpose of evaluating and measuring channel performances since tourism distribution decisions are critical for tourism enterprises, as they influence their entire marketing mix (Buhalis, 2000). If this is taken into consideration it can make a huge difference in the firm's competitive advantage (Pearce and Taniguchi, 2007).

Suppliers of tourism services and products in the northern tourist circuit should start designing budget tour packages for domestic tourists as a promotion strategy to stimulate domestic demand.

The government is advised to improve Kilimanjaro International Airport so as to attract more international direct flights so reducing the dominance of Jomo Kenyatta International Airport in Kenya.

It is also suggested that government should help local suppliers to access international markets by opening marketing offices in major markets to provide information year round about the destination and all registered tourism businesses. These offices should be used as booking points for tourists who want to visit Tanzania and such offices could be situated in overseas embassies.

\subsection{Avenues for future research}

This study has attempted to fill some gaps identified in the general literature on tourism distribution channels. It focused on safari tourism in the context of Tanzania. With the exception of Wynne et al (2001), no other such studies had 
previously been done in the whole continent of Africa. However, it is beyond the scope of this study to fill all the gaps, instead, avenues for future research in this and related areas are offered.

Tourist-based surveys could be conducted to find out the actual reasons why tourists book their holidays through overseas agents. This will enhance understanding of the motive behind using overseas agents and, where possible, the issues to be addressed. Similar studies could be conducted in other tourist zones in the country like Zanzibar that offer different product so as to find out if there are any commonalities and differences and reasons for these.

Extension of this study in other African countries with similar or different tourism products in different settings would allow wider comparison, enable broader patterns to be identified, and permit more specific questions to be pursued. Such studies will reveal to what extent are the findings in the northern tourist circuit are applicable to other areas and how influential are the contextual factors as Buhalis (2000) argues that "There are endless variations of the tourism distribution channel, depending on each particular industry structure and external environment".

Detailed studies with larger samples could be carried out between different sectors, like hotels versus ground operators, to investigate in detail other aspects in their relationships.

Distribution studies in other sectors like agriculture, mining and manufacturing should be conducted to find out similarities and difference with those observed in tourism and any factors that influence these.

Surveys could be conducted to find out the proportion of tourists who come to Tanzania through Kenya and the associated reasons for doing so. This is particularly important for businesses and the Tanzania government.

Further evaluation of channel performance needs more detailed studies and more systematic approaches. However, such studies may need processes of 
collecting relevant information by businesses to be established; this has been too complicated.

A more general study could also be conducted to investigate why there is a very small fluctuation in international arrivals between seasons but the impact is strongly felt by the businesses especially during the low seasons. Studies to find out the purpose of visitations by international visitors would help to reveal any reason for such observation.

As noted in Chapter Two, tourism distribution is perceived differently between consumers, intermediaries and suppliers. This study investigated only suppliers; to get the full understanding of the distribution systems in their entirety it needs other channel members: overseas intermediaries and consumers be studied as well. This is just the initial study that lays the foundation for further studies in the context of African destinations to follow. 


\section{References}

Adejuwon, F. (1986). "Trends of tourist demand in Africa", Tourism Review, 41(1), pp. 20-24.

Akama, J. S. and Kieti, D.M. (2003). "Measuring tourist satisfaction with Kenya's wildlife safari: a case study of Tsavo West National Park", Tourism Management, 24(1), pp. 73-81.

Alcázar Martínez, B. del (2002). "Los Canales de Distribución en el Sector Turístico", Madrid: ESIC Editorial.

Ali-Knight, J., and Wild, S. (1999). "British Airways' inbound leisure market to Manchester, England: Is direct marketing the answer?" Journal of Vacation Marketing, 6(1), pp. 9-20.

Almagor, U. (1985). “A Tourist's 'Vision Quest' in an African Reserve”, Annals of Tourism Research 12(2), pp. 31-47.

Bank of Tanzania (2008). Annual Economic Report. Dar es Salaam: Tanzania.

Bastakis, C., Buhalis, D., and Butler, R. (2004). "The perception of small and medium sized tourism accommodation providers on the impacts of the tour operators' power in Eastern Mediterranean”, Tourism Management, 25(2), pp. 151-170.

Batra, G.S. (1997). "Strategic management of tourism in India in turbulent times: Contemporary issues in modern management", Kanishka Publishers.

Beedie, P. (2003a). "Adventure tourism". In Sport and Adventure Tourism, Hudson S (ed.). Haworth Hospitality Press. New York; pp. 203-239.

Beedie, P. (2003b). "Mountain guiding and adventure tourism: reflections on the choreography of the experience", Leisure Studies 22(2), pp. 147-167.

Bentley T, Page SJ, and Laird I. (2003). "Managing tourist safety: the experience of the adventure tourism industry". In Managing Tourist Health and Safety in the New Millennium, Wilks, J., and Page S. J. (eds). Elsevier Science: Oxford; pp. 85-97.

Bentley, T, Page, S, Meyer, D., Chalmers, D., and Laird, I. (2001a). "How safe is adventure tourism in New Zealand? An exploratory analysis" Applied Ergonomics, 32(4), pp. 327-338.

Bentley, T. A., and Page, S. J. (2001b). "Scoping the extent of adventure tourism accidents", Annals of Tourism Research 28(3), pp. 705-726. 
Bentley, T. A., Page, S. J., and Laird, I. S. (2001b). "Accidents in the New Zealand adventure tourism industry”, Safety Science 38(1), pp. 31-48.

Britton, S. G. (1982). "The political economy of tourism in the Third World", Annals of Tourism Research, 9(3), pp. 331-358.

Brown, F., and Hall, D. (2000). "The paradox of peripherality" in Brown, F. and Hall, D. (eds) Tourism in Peripheral Areas: Case Studies. Channel View: UK.

Buhalis, D. (1999). "Tourism on the Greek Islands: Issues of peripherality, competitiveness and development", International Journal of Tourism Research, 1(3), pp. 341-358.

Buhalis, D. (2000). "Relationships in distribution channels of tourism: Conflicts between hoteliers and tour operators in the Mediterranean region", International Journal of Hospitality and Tourism Administration, 1(1), pp. 113-139.

Buhalis, D. (2001). "Touirsm distribution channels: practices and processes" in Buhalis, D. And Laws, E. (eds) Tourism Distribution Channels: Practices, Issues and Transformations. Continuum: London.

Buhalis, D., and Licata, M. C.(2002). "The future of eTourism intermediaries", Tourism Management, 23(3), pp. 207-220.

Callander, M., and Page, J. S. (2003). "Managing risk in adventure tourism operations in New Zealand: a review of the legal case history and potential for litigation", Tourism Management, 24(1), pp.13-23.

Cateora, P. R. (1987). International marketing. Homewood,I L: Richard D. Irwin, Inc.

Cater, E. (2002). "Spread and backwash effects in ecotourism: implications for sustainable development", International Journal of Sustainable Development, 5(3), pp. $265-281$.

Cavusgil, S. T. (1997). "Measuring the potential of emerging markets: An indexing approach”, Business Horizons, 40(1), pp. 87-91.

Charnley, S. (2005). "From Nature Tourism to Ecotourism? The Case of the Ngorongoro Conservation Area, Tanzania", Human Organization, 64(1), pp. $75-88$.

Chen, H.-M., and Tseng, C.-H. (2005). „,The performance of marketing alliances between the tourism industry and credit card issuing banks in Taiwan", Tourism Management, 26(1), pp. 15-24. 
Choi, S., and S. E. Kimes (2002). 'Electronic Distribution Channels' Effect on Hotel Revenue Management", Cornell Hotel and Restaurant Administration Quarterly, June: pp. 23-31.

Christopher, M. (1992). The strategy of distribution management. ButterworthHeinemann, Oxford.

Cloke, P., and Perkins, H. C. (2002). "Commodification and adventure in New Zealand tourism", Current Issues in Tourism, 5(6), pp. 521-549.

Cloke, P., Perkins, H. C. (1998). "Cracking the canyon with the awesome foursome': representations of adventure tourisminNew Zealand" Environment and Planning D: Society and Space 16(2), pp. 185-218.

CNN (2009).

[http://edition.cnn.com/2009/WORLD/africa/04/12/somalia.pirates/] accessed on 12th January, 2010.

Cooper, C., and Lewis, J. (2001). "Transformations and trends in the tourism industry: implications for distribution channels" in Buhalis, D. and Laws, E. (eds) Tourism Distribution Channels: Practices, Issues and Transformations. Continuum: London.

Cooper, C., Fletcher, F., Gilbert, D., and Wanhill, S. (1993). Tourism Principles and Practice. London: Pitman.

Crotts, J. C., Aziz, A., and Raschid, A. (1998). "Antecedents of suppliers' commitment to wholesale buyers in the international travel trade" Tourism Management, 19(2), pp. 127-134.

Daily News Tanzania (2009). [http://www.dailynews.co.tz] Accessed on 20th January 2010 and 11th November 2009.

Derek, J., Wade, B. C., Mwasaga, Paul, F. J. and Eagles (2001). "A history and market analysis of tourism in Tanzania", Tourism Management, 22 (1), pp. 93-101.

Dev, C. S., and Olsen, M. (2000). "Marketing challenges for the next decade", Cornell Hotel and Restaurant Administration Quarterly, 44 (1), pp. 41-47.

Drucker, P. F. (1958). "Marketing and economic development", The Journal of Marketing, 22(3), pp. 252-259.

East African Community (2010). EAC Protocol on Tourism and Wildlife Management, Arusha: Tanzania.

Fluker, M. R., and Turner, L. W. (2000). "Needs, motivations, and expectations of a commercial whitewater rafting experience", Journal of Travel Research, 38(4), pp. 380-389. 
Forstner, K. (2004). "Community ventures and access to markets: The role of intermediaries in marketing rural tourism products", Development Policy Review, 22,(5), pp. 497-514.

Forsyth, P., and Smith, N. (1992). "Corporated organisation and distribution channels in Japan: the tourism industry case", in P. Sheard (ed). International Adjustment and the Japanese Firm. St Leonards: NSW.

Frazier Gary, Robert Spekman, and Charles O’Neil (1988). "Just-in-Time Exchange Relationships in Industrial Marketing" Journal of Marketing 52(3), pp. 52-67.

Frazier, G. (1983). "On the measurement of inter-firm power in channels of distribution", Journal of Marketing Research, 20 (May), pp. 156-166.

Frazier, G., and Summers, J. O. (1984). "Interfirm influence strategies and their application within distribution channels", Journal of Marketing, 48(Summer), pp.43-55.

Friel, M. (1999). "Marketing practice in small tourism and hospitality firms", International Journal of Tourism Research, 1(2), pp. 97-109.

Garcia-Falcon, J. M. and Medina-Munoz, D. (1999). "The relationships between hotel companies and travel agencies: An empirical assessment of the United States market", The Services Industries Journal, 19(4), pp. 102122.

Gartner, W. C., and Bachri, T. (1994). "Tour operators role in the tourism distribution system; An Indonesian Case Study", Journal of International Consumer Marketing, 6 (3-4), pp. 161-179.

Gee, W. C., Makens, J. C., and Choy, D. L. (1989). The Travel Industry. New York: Van Nostrand Reinhold.

Green, C. E. (2005). De-Mystifying Distribution: Building a Distribution Strategy One Channel at a Time. HSMAI Foundation.

Gyimóthy, S., and Mykletun, R. (2004). "Play in adventure tourism: The Case of Arctic Trekking", Annals of Tourism Research, 31(4), pp. 855-878.

Healey, M. J., and Rawlinson, M. B. (1993). "Interviewing business owners and managers: a review of methods and techniques", Geoforum, 24(3), pp. 339-355.

Hill, E., O’Sullivan, C. and O’Sullivan, T. (2003) Creative Arts Marketing. Oxford: Butterworth-Heinemann, p. 242.

Holloway, C. (1989). The Business of Tourism (3rd edn). Plymouth: Pitman. 
Hudson, S., Snaith, T., Miller, G. A., and Hudson, P. (2001). "Travel retailing: 'switch selling' in the UK" in Buhalis, D. and Laws, E. (eds) Tourism Distribution Channels: Practices, Issues and Transformations. Continuum: London.

Jamison, D. (2003). "Marketing at the frontier: Exploring the role of informal marketers in Africa", Journal of African Business, 4(3), pp. 5-24.

Kane, M. J., and Zink, R. (2004). „Package adventure tours: Markers in serious leisure careers" Leisure Studies, 23(4), 329-345.

Karamustafa, K. (2000). “Marketing-channel relationships: Turkey's resort purveyors' interactions with international tour operators", Cornell Hotel and Restaurant Association Quarterly, 41(4), 21-31.

Katsikeas, Constantine S., M. M. H. Goode and E. Katsikeas (2000) "Sources of Power in Kimes, S. E. and Lord, D. C. (1994). Wholesalers and Caribbean resort hotels. Cornell Hotel and Restaurant Association Quarterly, 35(5), $70-75$.

Knowles, T., and P. Grabowski (1999). "Strategic Marketing in the Tour Operator Sector." In The International Marketing of Travel and Tourism: A Strategic Approach, edited by F. Vellas and L. Bécherel. New York:St. Martin's.

Kotler, P., Bowen, J., \& Makens, J. (1996). Marketing for hospitality band tourism. New Jersey: Prentice Hall.

Kweka, J. and Ngowi, D. (2007). "The development dimensions of TFDI in Tanzania", report for the UNCTAD, Geneva.

Kweka, J., Morrisey, O., and Blake, A. (2003). "The economic potential of tourism in Tanzania", Journal of International Development, 15, pp. 335351.

Lumsdon, L. M. and Swift, J. W. (1999). "The role of tour operator in South America: Argentina, Chile, Paraguay and Uruguay", International Journal of Tourism Research,1(6), pp. 429-439.

Malhotra, N.K. (1986). "An approach to the measurement of consumer references using limited information", Journal of Marketing Research, 23(1), pp. 33-40.

March, R. (1996). “Organisational Linkages in Australia's Japanese Inbound Travel Market" In Prosser, G. (ed) Tourism and Hospitality Research: Australian and International Perspectives, Canberra: Bureau of Travel Research. 
March, R. (1997). "An explanatory study of buyer-supplier relationships in international tourism: The Case of Japanese Wholesalers and Australian Suppliers", In Marketing Issues in Pacific Area Tourism, pp. 55-68.

March, R. (2000). "Buyer decision-making behaviour in international tourism channels", International Journal of Hospitality and Tourism Administration, 1(1), pp. 11-25.

Medina-Muñoz, D.,\&García-Falcón, J. M. (2000). "Successful relationships between hotels and agencies" Annals of Tourism Research, 27(3), 737762.

Medina-Muñoz, R. D., Medina-Muñoz, D. R., and García-Falcón, J. M. (2003). 'Understanding European tour operators' control on accommodation companies: An empirical evidence", Tourism Management, 24(2), 135147.

Middleton, V., (1994) Marketing in travel and tourism, 2nd ButterworthHeinemann, London.

Middleton, V., and J. Clarke (2001). Marketing in Travel and Tourism. 3rd ed. Oxford: Butterworth-Heinneman.

Mill, P. and Morrison, A. (eds) (1992). The Tourism System: An Introductory Text, 2nd ed. Prentice Hall International Editions: New Jersey.

Ministry of Natural Resources and Tourism (2004). The 2004 Tanzania Tourism Sector Survey: International visitor's exit surveys report. Dar es Salaam: Tanzania.

Ministry of Natural Resources and Tourism (2008). Tourism Statistical Bulletin, Dar es Salaam, Tanzania.

Ministry of Natural Resources and Tourism (2009). Tourism Statistical Bulletin, Dar es Salaam, Tanzania.

MNRT and CHL Consulting Group (2006). Tourism Master Plan. Dar es Salaam: Tanzania.

Morgan, D., and Fluker, M. (2003). "Risk management for Australian commercial adventure tourism operations", Journal of Hospitality and Tourism Management, 10(1), pp. 46-50.

Morrell, P. S. (1998). "Airline sales and distribution channels: The impact of technology", Tourism Economics, 4 (1), pp. 5-19.

Morrison, A. (1992). "Marketing Strategic Alliances: The small Hotel firm", International Journal of Contemporary Hospitality Management, 6(3), pp. 25-30. 
Morrison, A., and A. Harrison (1998). "From Corner Shop to Electronic Shopping Mall?" Progress in Tourism and Hospitality Research, 4(4), pp. 349-56.

National Bureau of Statistics (2002). National Census, Dar es Salaam: Tanzania.

National Bureau of Statistics (2009). Annual Report, Dar es Salaam: Tanzania.

NBS and MNRT (2008). Tourism surveys report, Dar es Salaam: Tanzania.

Noone, B., and P. Griffin (1997). "Enhancing Yield Management with Customer Profitability Analysis", International Journal of Contemporary Hospitality Management, 9 (2), pp. 75-9.

Norton, A. (1999). "Experiencing Nature: The Reproduction of Environmental Discourse Through Safari Tourism in East Africa", Geoforum, 27(3), pp. 355-373.

Oppermann, M. (1998). "Service attributes of travel agencies: a comparative perspective of users and providers", Journal of Vacation Marketing, 4(3), pp. 265-281.

Pacific Asia Travel Association (PATA). 2003. Adventur Travel Market Australia and New Zealand. Report prepared by Roy Morgan Research. PATA Headquarters: Bangkok, Thailand.

Pearce, D. G. (2009). "Channel design for effective tourism distribution strategies", Journal of Travel and Tourism Marketing, 26(5\&6), pp. 507521.

Pearce, D. G. and Sahli, M. (2007) "Surface transport distribution channels in New Zealand: a comparative analysis", Journal of Travel and Tourism Marketing, 22(2), pp. 57-73.

Pearce, D. G. and Tan, R. (2002). "Tourism Distribution Channels: A destination perspective" in W. G. Croy (ed), New Zealand Tourism and Hospitality Conference Proceedings, pp. 242-250. Rotorua: Wairaki Institute of Technology.

Pearce, D. G. and Tan, R. (2004). "Distribution channels for heritage and cultural tourism in New Zealand", Asia Pacific Journal of Tourism Research, 9(3), pp. 225-237.

Pearce, D. G. and Tan, R. (2006). "The distribution mix for tourism attractions in Rotorua, New Zealand”, Journal of Travel Research, 44(2), pp. 250-258.

Pearce, D. G. and Taniguchi, M. (2007). "Channel performance in multi-channel tourism distribution systems", Journal of Travel Research, 46(3), pp. 256267. 
Pearce, D. G., Tan, R., and Schott, C. (2003). "Distribution channels for urban tourism: Issues and examples from Wellington, New Zealand", Paper presented at the Travel and Tourism research Association Conference; 'Urban Tourism - Mapping the Future', Glasgow-Hill: Australia.

Pearce, D.G. (2007). "Supplier selection in the New Zealand inbound tourism industry", Journal of Travel and Tourism Marketing, 23 (1), pp.57-69.

Pearce, Douglas G. (2002). "Tourism and Peripherality: Perspectives from Asia and the South Pacific", Tourism and Hospitality Research, 3(4), pp. 295310.

Pearce, P. L., Morrison, A. M., and Rutledge, J. L. (1998). Tourism: Bridges across continents. McGraw-Hill: Australia.

Peterson, K. I. (1994). "Qualitative research methods for the travel and tourism industry", in Ritchie, J. B. R., and Goeldner, C. R. (eds) Travel, Tourism and Hospitality Research - a handbook for managers and researchers. Wiley: Canada.

Pomfret, G. (2006). "Mountaineering adventure tourists: a conceptual framework for research", Tourism Management, 27(1), pp. 113-123.

Radburn, M and Goodall, B. (1990). "Marketing through travel agencies" in Ashworth, G. and Goodall, B. (eds) Marketing Tourism Places. Routledge: London.

Reinders, J., and Baker, M. (1998). "The future for direct retailing of travel and tourism products: The influence of information technology", Progress in Tourism and Hospitality Research, 4(1), pp. 1-15.

Rewtrakunphaiboon, W., and Oppewal, H. (2003). "Holiday packaging and tourist decision making”, Tourism Analysis, 8(2), pp. 193-1896.

Richardson, J. I. (1996). "Marketing Australian travel and tourism: Principles and Practice", Hospitality Press: Australia.

Rosenbloom, B. (1999). Marketing Channels: A Management View, 6th ed. Fort.

Rosenbloom, B., T. Larsen, and B. Smith (2004). "The Effectiveness of Upstream Influence Attempts in High and Low Context Export marketing Channels." Journal of Marketing Channels 11 (4), pp. 3-19.

Ryan, C. (2003). Risk acceptance in adventure tourism paradox and context. In Managing Tourist Health and Safety in the New Millennium, Wilks J, Page SJ. Elsevier Science: Oxford; 55-65. 
Samiee, S. (1993). "Retailing and channel considerations in developing countries: A review and research propositions", Journal of Business Research, 27(2), pp. 103-129.

Sanchez, J. F., and A. Satir (2005). "Hotel Yield Management using Different Reservation Modes" International Journal of Contemporary Hospitality Management, 17(2), pp. 136-46.

Schott, C. (2007). "Selling adventure tourism: A distribution channels perspective", The International Journal of Tourism Research, 9(4), pp. 257-274.

Sharda, S. (2005). The structure and behaviour of distribution channels linking destination New Zealand to an emerging market: A case of the Indian outbound travel industry, Master of Tourism Management Thesis, Victoria Management School, Victoria University of Wellington.

Sharda, S. and Pearce, D. G. (2005). "Distribution in Emerging Tourism Markets: the case of Indian travel to New Zealand", in S-J Suh and Y-H Hwang (eds), Proceedings of the Asia Pacific Tourism Association 11th Conference "New Tourism for Asia Pacific", (Goyang, Korea, 2005), pp. 595-605.

Sharda, S. and Pearce, D. G. (2006)."Tourism distribution in emerging markets: the case of Indian travel to New Zealand", Asia Pacific Journal of Tourism Research, 11(4), pp. 339-353.

Sindiga, I. (1995). "Wildlife-based Tourism in Kenya: Land use conflicts and government compensation policies over protected areas", The Journal of Tourism Studies, 6(2), pp. 45-55.

Smith, K. (2007). "Distribution channels for events: Supply and demand-side perspective", Journal of Vacation Marketing, 13(4), pp. 321-338.

Stern, L. W., and El-Ansary, A. I. (1992). "Marketing Channels" (4th ed). Englewood Cliffs, NJ: Prentice-Hall.

Stuart, P. (2004). Tourism distribution channels for peripheral areas: A case study of Southland, New Zealand, Master of Tourism Management Thesis, Victoria Management School, Victoria University of Wellington.

Stuart, P., Pearce, D. G. and Weaver, A. (2005). "Tourism distribution channels in peripheral regions: the case of Southland, New Zealand", Tourism Geographies, 7(3), pp. 235-256.

Sung, H. H. (2004). "Classification of adventure travellers: behaviour, decisionmaking and target Markets", Journal of Travel Research 42(4), pp. 343356. 
Swarbrooke J., Beard C., Leckie S. and Pomfret G., 2003: Adventure Tourism: The New Frontier. Butterworth-Heinemann, London.

Tan, R. (2002). Channels of distribution characterising Singapore holiday travel to New Zealand: Structure and Implications, Master of Tourism Management Thesis, Victoria Management School, Victoria University of Wellington.

TANAPA (2006). Tanzania National Parks Annual Report.

Times (2009). How Somali fishermen became pirates [http://www.time.com/time/world/article/0,8599,1892376,00.html] accessed on 12th January, 2010.

Toyne, B., and Walters, P. G. (1989). Global Marketing Management: A strategic perspective, Allyn and Bacon, Boston, MA.

TTBA (1992). Tanzania Tourist Board Act, United Republic of Tanzania National Parliament, Dodoma: Tanzania.

Tybout, J. (2000). 'Manufacturing Firms in Developing Countries: How Well Do They Do, and Why?' Journal of Economic Literature, XXXVIII: pp. 11-44.

Ujma, D. (2001). "Distribution channels for tourism: theory and issues" in Buhalis, D. and Laws, E. (eds) Tourism Distribution Channels: Practices, Issues and Transformations. Continuum: London.

UNCTAD (2001). "World Investment Report”, Geneva.

UNCTAD (2008). "FDI in tourism. The development dimensions", Geneva.

UNESCO (1998). "World Heritage List", Paris.

Wade, D. J., Mwasaga, B. C., and Eagles, P. F. J. (1999). “A history and market analysis of tourism in Tanzania", Tourism Management, 22(1), pp. 93-101.

Wahab, S., Crampon, L. J., and Rothfield, L. M. (1976). “Tourism Marketing”. London: Tourism International Press.

Walker, R. (1985). Applied qualitative research. England: Gower Publishing Company Ltd.

Walker, R. (Ed.), (1985). Applied Qualitative Research Gower, Aldershot, Hants.

Walle, A. H. (1995). "Tourism and the Internet: Opportunities for direct marketing", Journal of Travel Research, 36(2), pp. 72-77. 
Walle, A. H. (1997). "Quantitative versus qualitative tourism research", Annals of Tourism Research, 21(3), pp. 524-536.

Wanhill, S. (1993). "Intermediaries", in Cooper, C., Fletcher, F., Gilbert, D., and Wanhill, S. (1993). Tourism - Principles and Practice. London: Pitman, pp. 189-203.

Wanhill, S. (1997). "Peripheral area tourism: A European perspective", Progress in Tourism and Hospitality Research, 3(1), pp. 47-70.

Wanhill, St., and Buhalis, D. (1999). "Introduction: Challenges of tourism in peripheral areas" International Journal of Tourism Research, 1(5), pp. 295-297.

WCA (2008). Wildlife Conservation Act of Tanzania, United Republic of Tanzania National Parliament, Dodoma.

World Economic Forum (2008). The Global Competitiveness Report. Geneva. Worth: Dryden.

Wynne, C., Brethon, P., Pitt, L., Ewing, M., and Napoli, J. (2001). "The impact of the internet on the distribution value chain", International Marketing Review, 18(4), pp. 420-431.

Yamamoto, D., and Gill, A. (2002). "Issues of globalisation and reflexivity in the Japanese tourism production system: The case of Whistler, British Colombia", The professional Geographer, 54(1), pp. 83-93.

Yilmaz, Y., and Bititci, U. (2006). "Performance measurement in the value chain: manufacturing v. tourism", International Journal of Productivity and Performance Management, 55(5), pp. 371-389. 


\section{TOURISM DISTRIBUTION CHANNELS IN THE NORTHERN TOURIST CIRCUIT OF TANZANIA}

Sector:

Name of company:

Name/Position of Interviewee:

\section{Company information}

1. Could you please tell me about your company/business (establishment of the company, size, ownership, structure, mission and objectives)?

2. Are there other offices of your company located in other parts of Tanzania? (If there are, what are purposes of establishing these offices)

3. What type of products/brands do you have?

4. What service levels does your company offers (here I need to know whether your services are limited, medium, full services, luxury, economy etc depends on how you classify)

5. What are your major markets (Here I need to know in terms of percentage proportion of domestic/international, business men, conferences/leisure and how much i.e. percentage proportional of sales come through different channels of distribution and how the actual bookings are made) 


\section{Distribution channels and relationships in the channels}

6. How do you get your products get known to possible customers? (domestic and international) if there are differences between the strategies used for domestic and international customers, (Reasons, would also like to know what factors make you choose certain strategies for certain customers)

7. If you use intermediaries (Inbound, Outbound Tour Operators or other Suppliers), how do you choose the perfect channel partners to work with? (factors you do consider)

8. If you use intermediaries, how many and which intermediaries do you deal with? (history with these intermediaries)

9. If you are dealing with other channel members or other suppliers, how influential on the channel are they? And why?

10. If you are dealing with intermediaries, how formal is your partnerships with intermediaries are?

11. What types of travel agents/partners that your company has formal/legal relationships and the reasons for formalising the partnerships

12. How many booking/reservations are coming from other partners? (Inbound and Outbound, and other suppliers in you region)

13. If you do use both direct and indirect distribution strategies, what are the advantages and disadvantages of each strategy? (How do you maximize advantages and minimizing disadvantages?)

14. Are there any problems/issues in the channels you are using? (If there are any problems, how do you deal with them?)

\section{Influence of Information Technology}

15. Does your company have website? If Yes what is it for? If No why not?

16. How does the internet affects your daily business activities?

17. How many languages does your website offers? Why these languages?

18. If you do have website, what kind of information you do put on the website? 
19. If you do have website, how often do you update the information on the website?

20. What marketing opportunities do you see the internet offers to your company?

21. How many/proportion of reservation/bookings do you get through internet? Are most of them coming direct from consumers or from other intermediaries?

\section{General questions}

22. What are the challenges you face in distributing your products?

23. What changes are you planning to make? (why changes)

24. Do you participate in Karibu Tourism Fair? (Why/Why not)

25. Are there any other issues that you would like to raise?

\section{Thank you for your participation in this study}


Appendix 2: List of Businesses Interviewed

\begin{tabular}{|l|}
\hline Ground Tour Operators \\
\hline Akaro Tours \\
\hline Chagga Tours \\
\hline Crown Eagle Tours \\
\hline Hoopoe Adventure \\
\hline Imagine Tanzania Tours \\
\hline Kilimanjaro Crane Tours \\
\hline Kilimanjaro Crown bird Tours and Safaris \\
\hline Mauly Tours \\
\hline Mem Tours \\
\hline Evans Adventure \\
\hline King of Kilimanjaro Tours \\
\hline Ranger Safaris \\
\hline Rungwa Game Safari \\
\hline Tandala Hunting \\
\hline Tanganyika Tours \\
\hline Tanzania Big Game Safaris \\
\hline Tanzania Safaris Hunting \\
\hline Tawico \\
\hline Sunny Adventure \\
\hline Ker \& Downery Photographic Safaris \\
\hline Tanzania Game Tracker Safaris \\
\hline Tusker Trails \\
\hline Zara Tours \\
\hline TinTin Tours \\
\hline Ahsante Tours \\
\hline Victoria Expeditions \\
\hline
\end{tabular}




\begin{tabular}{|l|}
\hline Hotels \\
\hline Serena Hotels and Lodges \\
\hline Meru House Inn \\
\hline Arusha Backpackers \\
\hline Arusha Tourist Inn \\
\hline Kilimanjaro Crane Hotel \\
\hline Kibo Palace Hotel \\
\hline East African Hotel \\
\hline Impala Hotel \\
\hline Arumeru River Lodge \\
\hline Aquilline Hotel \\
\hline Keys Hotel \\
\hline \\
\hline Air Charters \\
\hline Regional Air \\
\hline Northern Air \\
\hline
\end{tabular}

